\title{
Palladium-Catalyzed Synthesis of $\alpha$-Iminonitriles from Aryl Halides via Isocyanide Double Insertion Reaction
}

Zhen-Bang Chen, ${ }^{\dagger}$ Ying Zhang, ${ }^{\dagger}$ Qing Yuan, ${ }^{\dagger}$ Fang-Ling Zhang, ${ }^{\dagger}$ Yong-Ming Zhu, ${ }^{*}{ }^{\dagger}$ and Jing-Kang Shen*

†College of Pharmaceutical Sciences, Soochow University, Suzhou, 215123, China

\$Shanghai Institute of Materia Medica, Chinese Academy of Sciences, Shanghai, 201203, China 


\section{Contents}

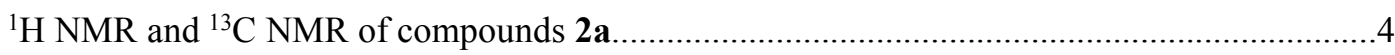

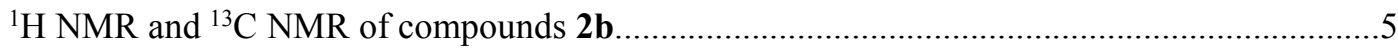

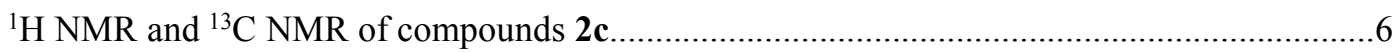

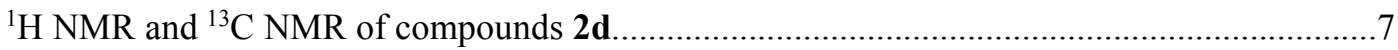

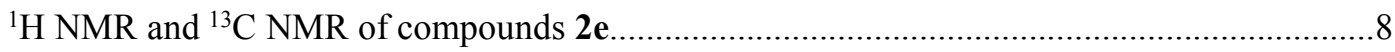

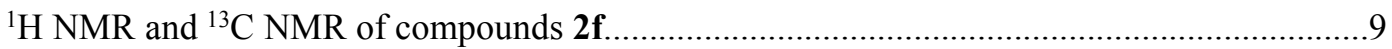

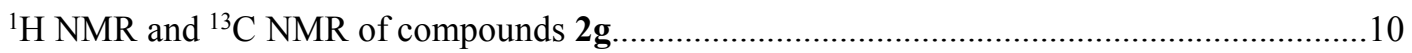

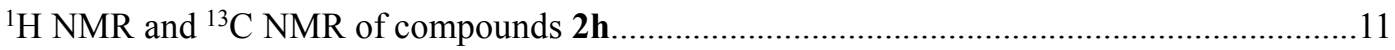

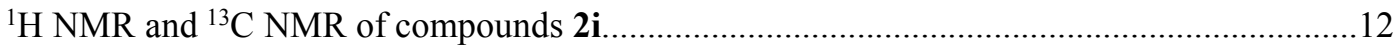

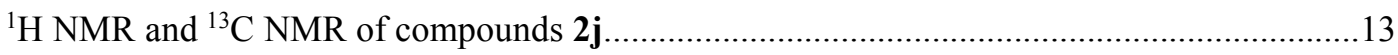

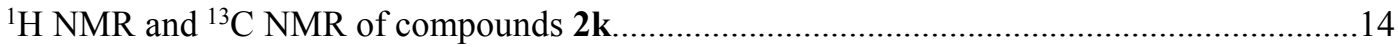

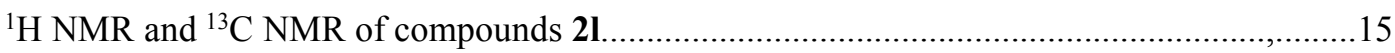

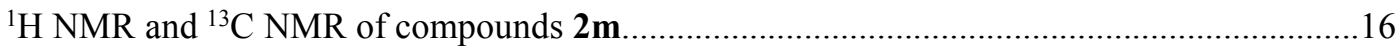

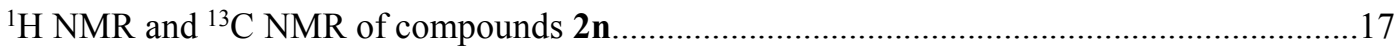

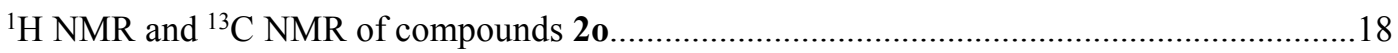

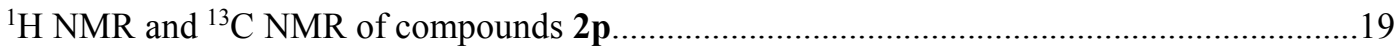

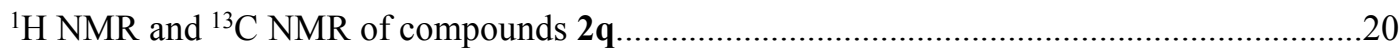

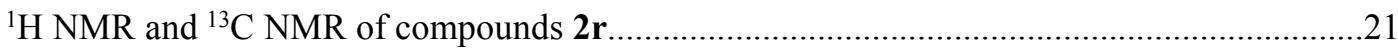

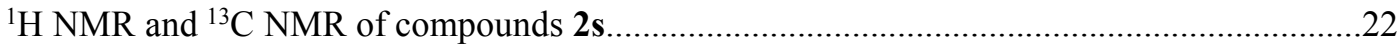

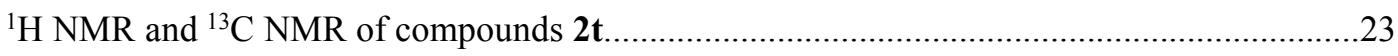

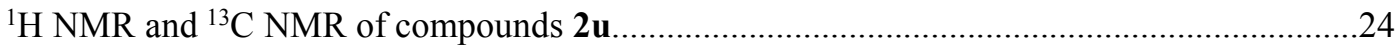

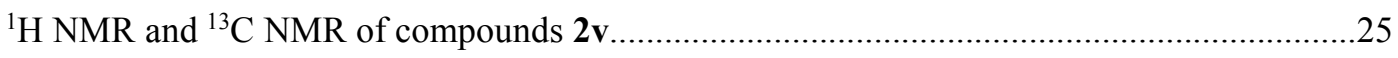

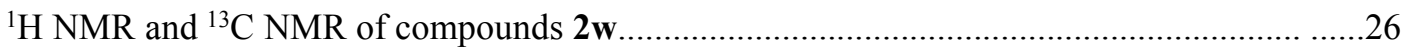

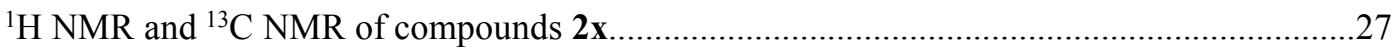

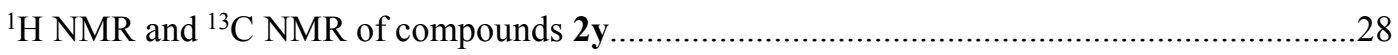

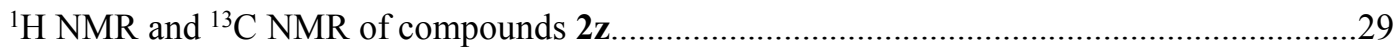

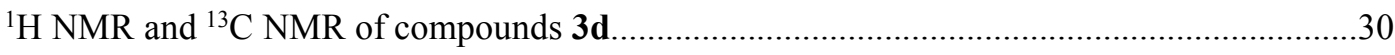


${ }^{1} \mathrm{H}$ NMR and ${ }^{13} \mathrm{C}$ NMR of compounds $4 \mathbf{a} .$.

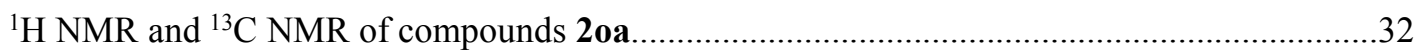




\section{H NMR and 13C NMR spectra}

${ }^{1} \mathrm{H}$ NMR spectrum of compound $\mathbf{2 a}$
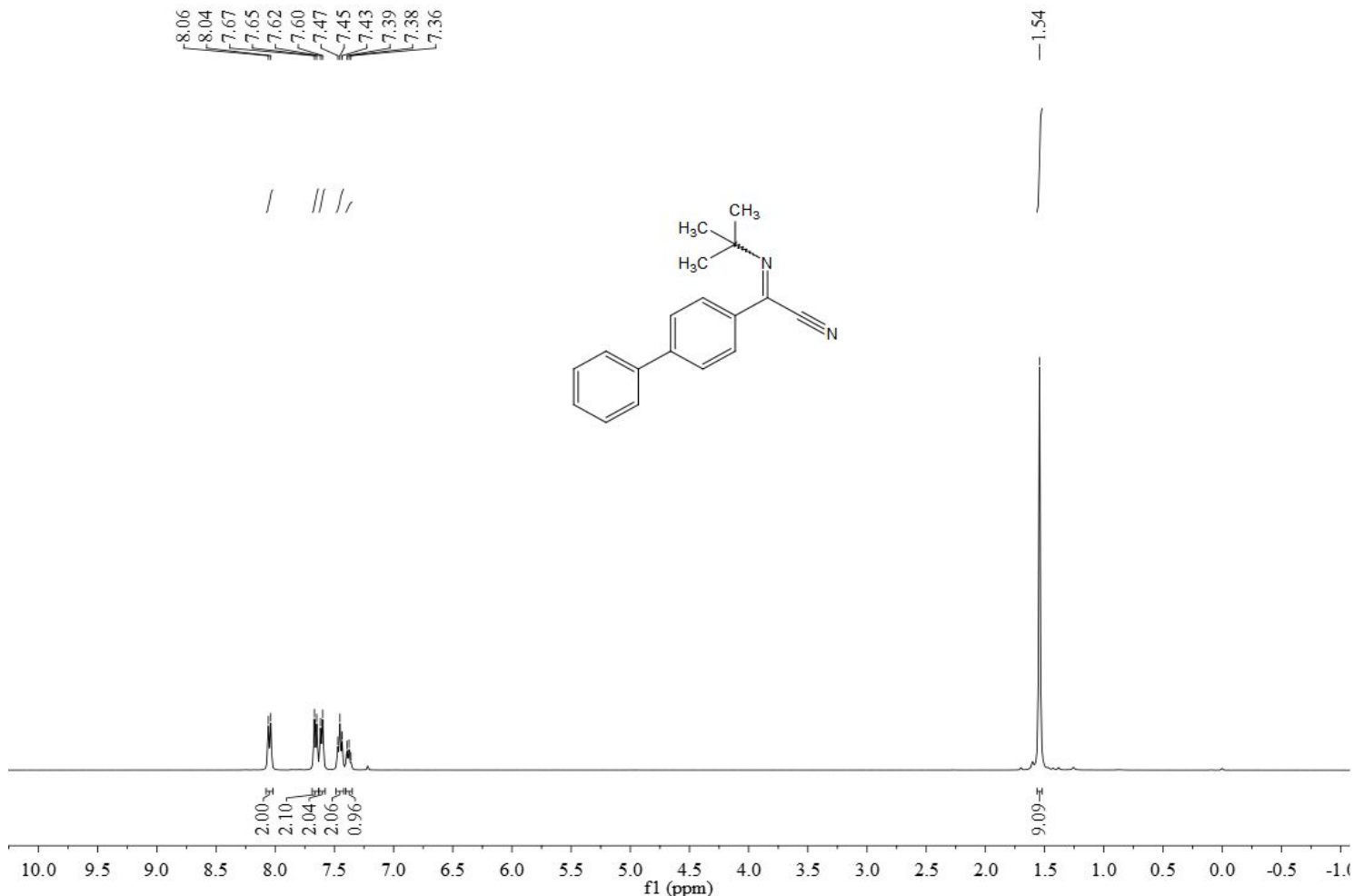

${ }^{13} \mathrm{C}$ NMR spectrum of compound 2a
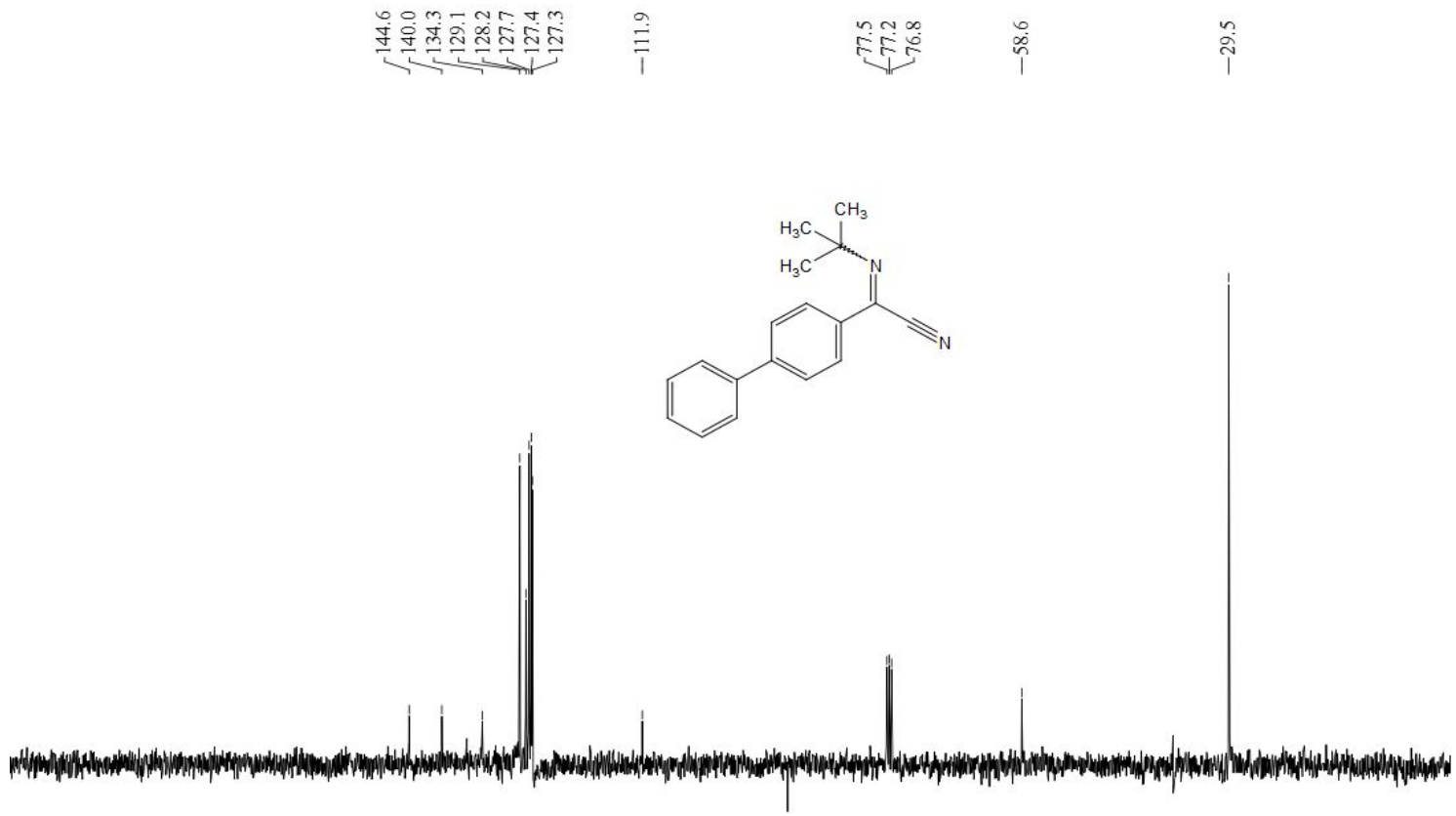
190
$180 \quad 170 \quad 160$
$150 \quad 1$
$40 \quad 130$
120
$110 \begin{gathered}100 \\ \mathrm{f} 1(\mathrm{ppm})\end{gathered}$

$90 \quad 80 \quad 70 \quad 60$

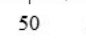

$\begin{array}{lll}30 & 20 & 10\end{array}$ 
${ }^{1} \mathrm{H}$ NMR spectrum of compound $\mathbf{2 b}$

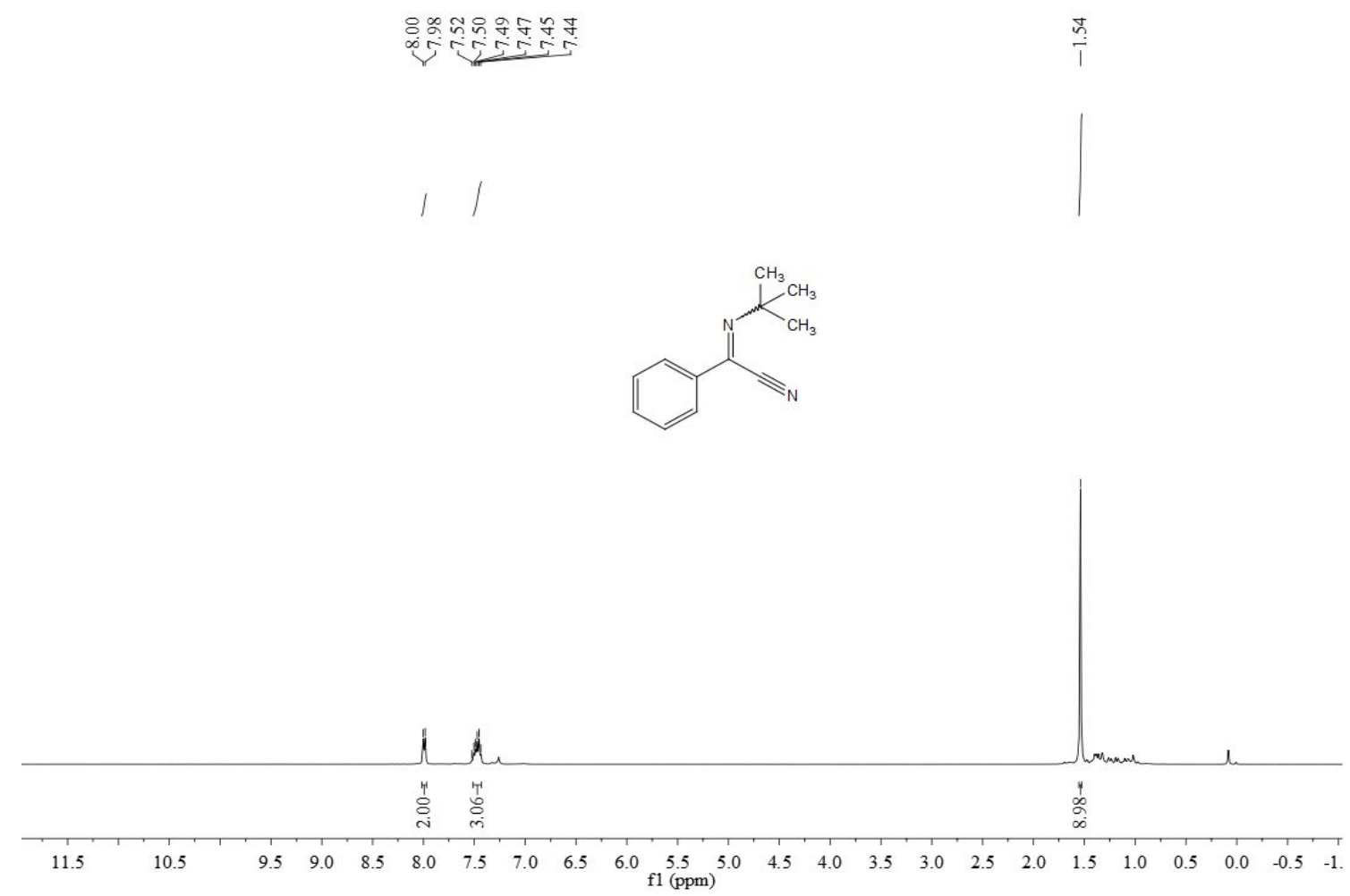

${ }^{13} \mathrm{C}$ NMR spectrum of compound $\mathbf{2 b}$

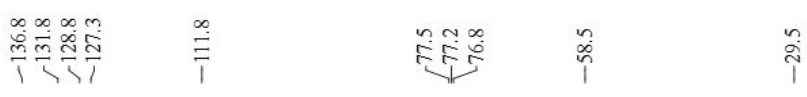<smiles>CC(C)(C)N=C(C#N)c1ccccc1</smiles>

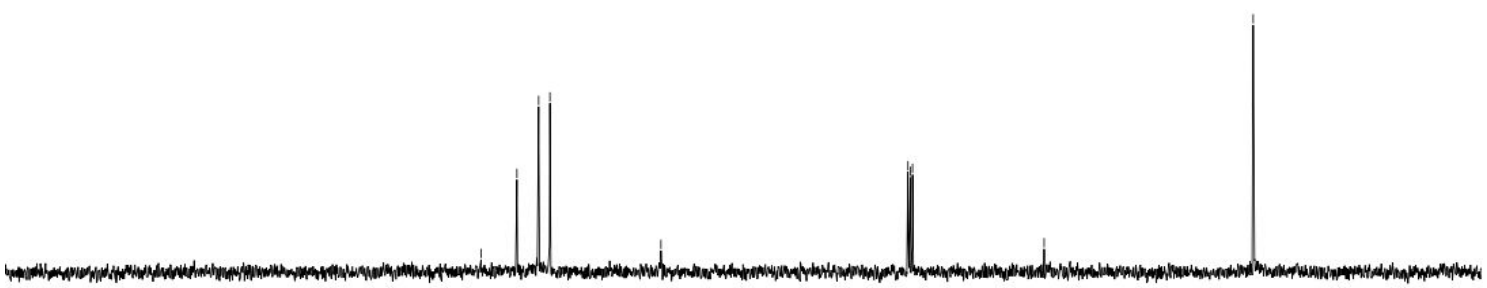

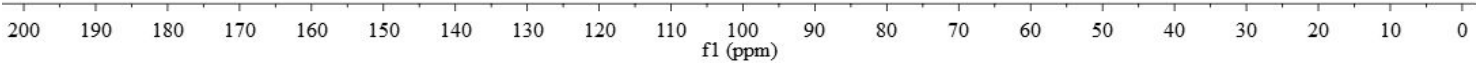


${ }^{1} \mathrm{H}$ NMR spectrum of compound $\mathbf{2 c}$

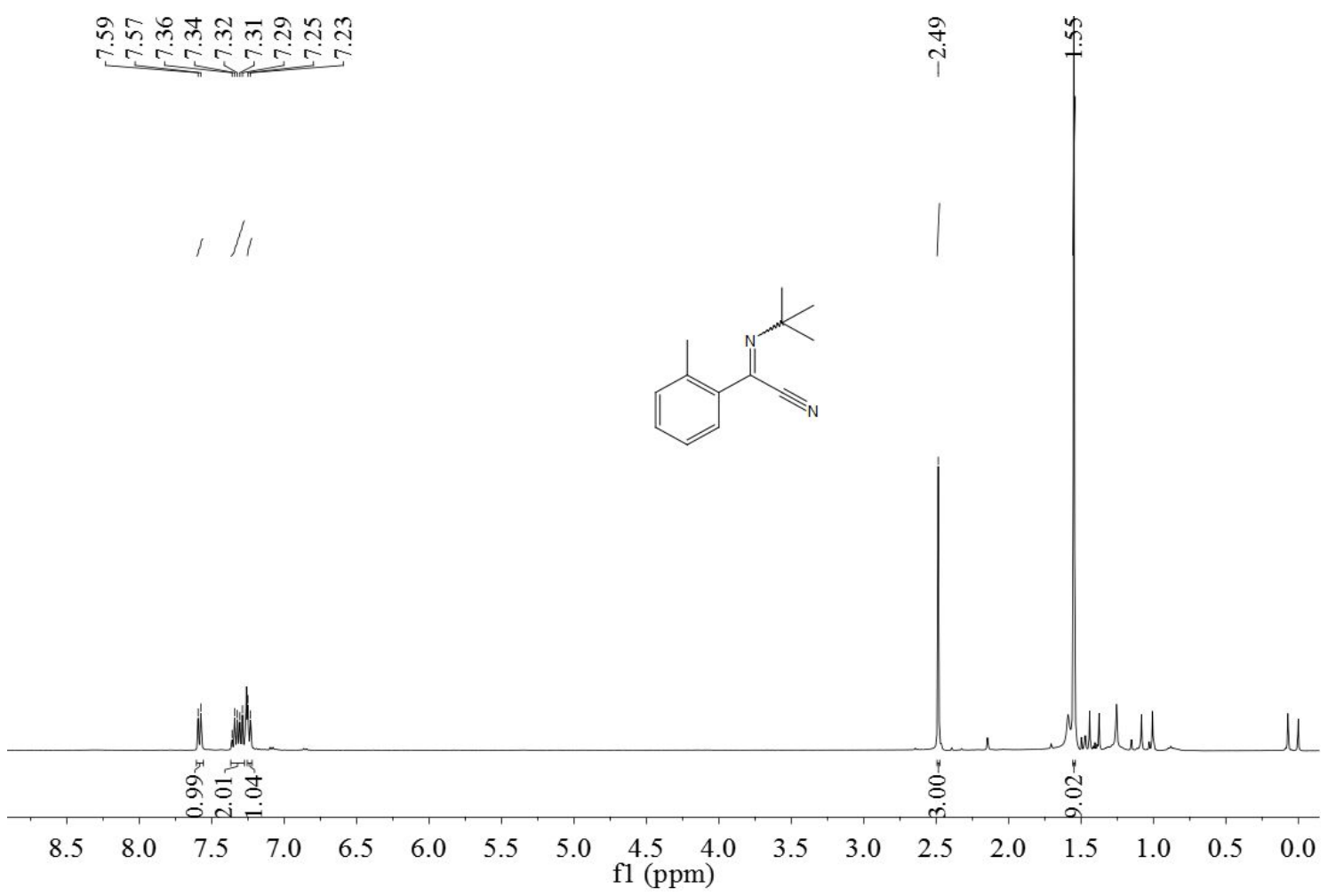

${ }^{13} \mathrm{C}$ NMR spectrum of compound $\mathbf{2 c}$
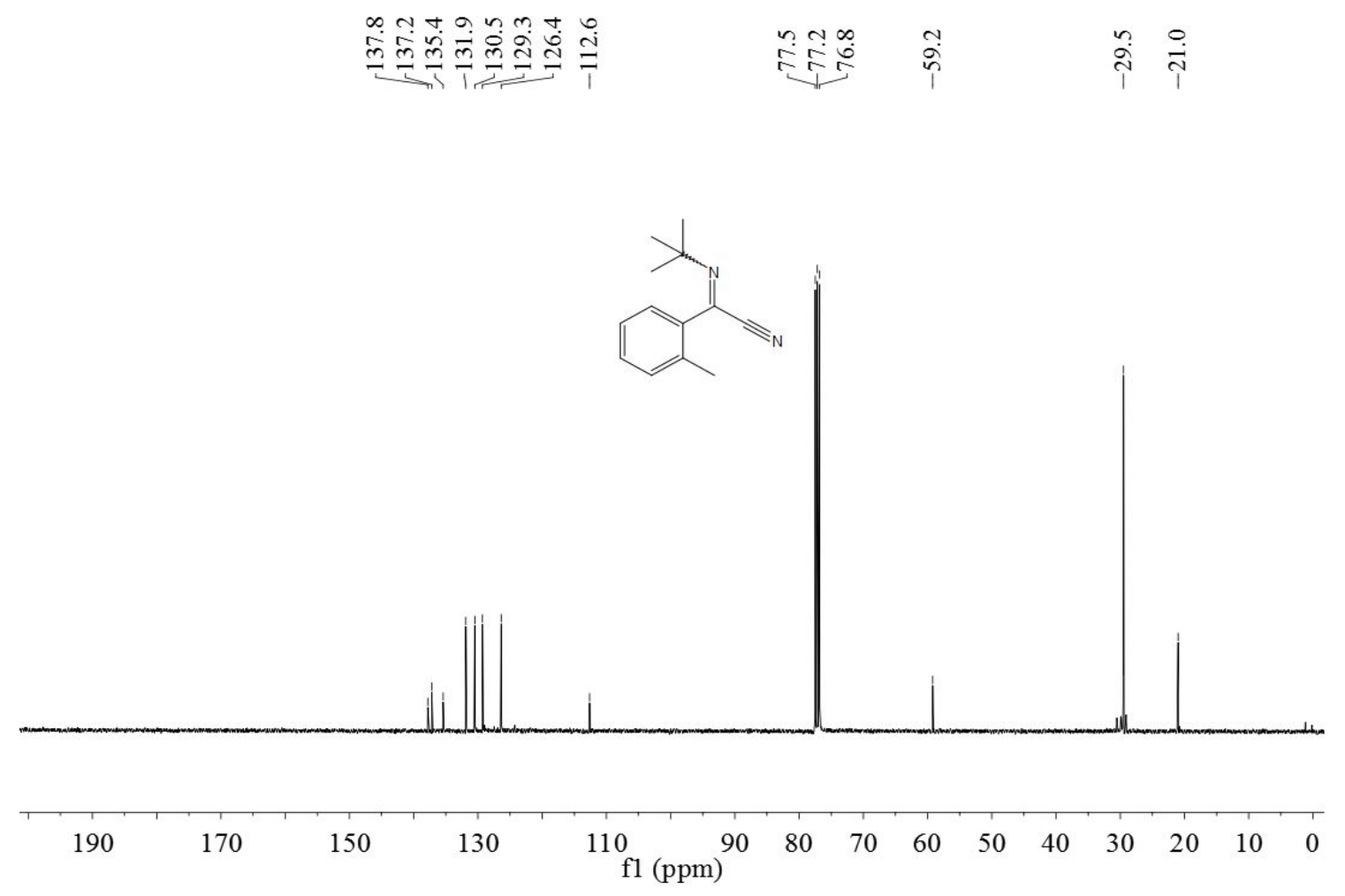
${ }^{1} \mathrm{H}$ NMR spectrum of compound $\mathbf{2 d}$

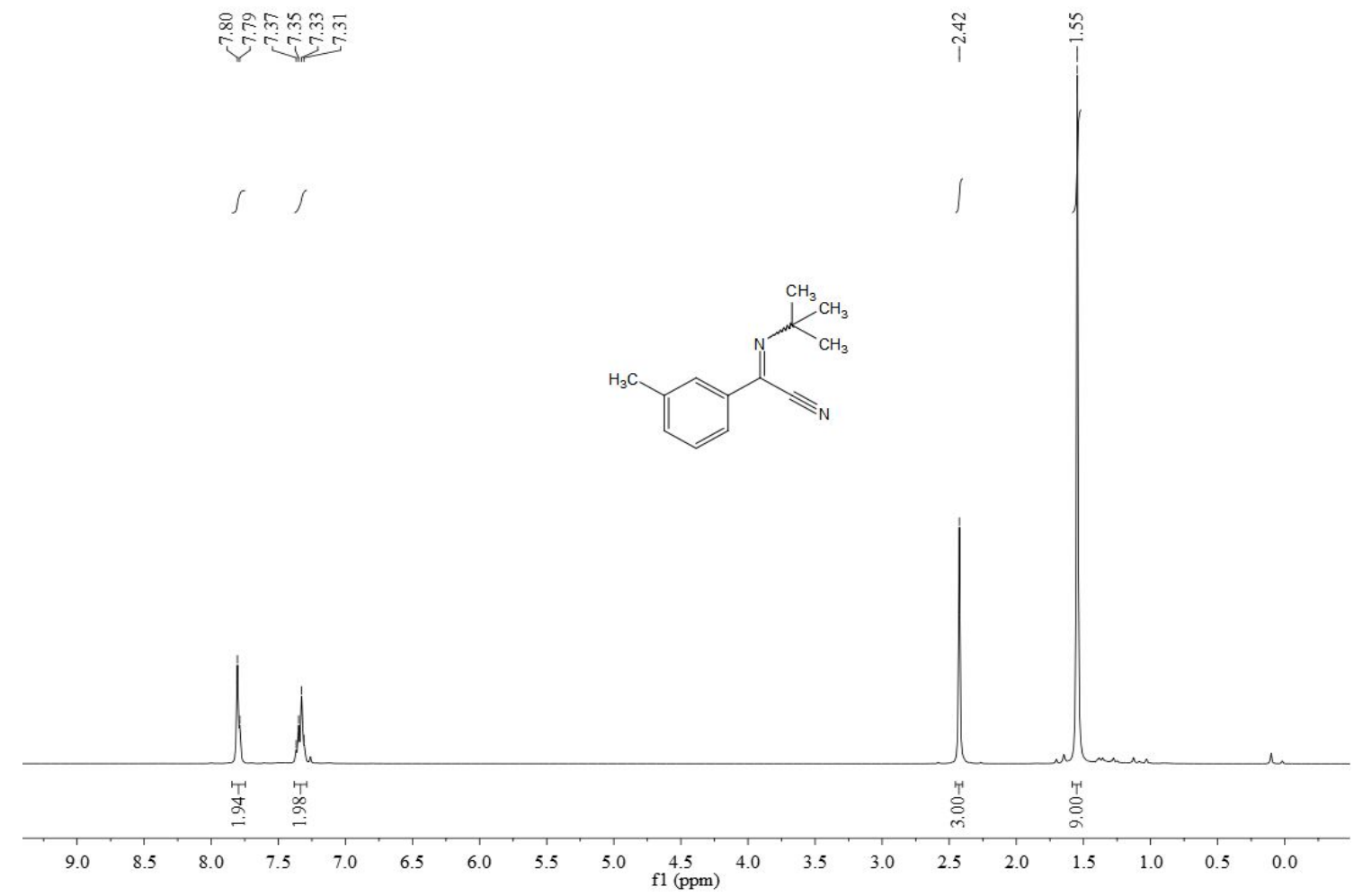

${ }^{13} \mathrm{C}$ NMR spectrum of compound $\mathbf{2 d}$

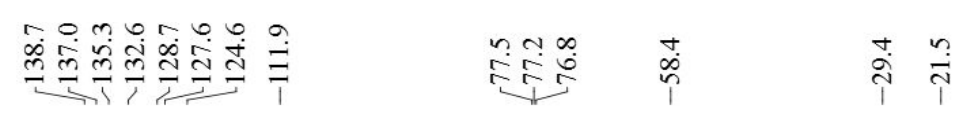<smiles>Cc1cccc(C(C#N)=NC(C)(C)C)c1</smiles>

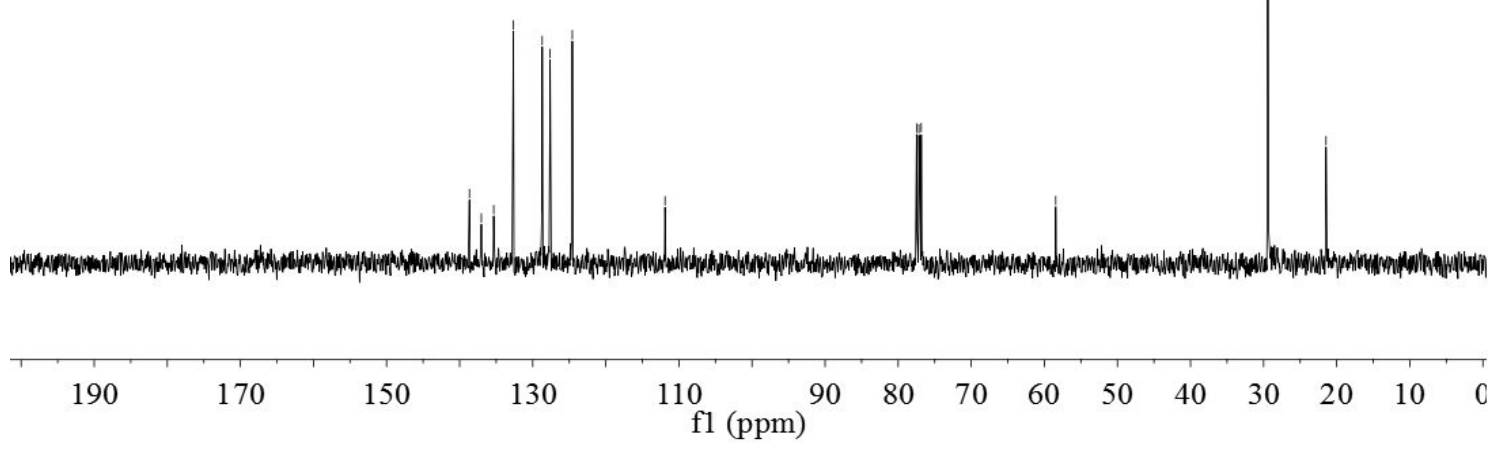


${ }^{1} \mathrm{H}$ NMR spectrum of compound $\mathbf{2 e}$

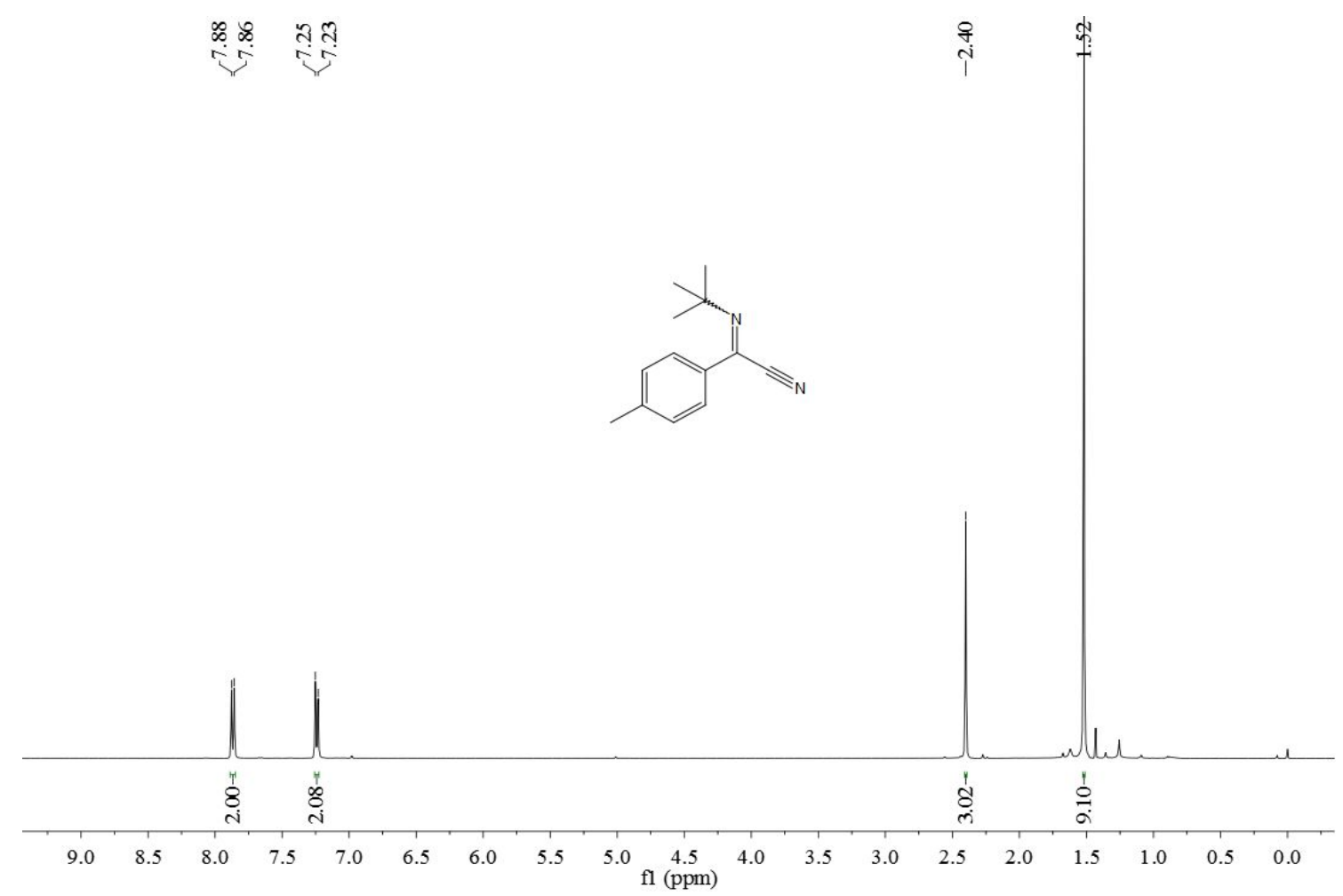

${ }^{13} \mathrm{C}$ NMR spectrum of compound $\mathbf{2 e}$
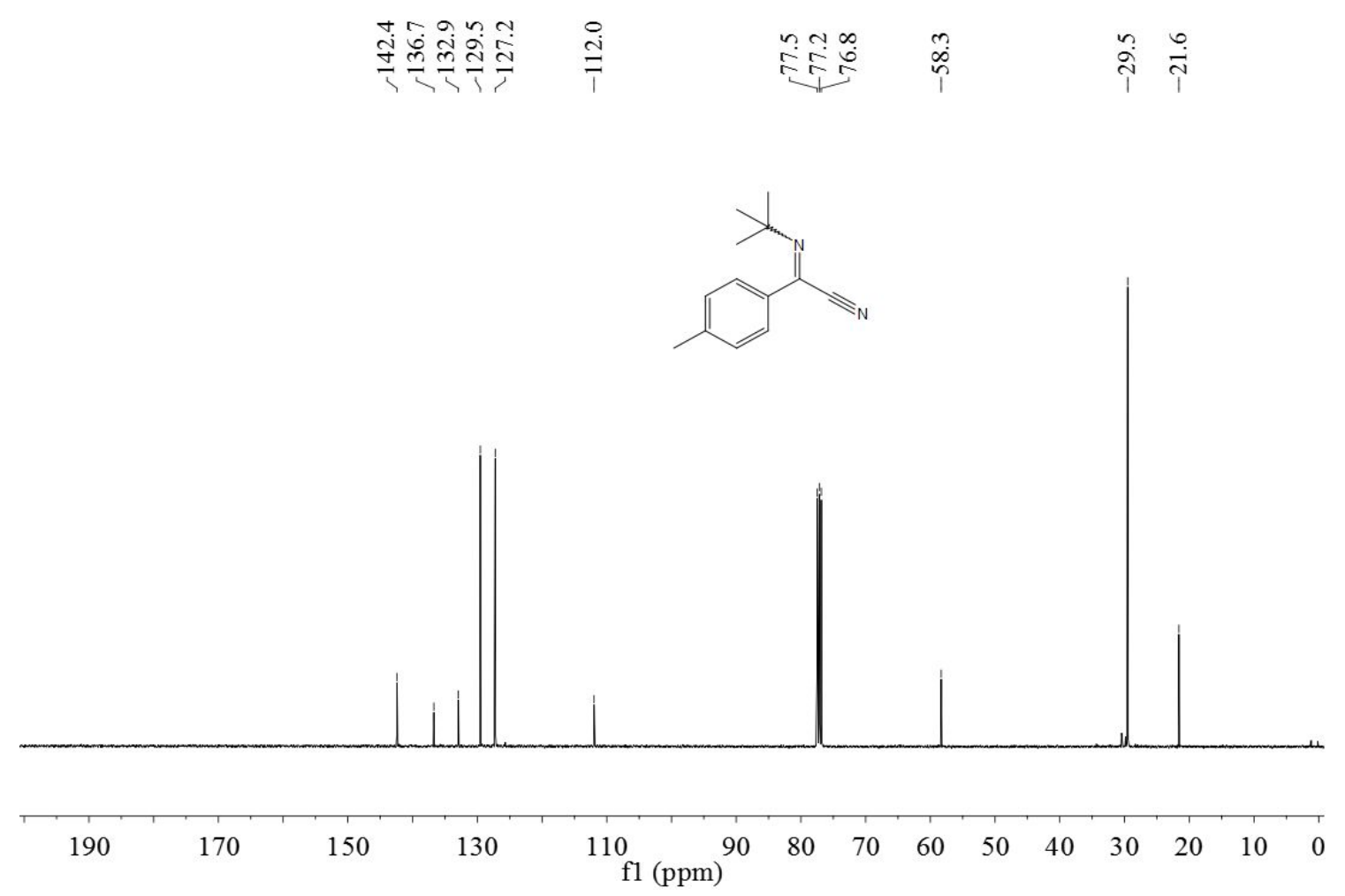
${ }^{1} \mathrm{H}$ NMR spectrum of compound $\mathbf{2 f}$

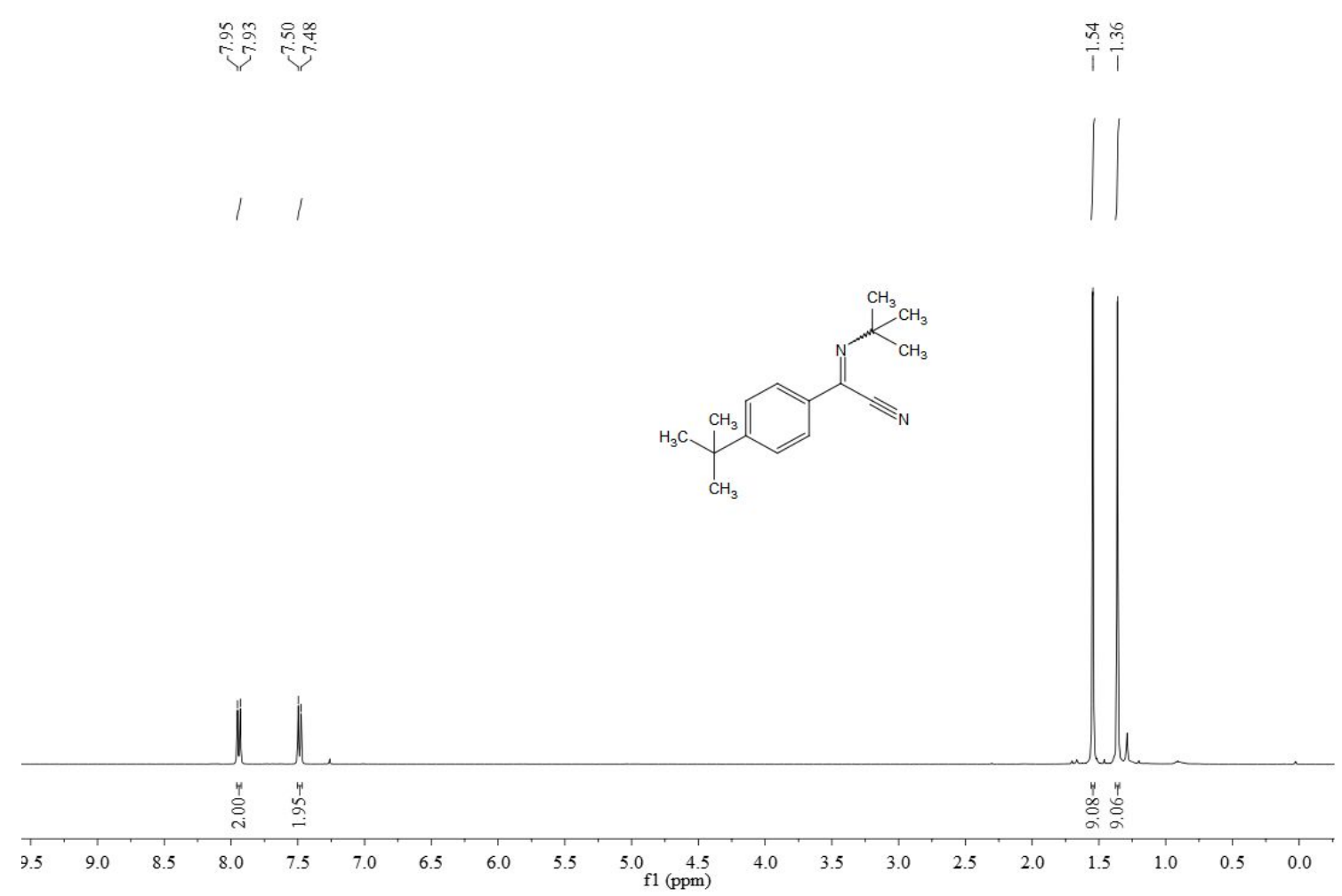

${ }^{13} \mathrm{C}$ NMR spectrum of compound $\mathbf{2 f}$

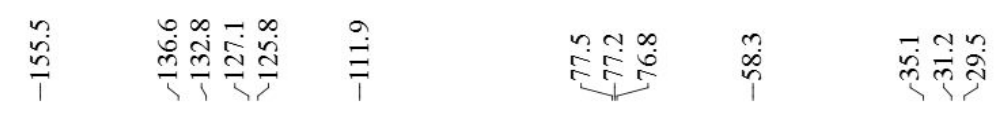

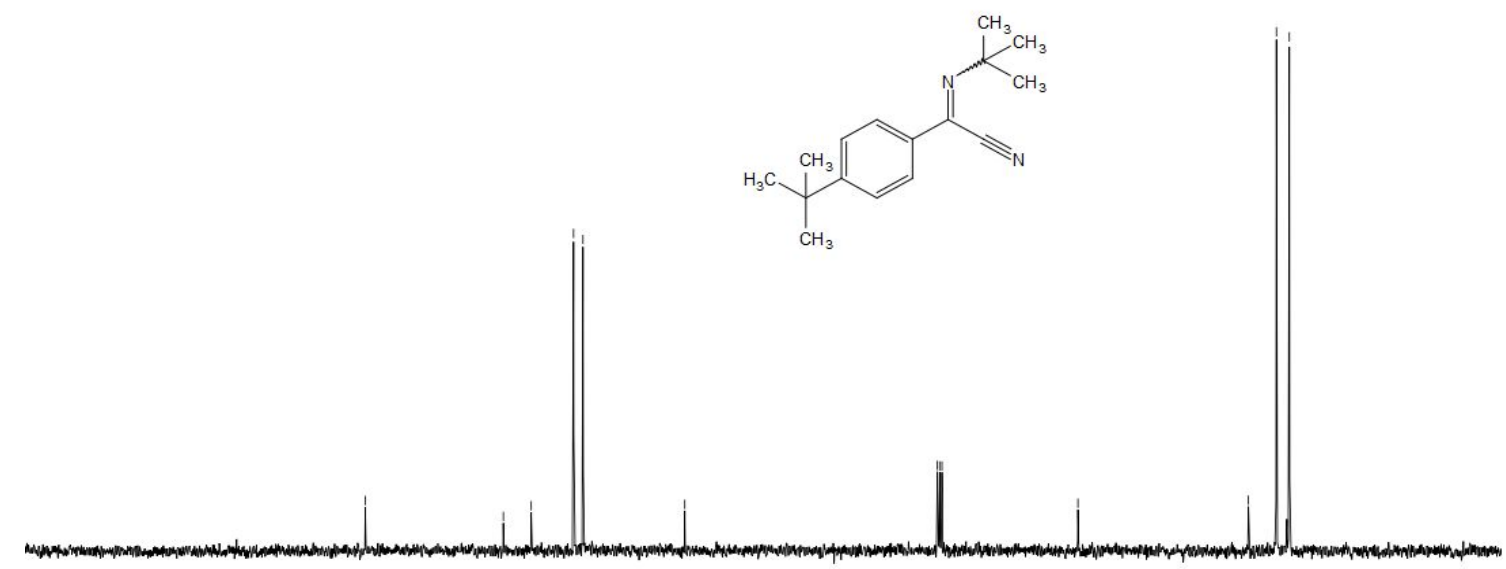

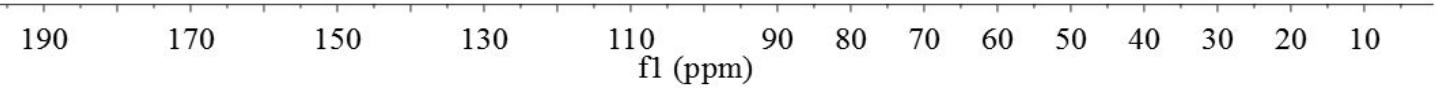


${ }^{1} \mathrm{H}$ NMR spectrum of compound $\mathbf{2 g}$

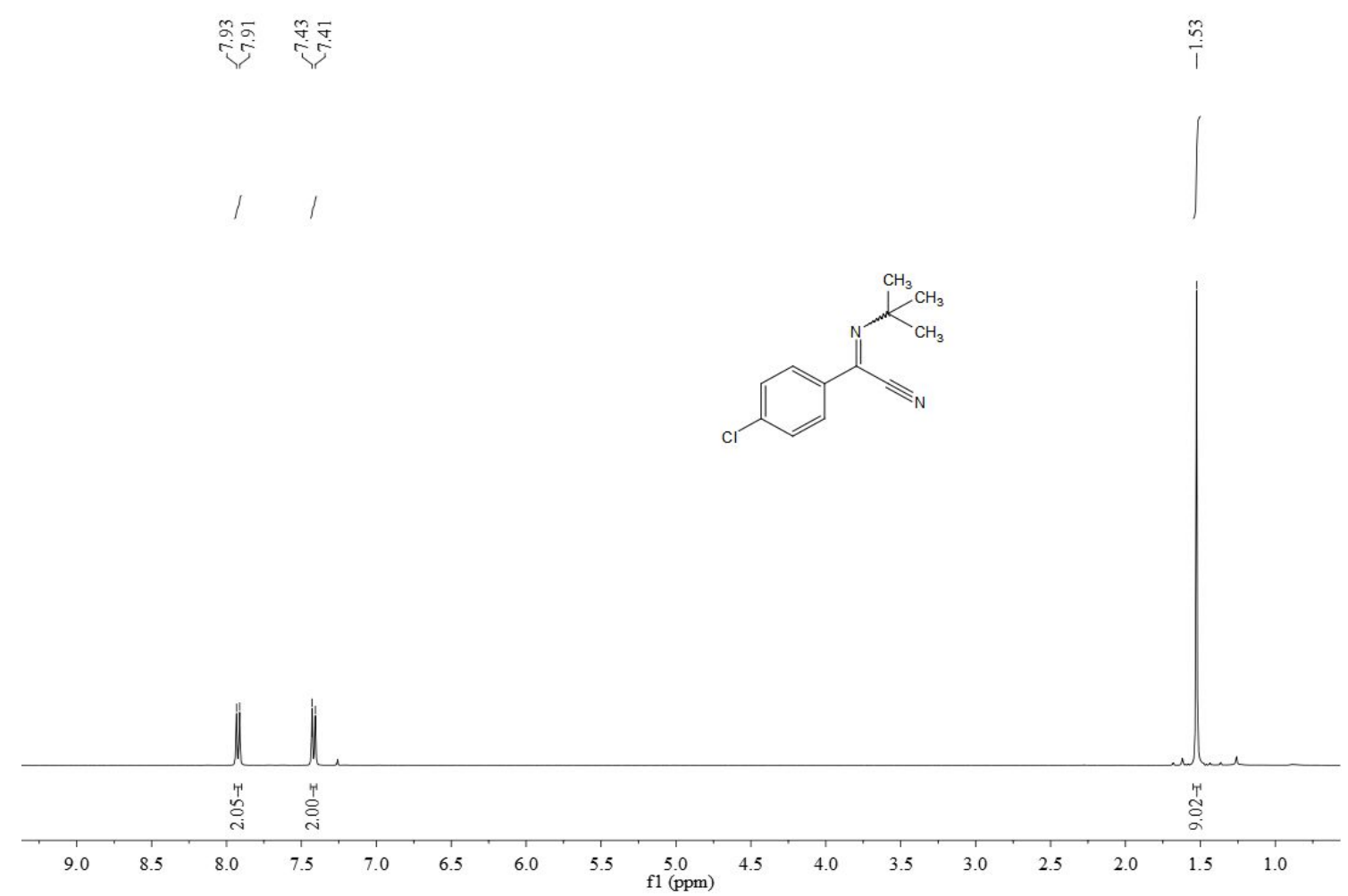

${ }^{13} \mathrm{C}$ NMR spectrum of compound $\mathbf{2 g}$
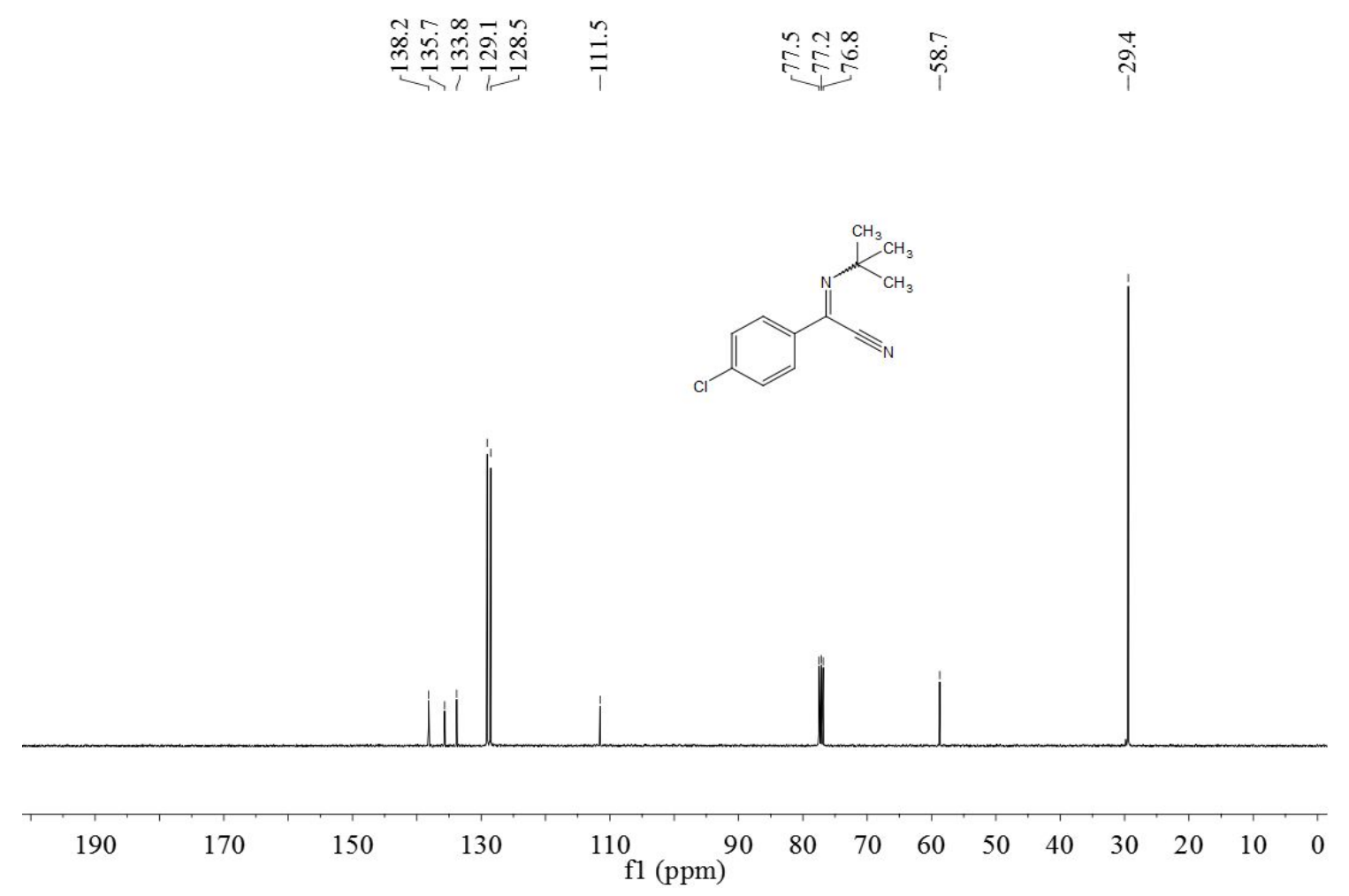
${ }^{1} \mathrm{H}$ NMR spectrum of compound $\mathbf{2 h}$

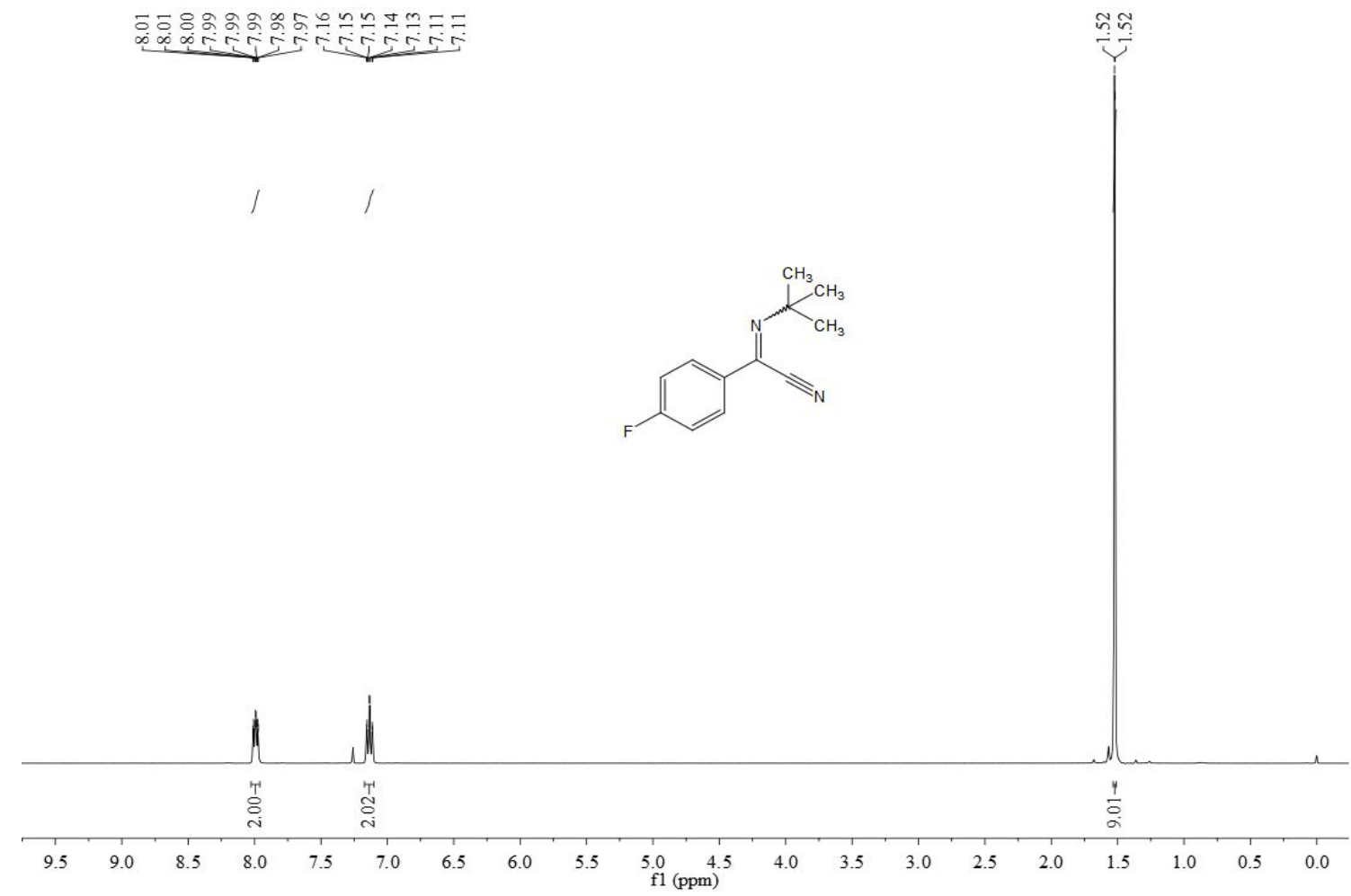

${ }^{13} \mathrm{C}$ NMR spectrum of compound $\mathbf{2 h}$

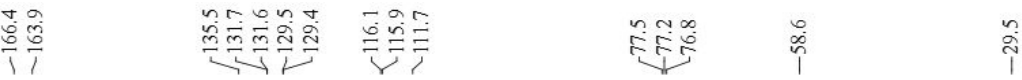<smiles>CC(C)(C)N=C(C#N)c1ccc(F)cc1</smiles>

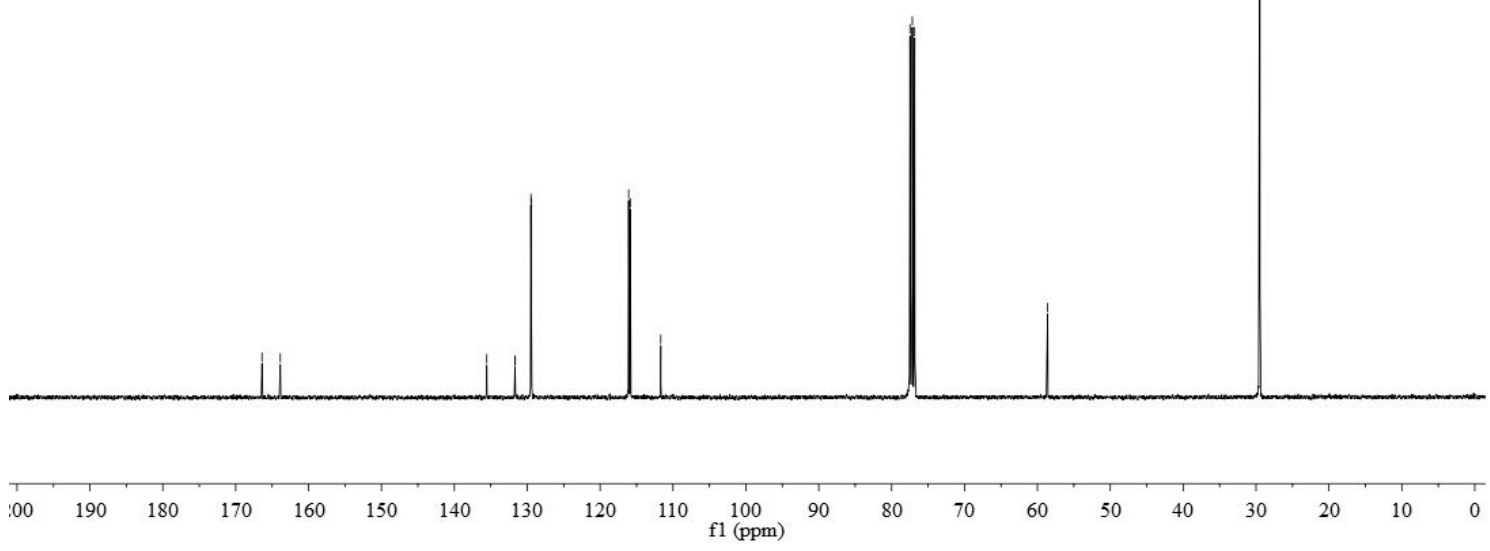


${ }^{1} \mathrm{H}$ NMR spectrum of compound $\mathbf{2 i}$

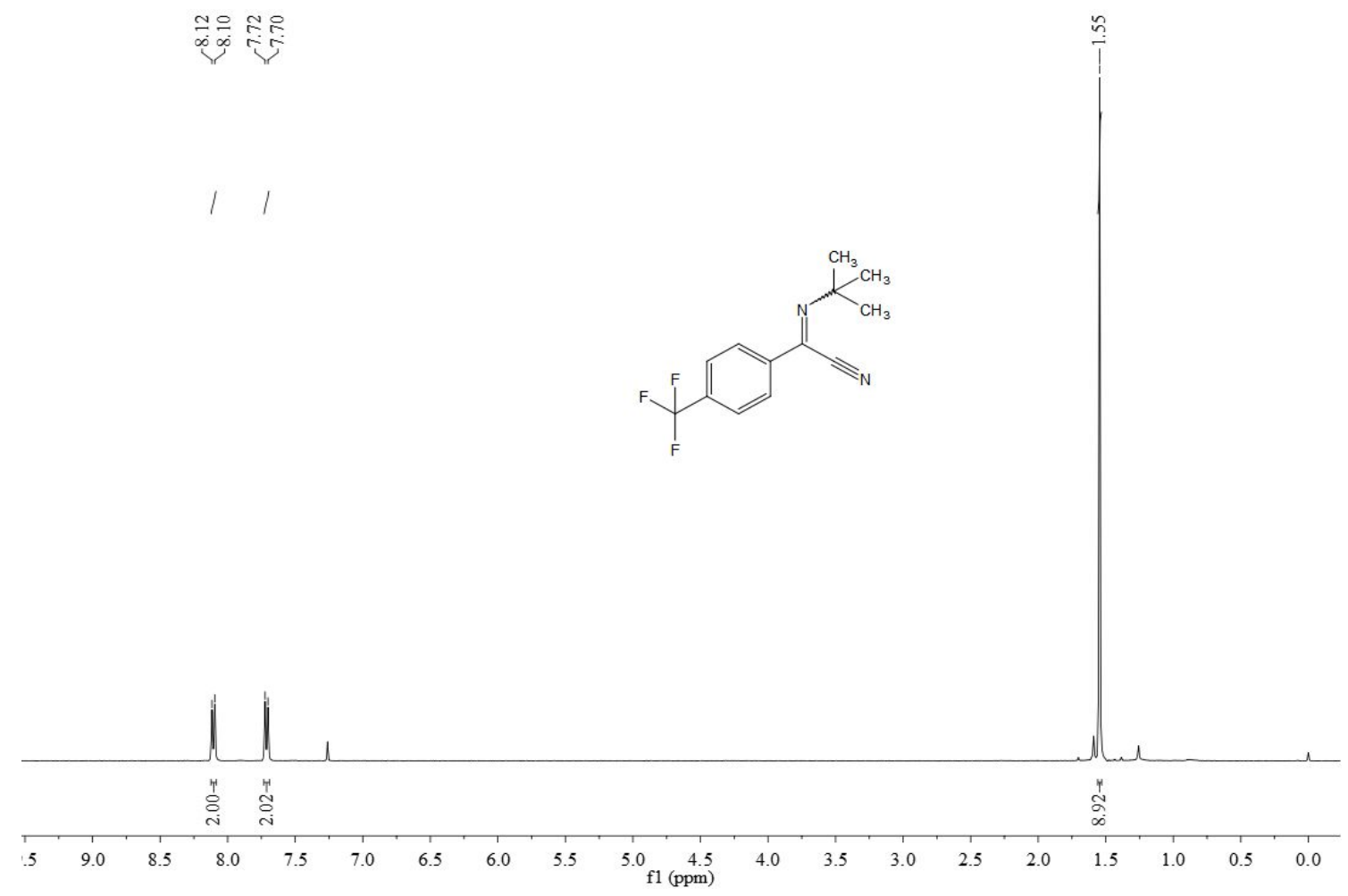

${ }^{13} \mathrm{C}$ NMR spectrum of compound $\mathbf{2 i}$
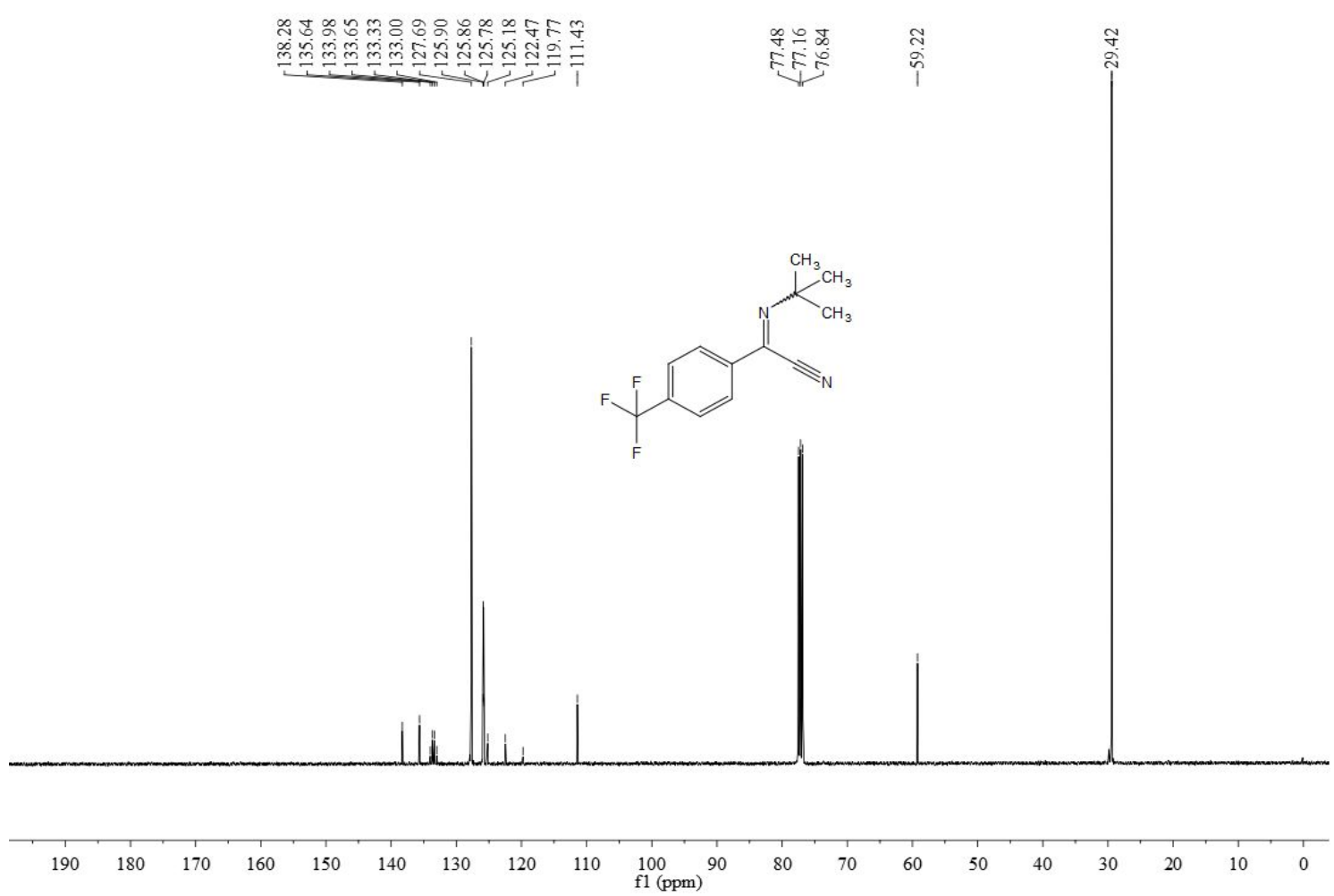
${ }^{1} \mathrm{H}$ NMR spectrum of compound $\mathbf{2} \mathbf{j}$

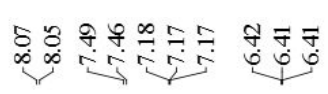
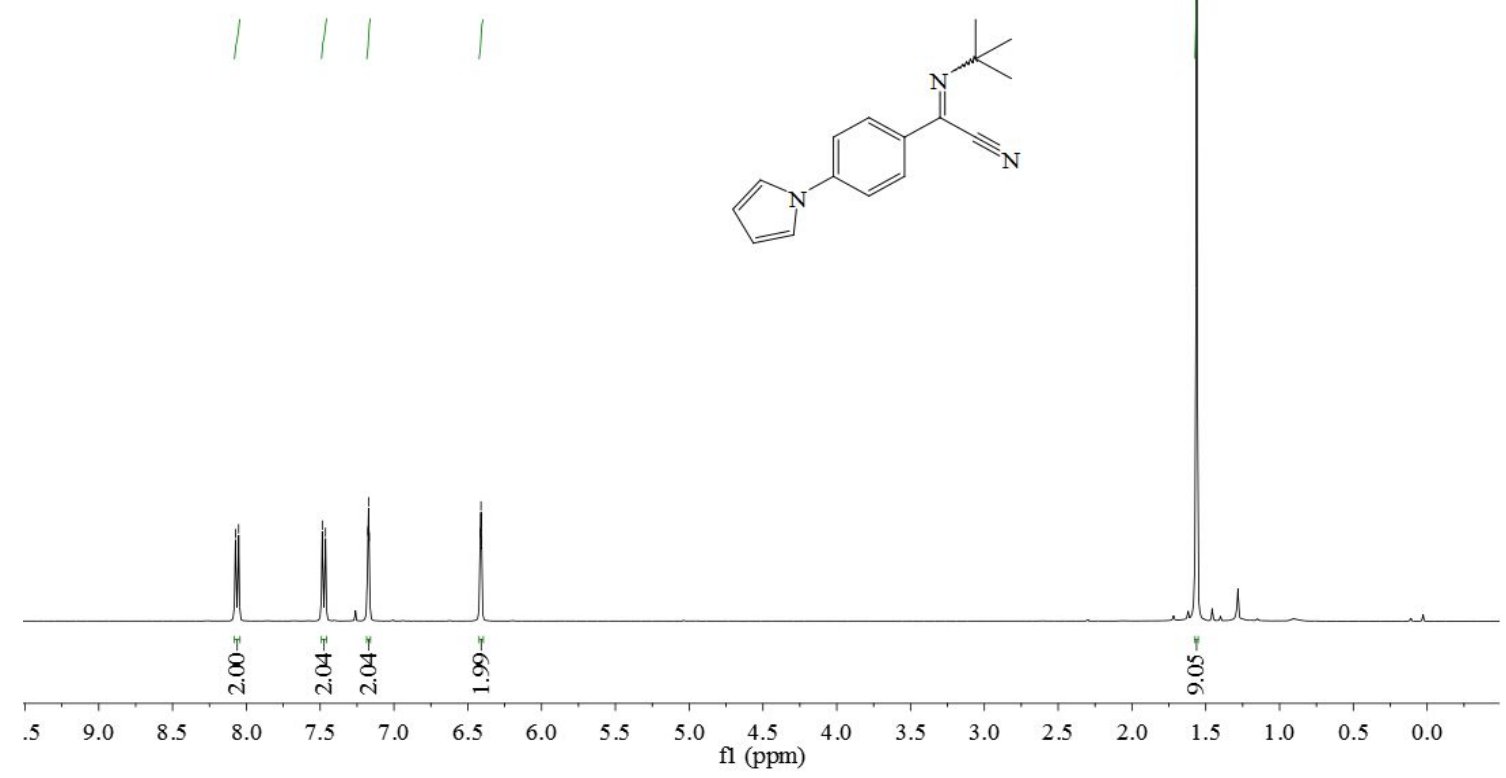

${ }^{13} \mathrm{C}$ NMR spectrum of compound $\mathbf{2} \mathbf{j}$

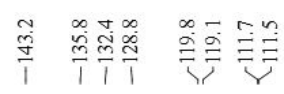

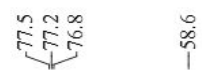

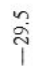

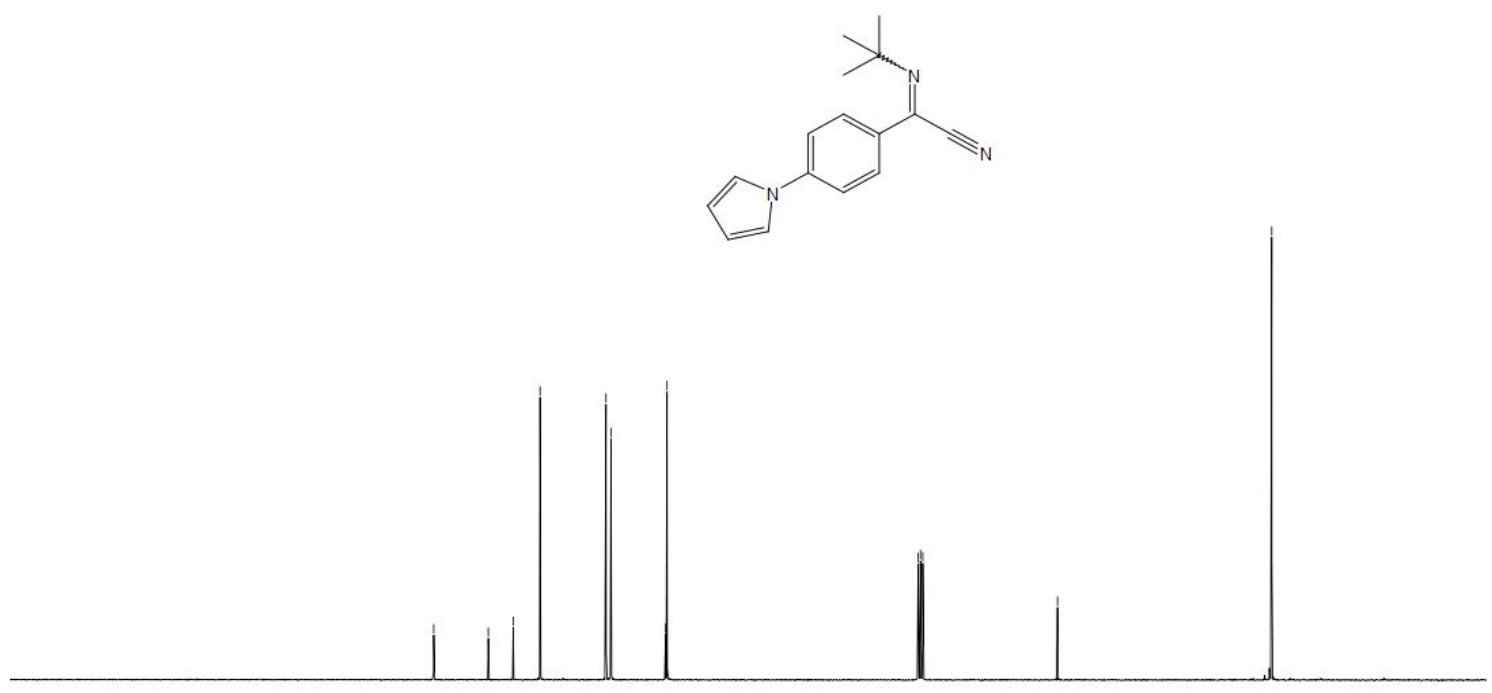

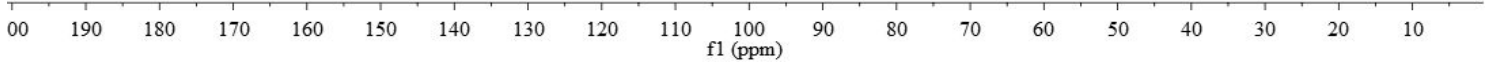


${ }^{1} \mathrm{H}$ NMR spectrum of compound $\mathbf{2 k}$

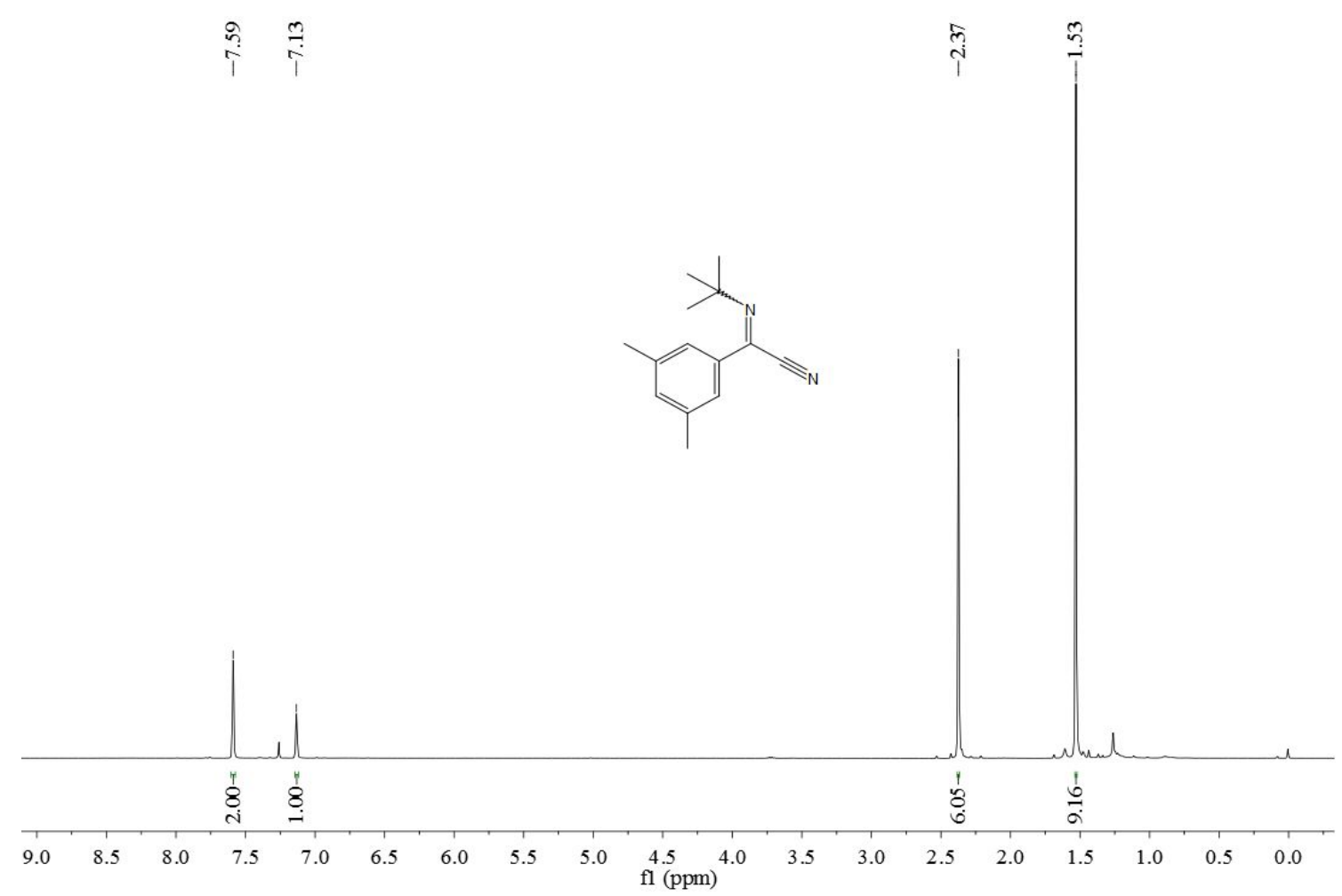

${ }^{13} \mathrm{C}$ NMR spectrum of compound $\mathbf{2 k}$

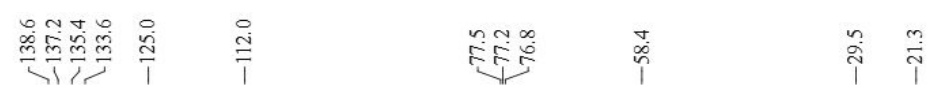

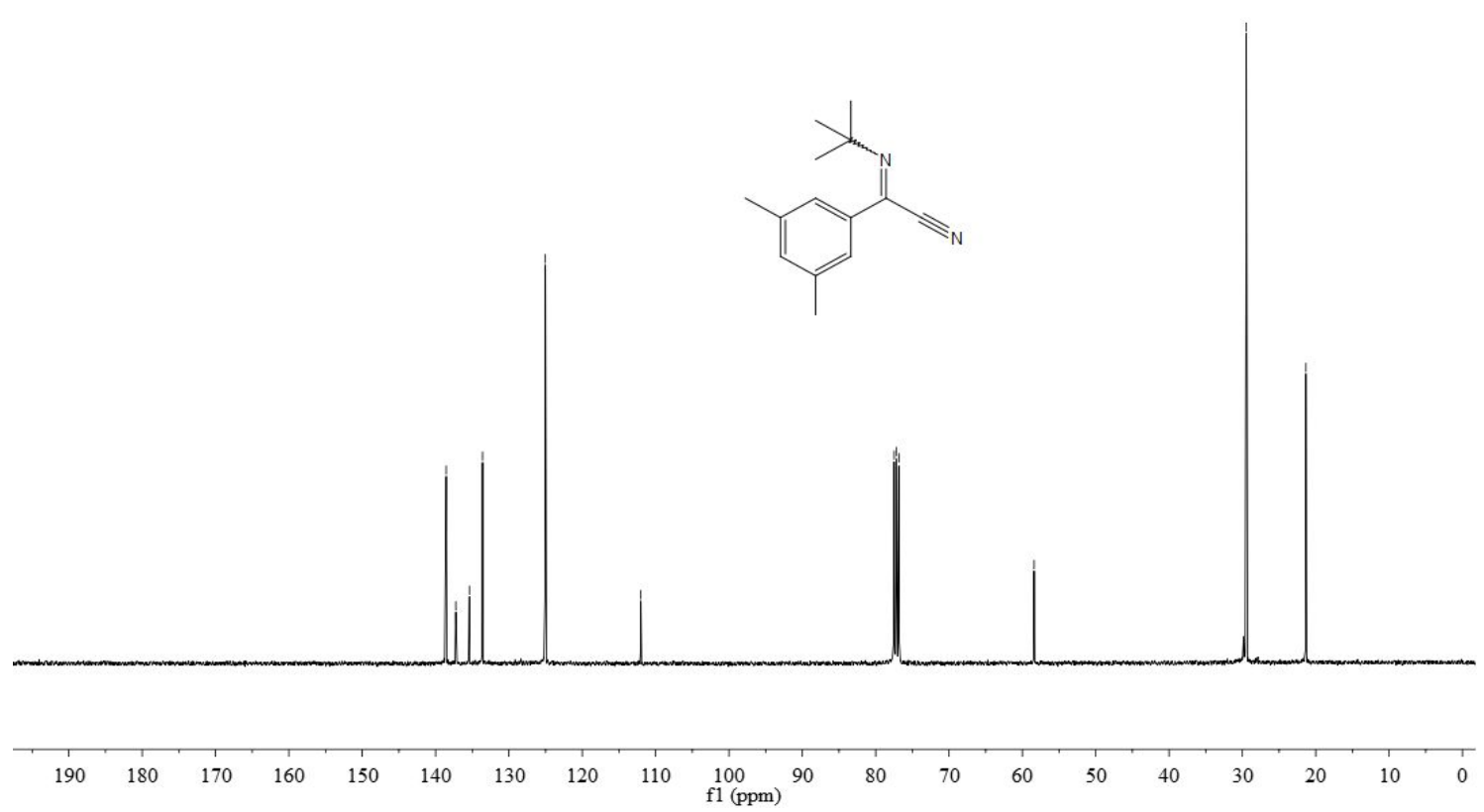


${ }^{1} \mathrm{H}$ NMR spectrum of compound $\mathbf{2 l}$

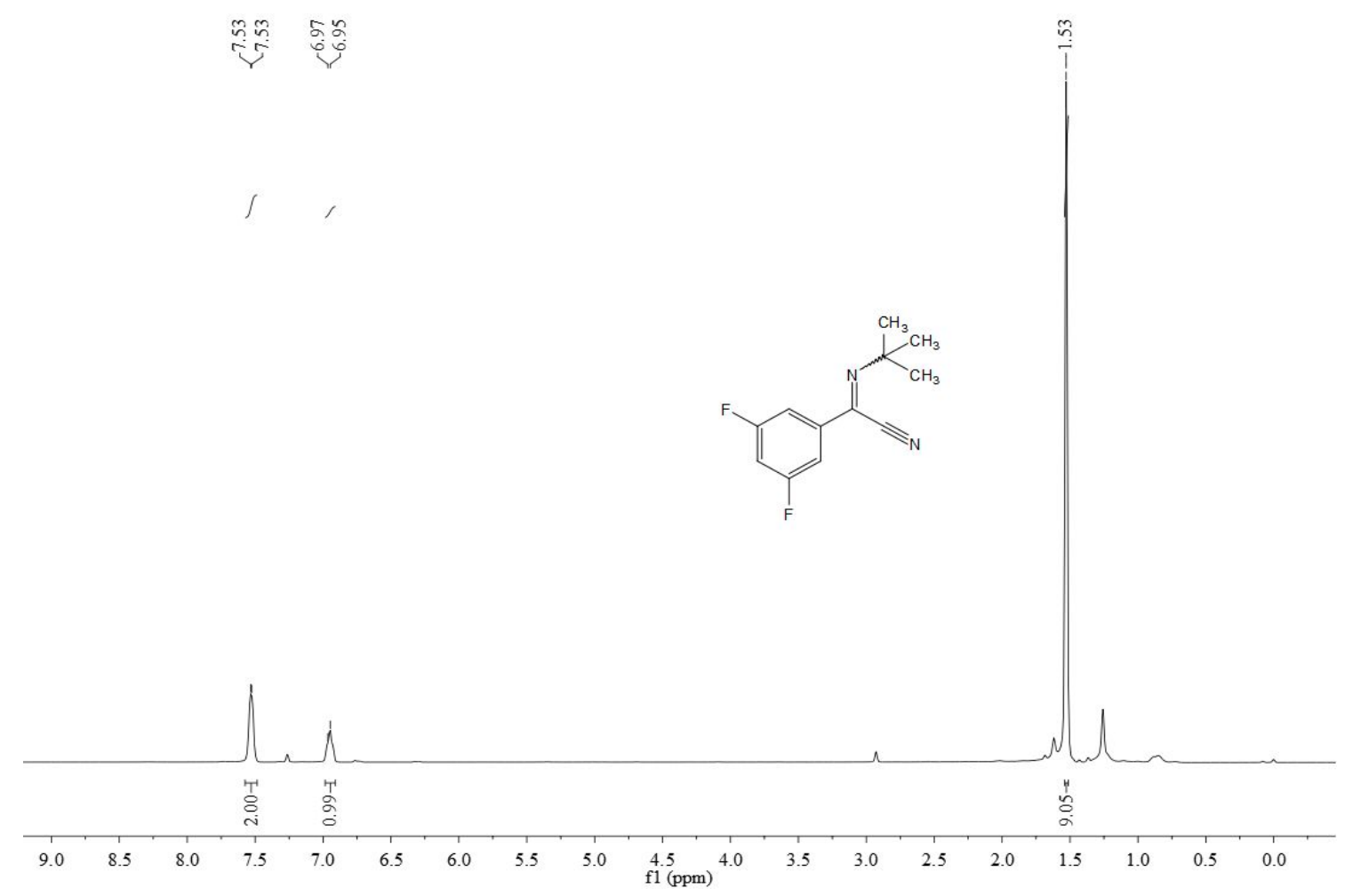

${ }^{13} \mathrm{C}$ NMR spectrum of compound $2 \mathbf{I}$
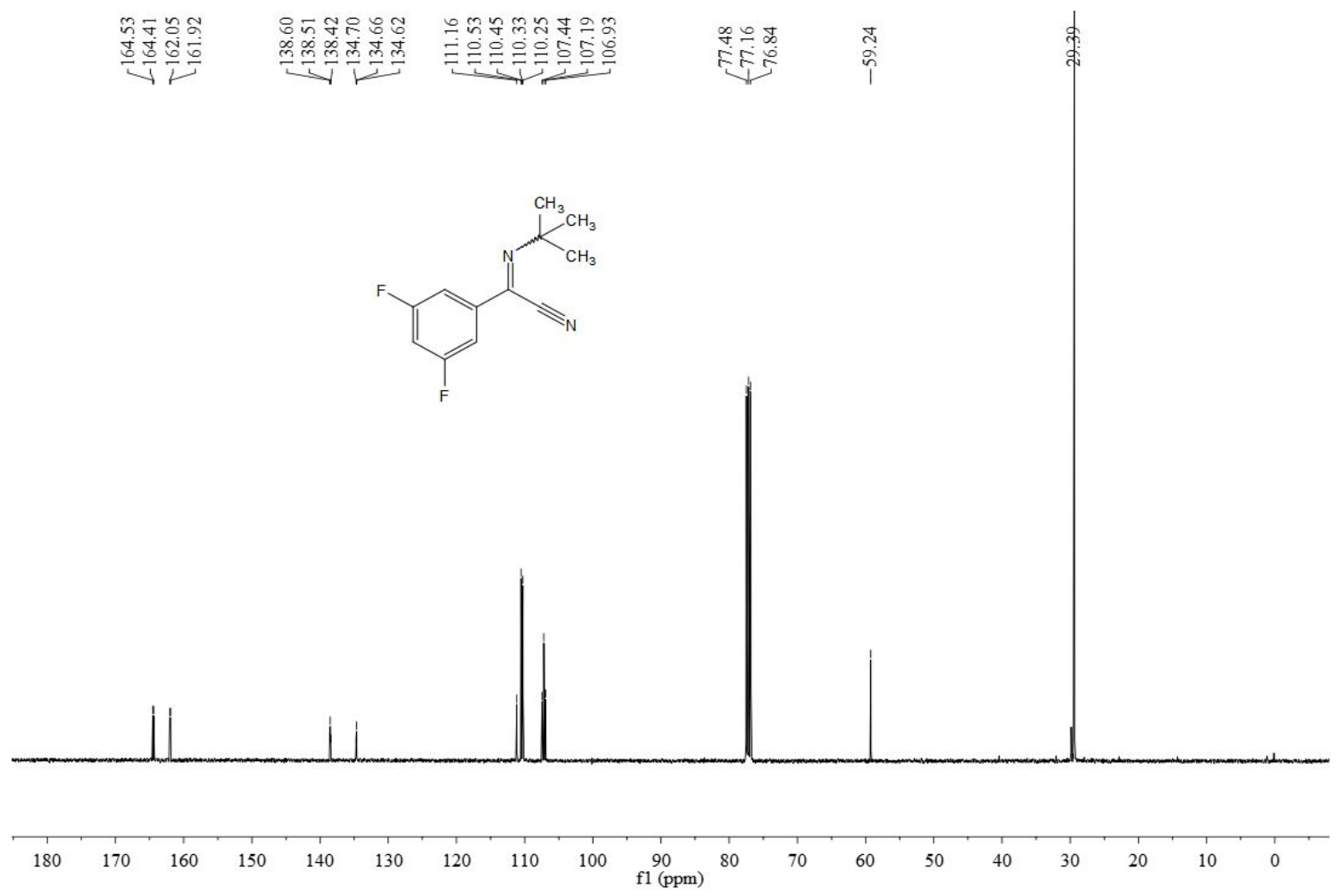
${ }^{1} \mathrm{H}$ NMR spectrum of compound $\mathbf{2 m}$

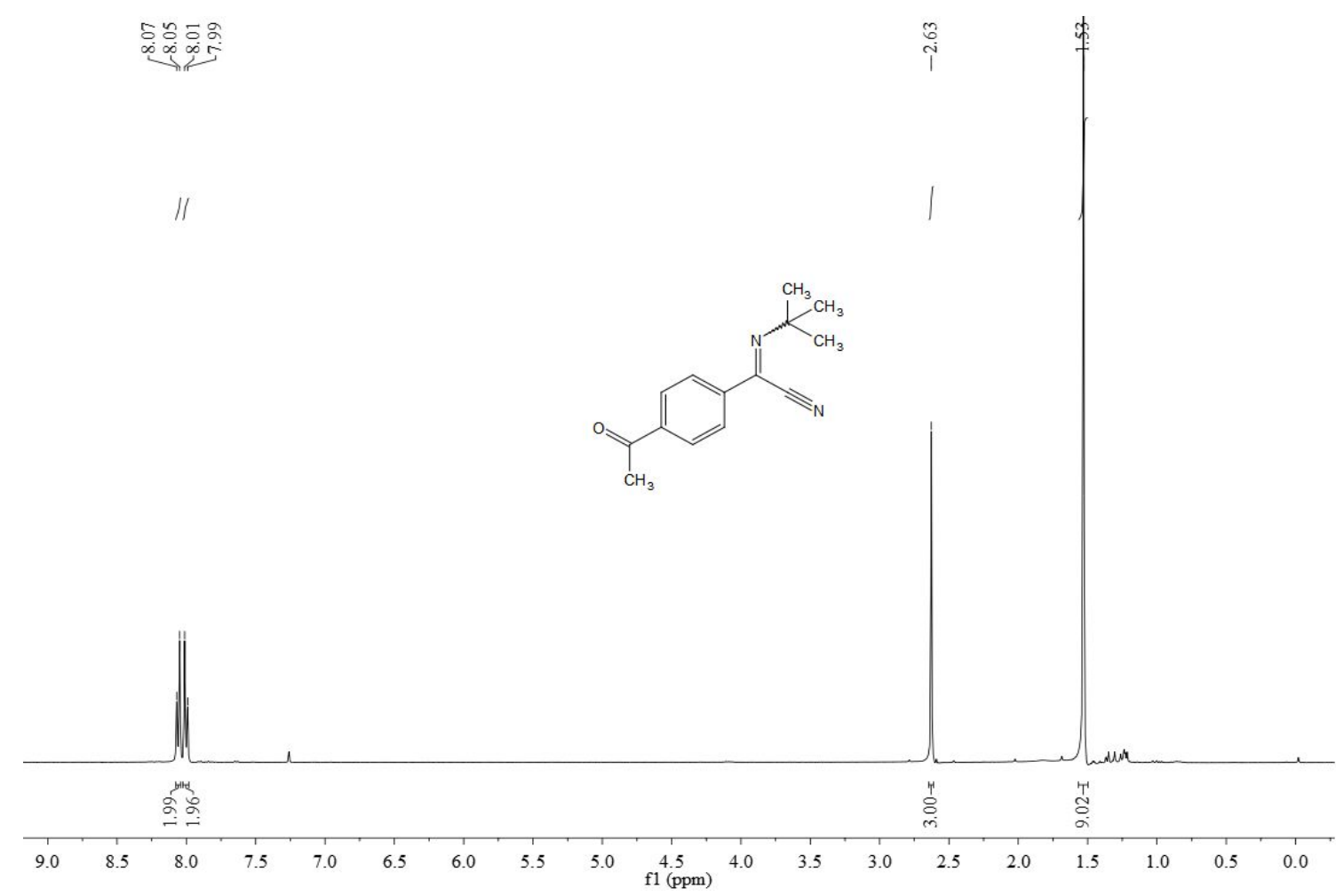

${ }^{13} \mathrm{C}$ NMR spectrum of compound $\mathbf{2 m}$

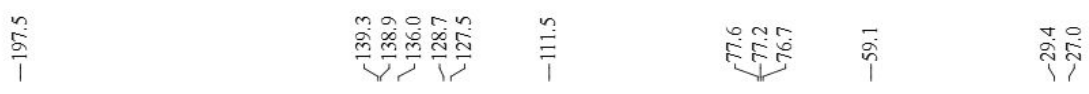

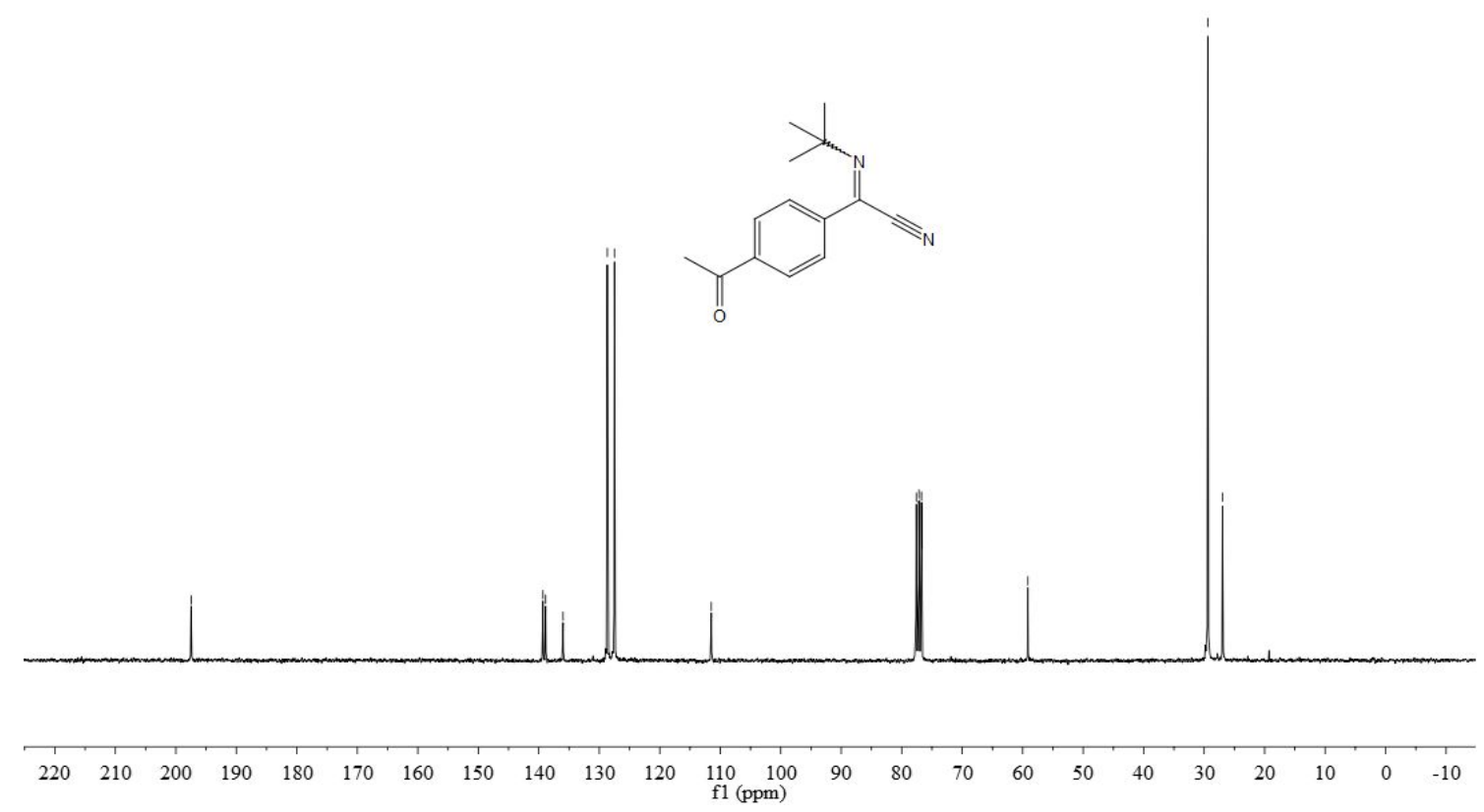


${ }^{1} \mathrm{H}$ NMR spectrum of compound $\mathbf{2 n}$

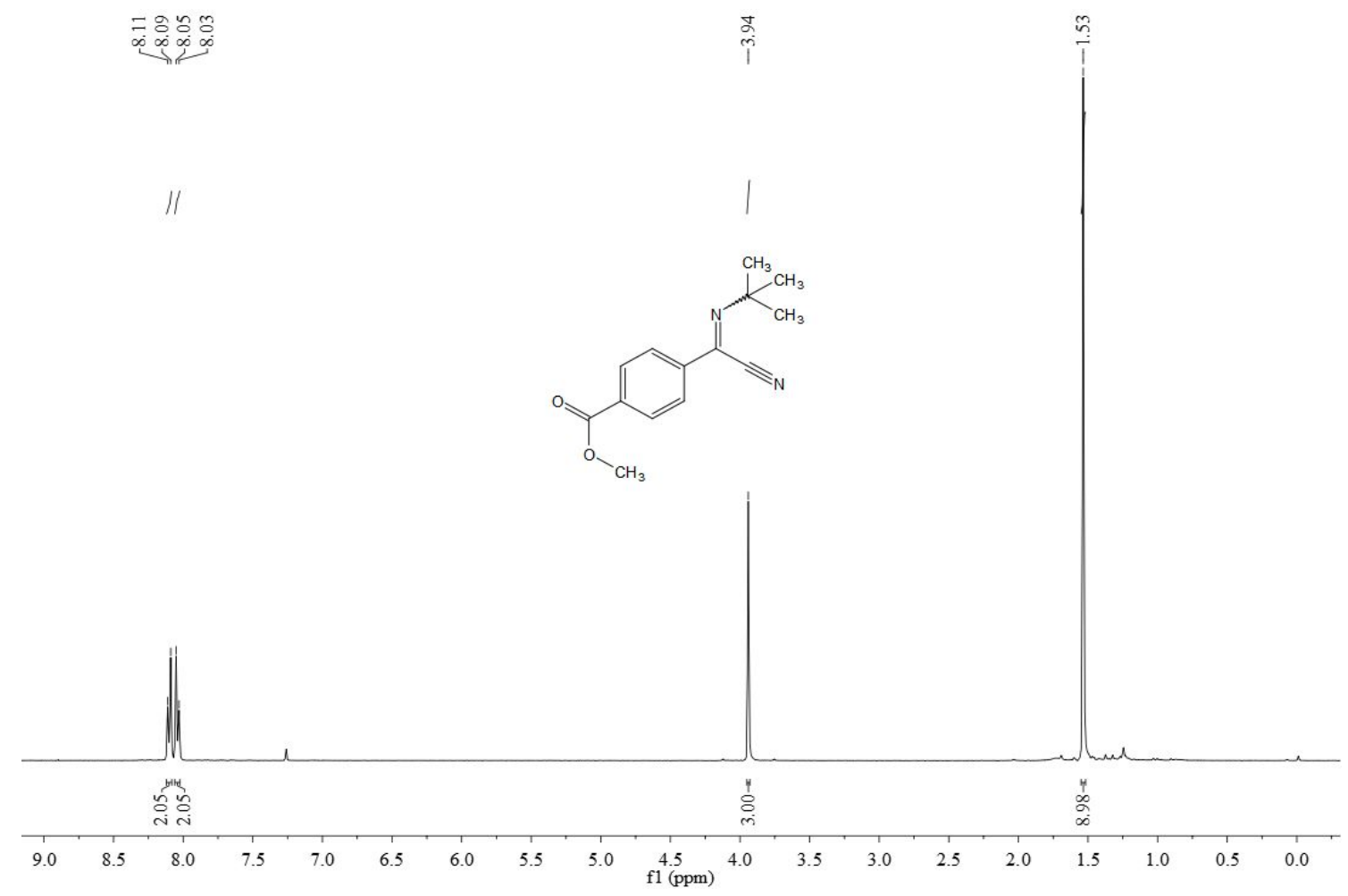

${ }^{13} \mathrm{C}$ NMR spectrum of compound $\mathbf{2 n}$

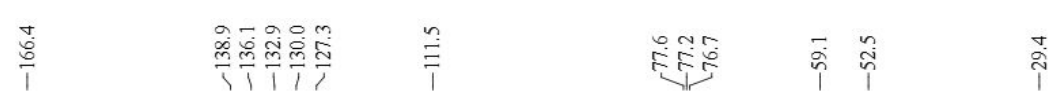<smiles>COC(=O)c1ccc(/C(C#N)=N\C(C)(C)C)cc1</smiles>

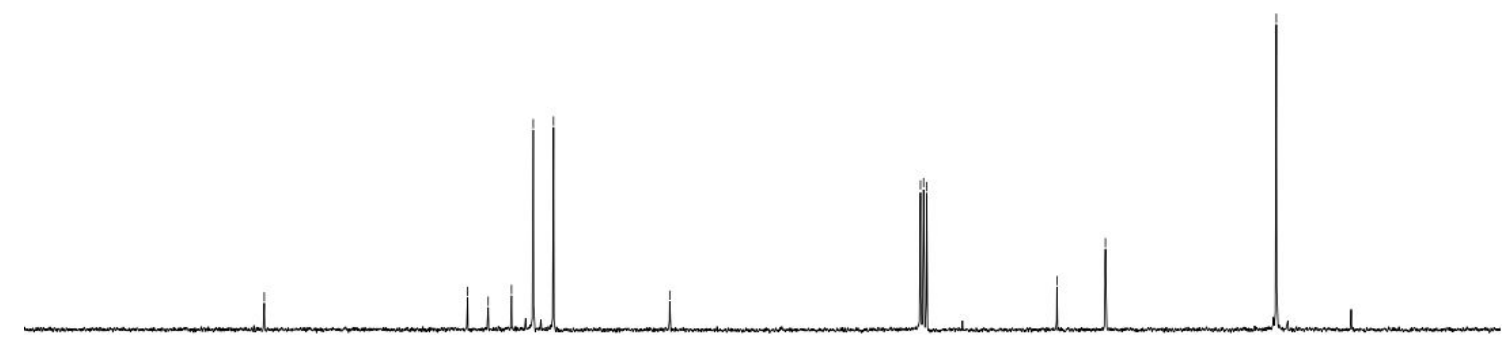

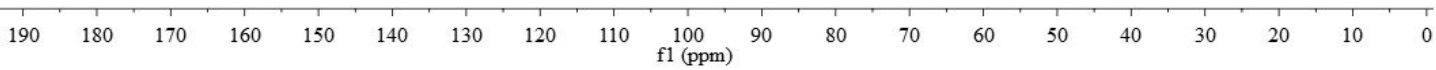


${ }^{1} \mathrm{H}$ NMR spectrum of compound $\mathbf{2 0}$

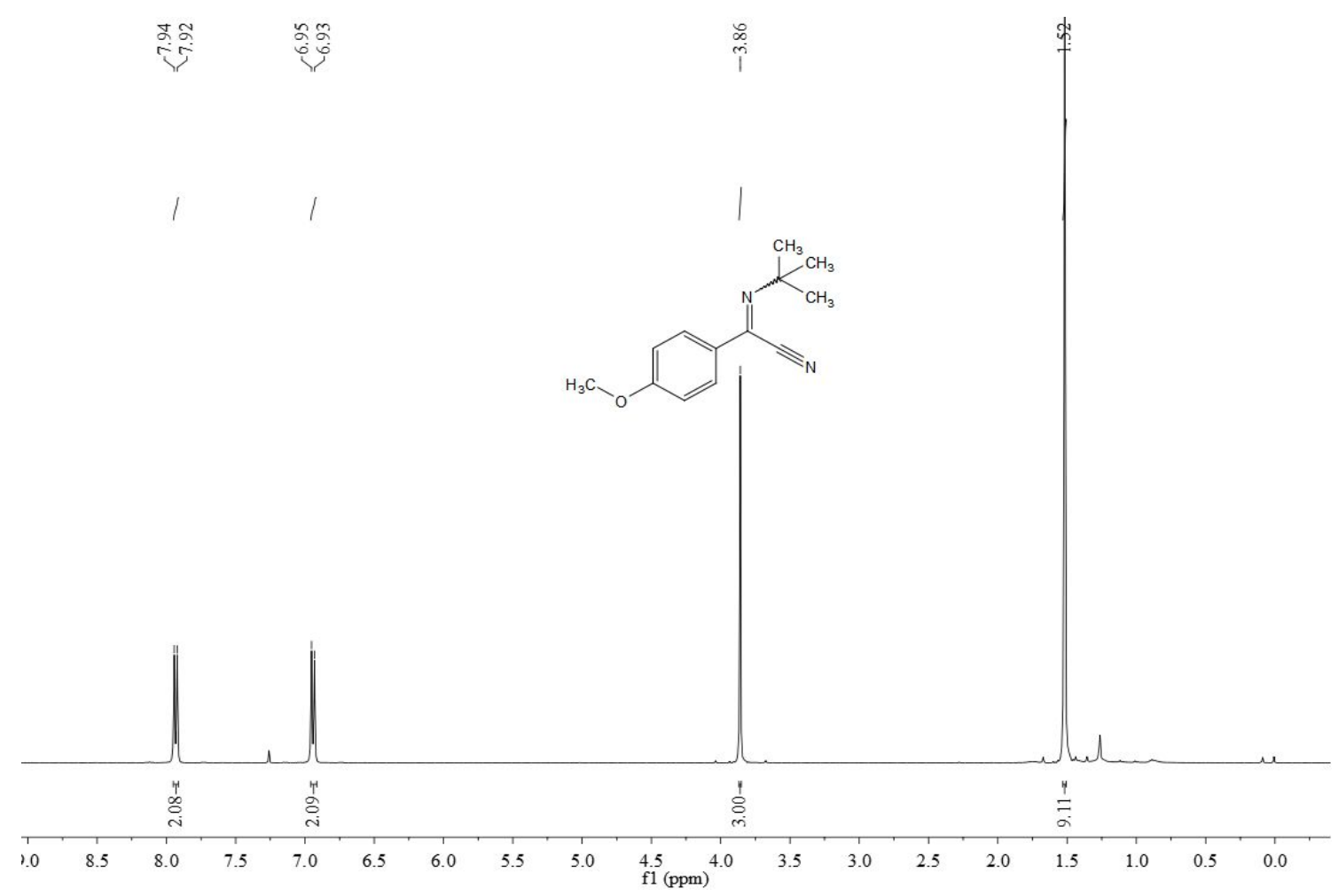

${ }^{13} \mathrm{C}$ NMR spectrum of compound 20
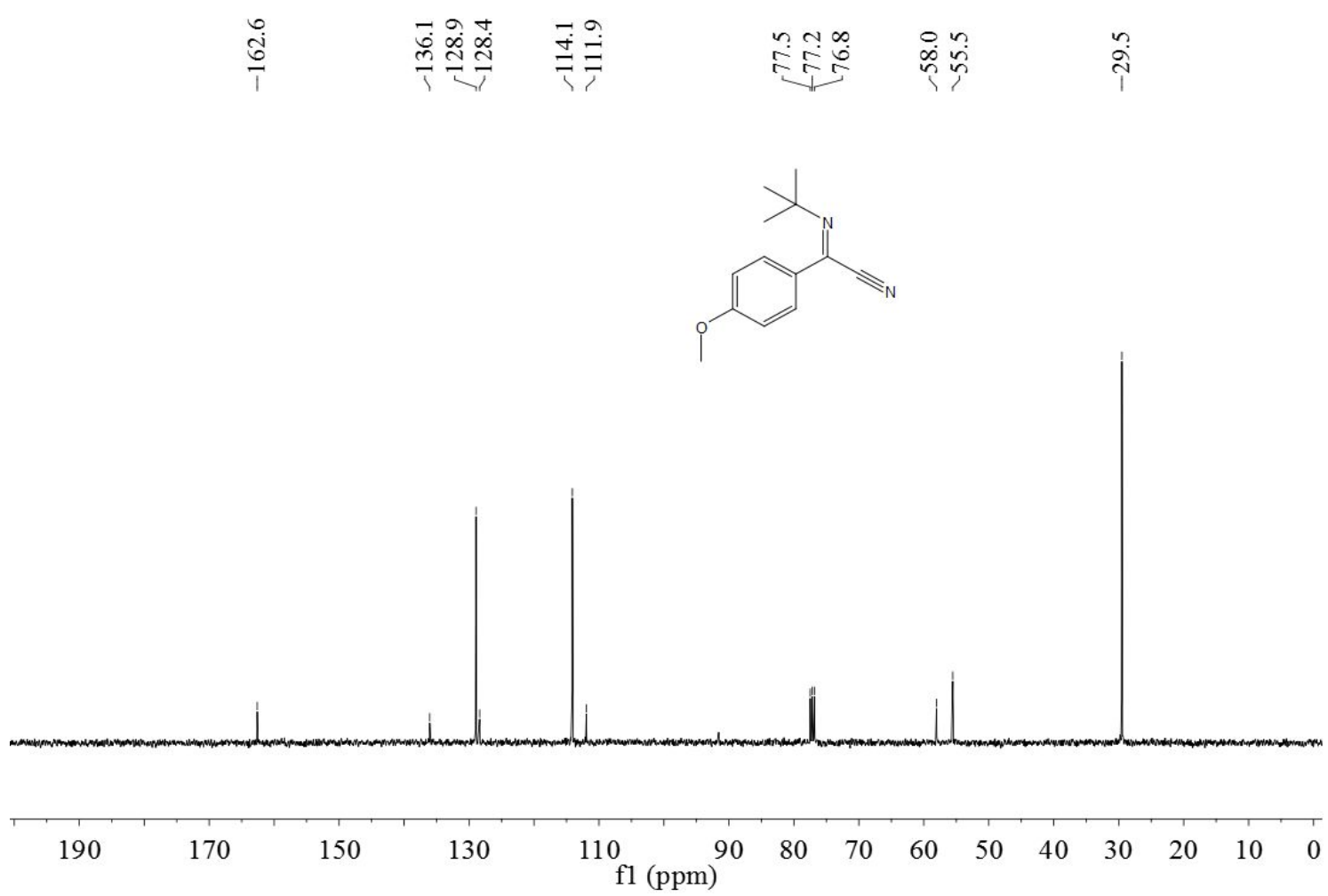
${ }^{1} \mathrm{H}$ NMR spectrum of compound $\mathbf{2 p}$

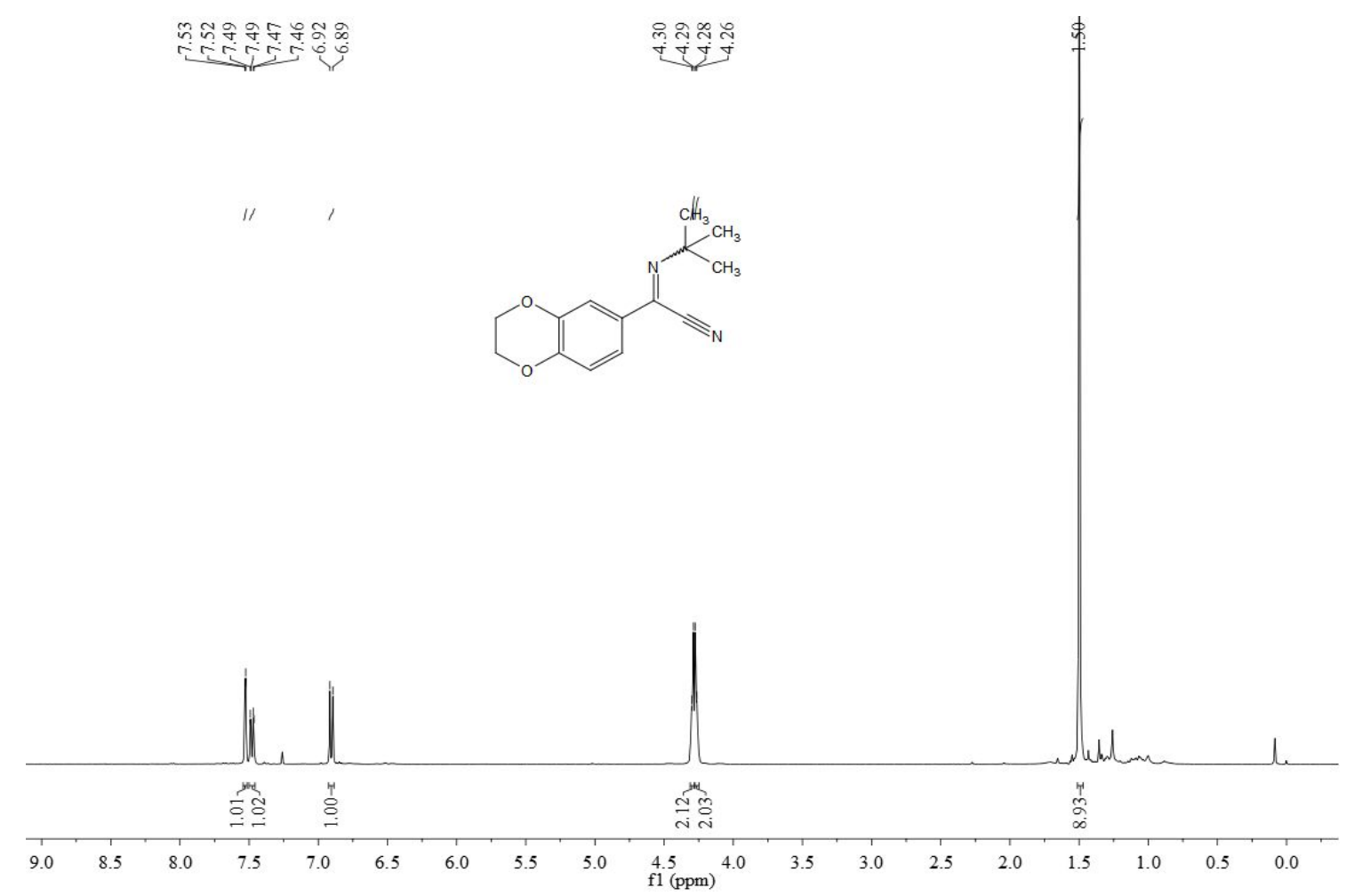

${ }^{13} \mathrm{C}$ NMR spectrum of compound $\mathbf{2 p}$

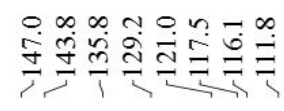

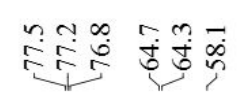
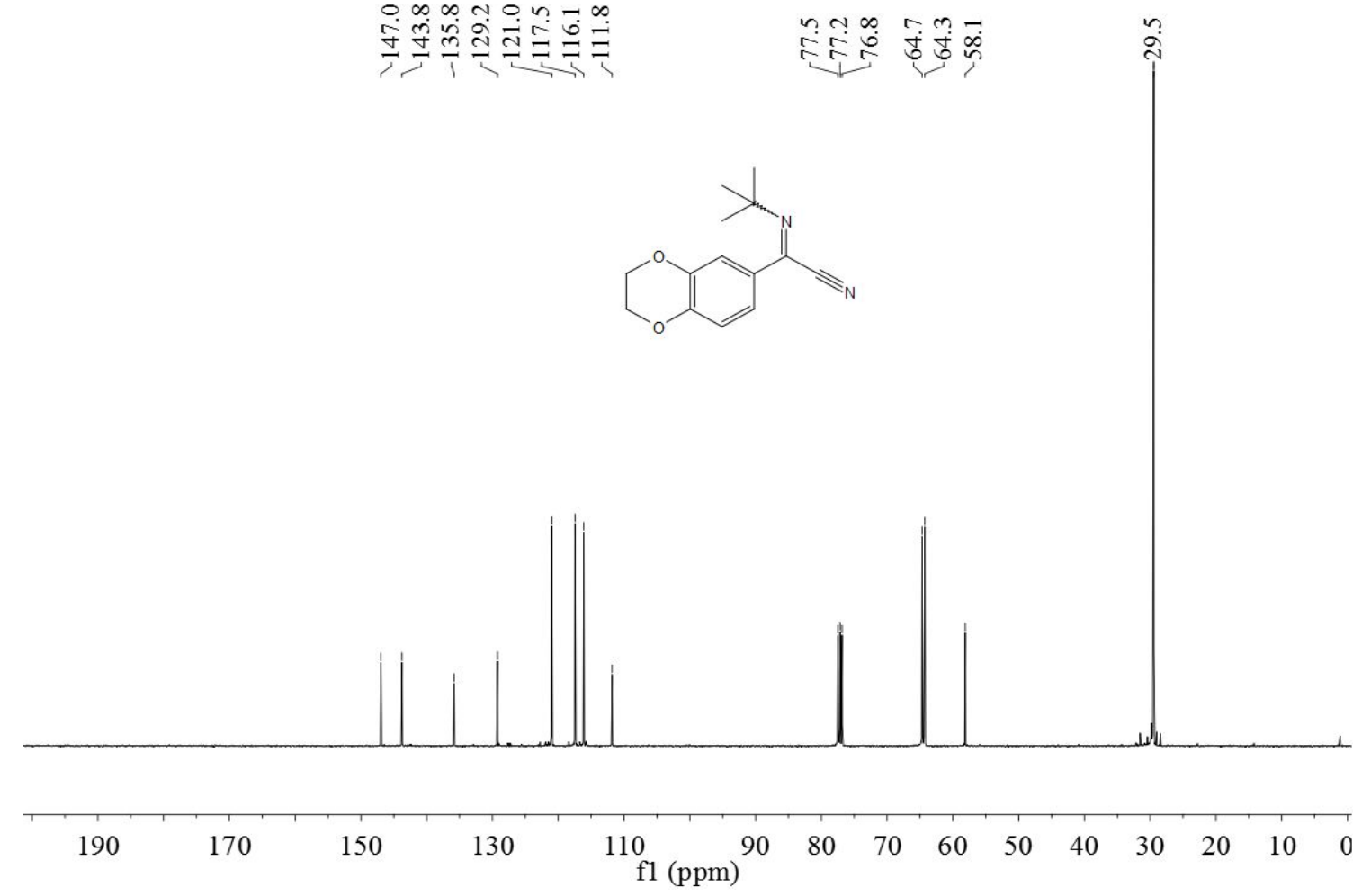
${ }^{1} \mathrm{H}$ NMR spectrum of compound $\mathbf{2 q}$

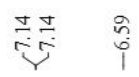

$\underset{\substack{i \\ i}}{\stackrel{\infty}{i}}$

กิ

1,

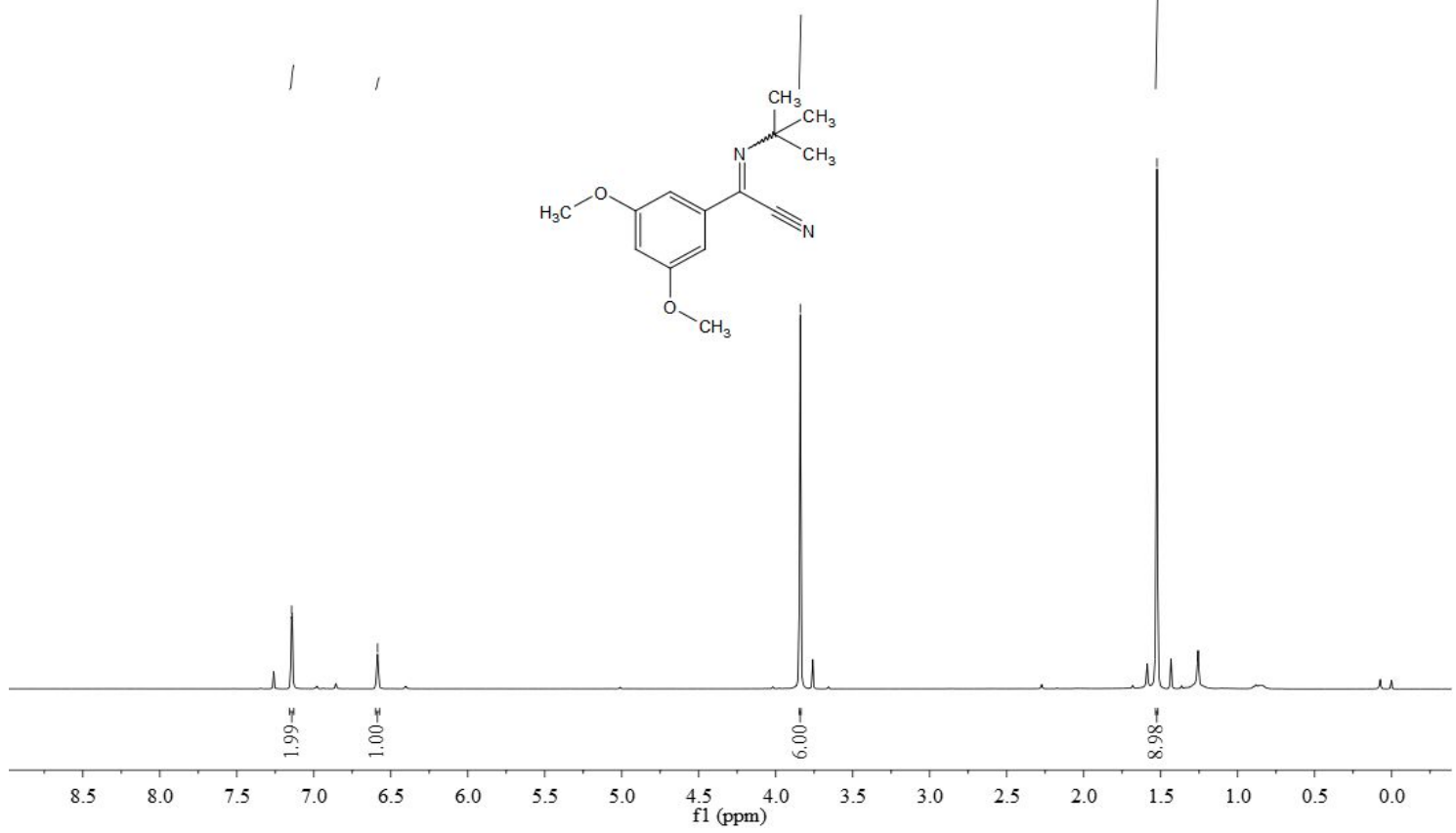

${ }^{13} \mathrm{C}$ NMR spectrum of compound $\mathbf{2 q}$

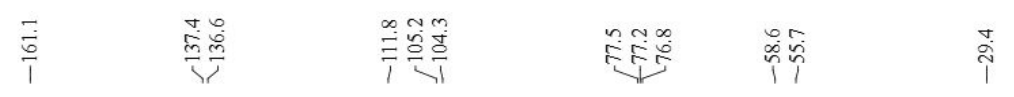<smiles>COc1cc(OC)cc(/C(C#N)=N/C(C)(C)C)c1</smiles>

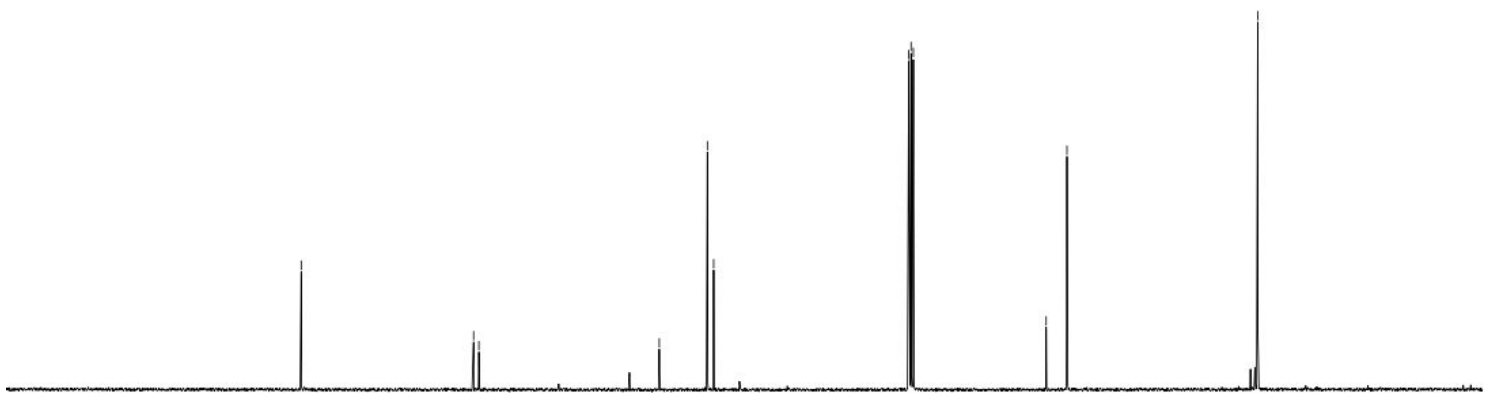

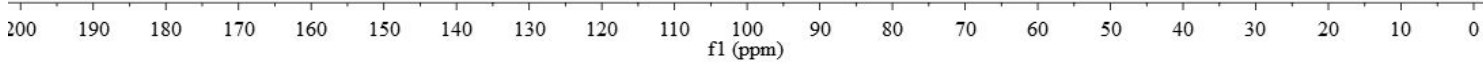


${ }^{1} \mathrm{H}$ NMR spectrum of compound $\mathbf{2 r}$
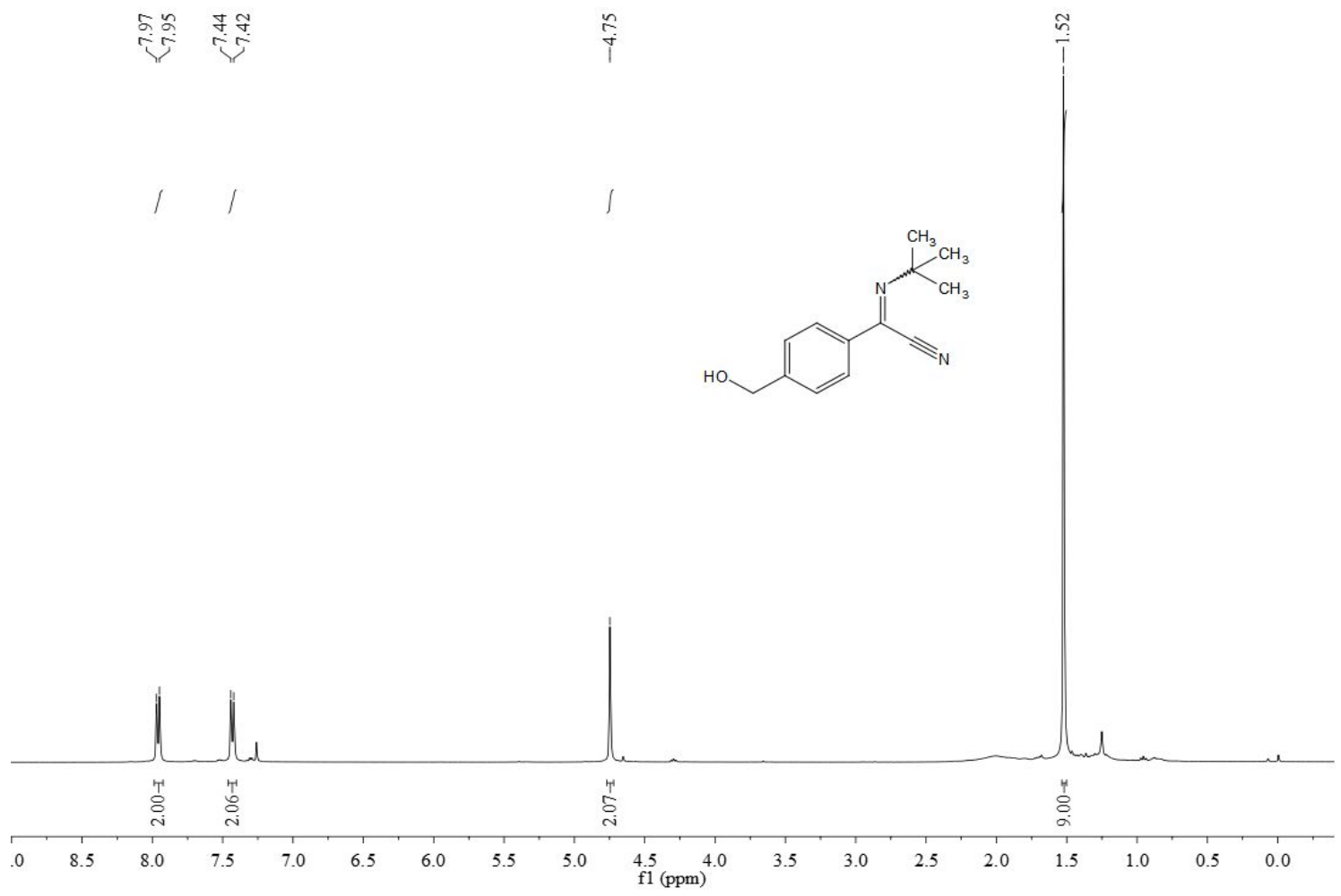

${ }^{13} \mathrm{C}$ NMR spectrum of compound $\mathbf{2 r}$

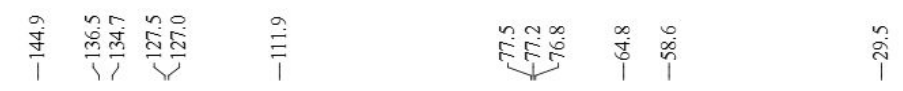

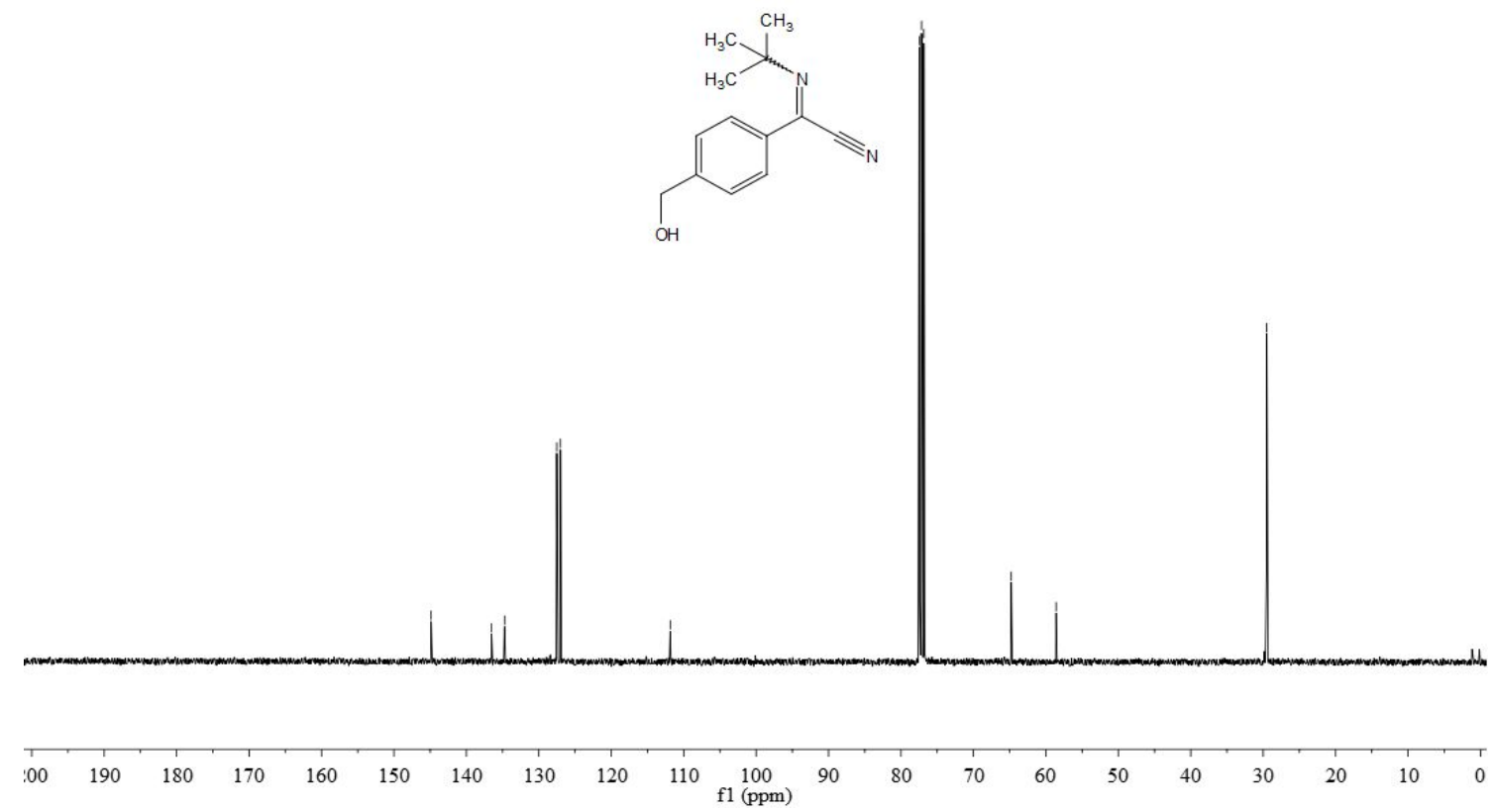


${ }^{1} \mathrm{H}$ NMR spectrum of compound $\mathbf{2 s}$
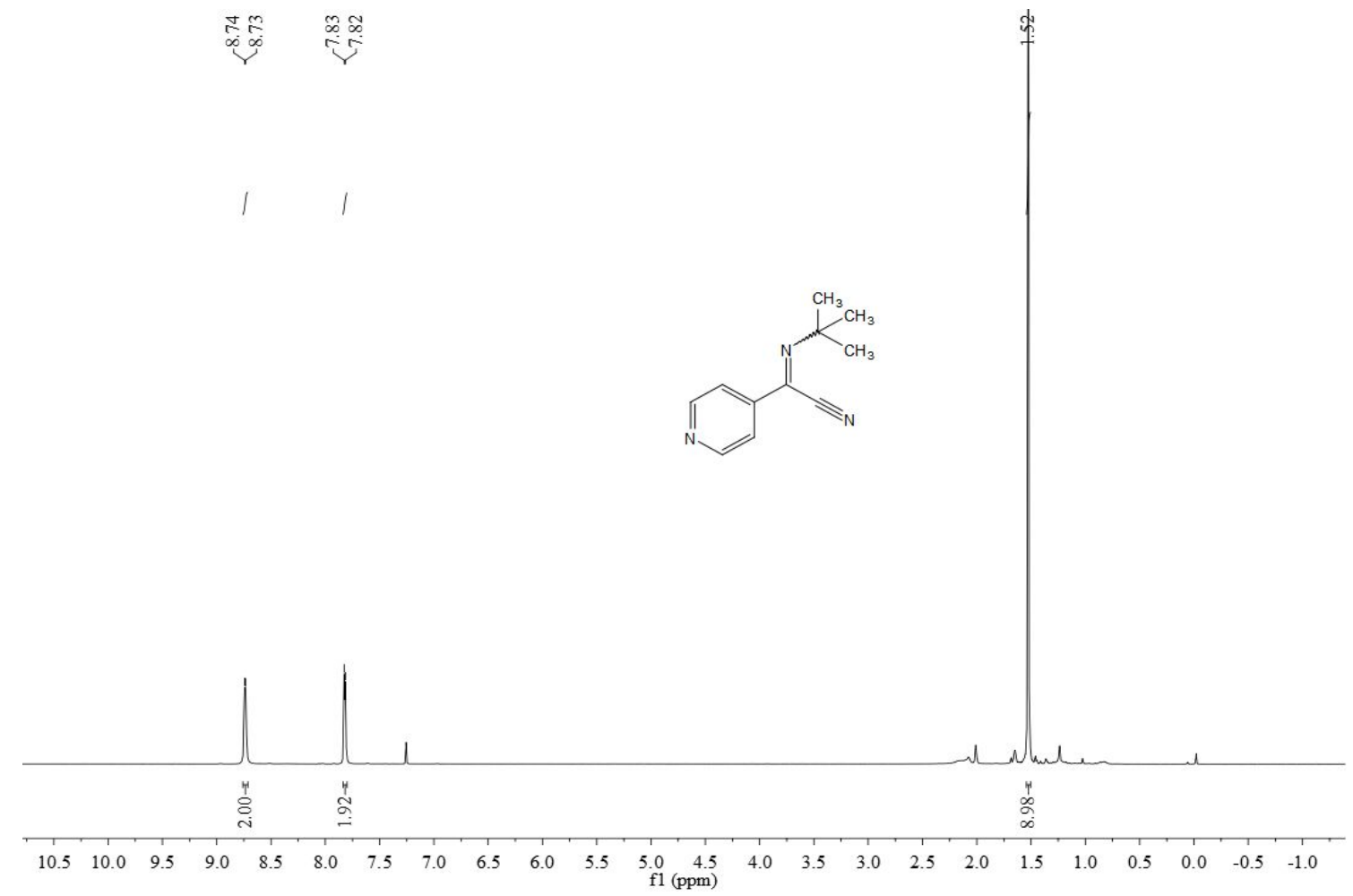

${ }^{13} \mathrm{C}$ NMR spectrum of compound $2 \mathrm{~s}$

\begin{tabular}{|c|c|c|c|c|c|c|}
\hline$\frac{m}{i}$ & $\frac{\stackrel{\circ}{\mathbb{V}}}{1}$ & $\underset{m}{\stackrel{v}{r}}$ & 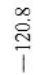 & $\stackrel{\circ}{\frac{O}{\Xi}}$ & 悉悉 & $\stackrel{\circ}{\circ}$ \\
\hline
\end{tabular}<smiles>CC(C)(C)N=C(C#N)c1ccncc1</smiles>
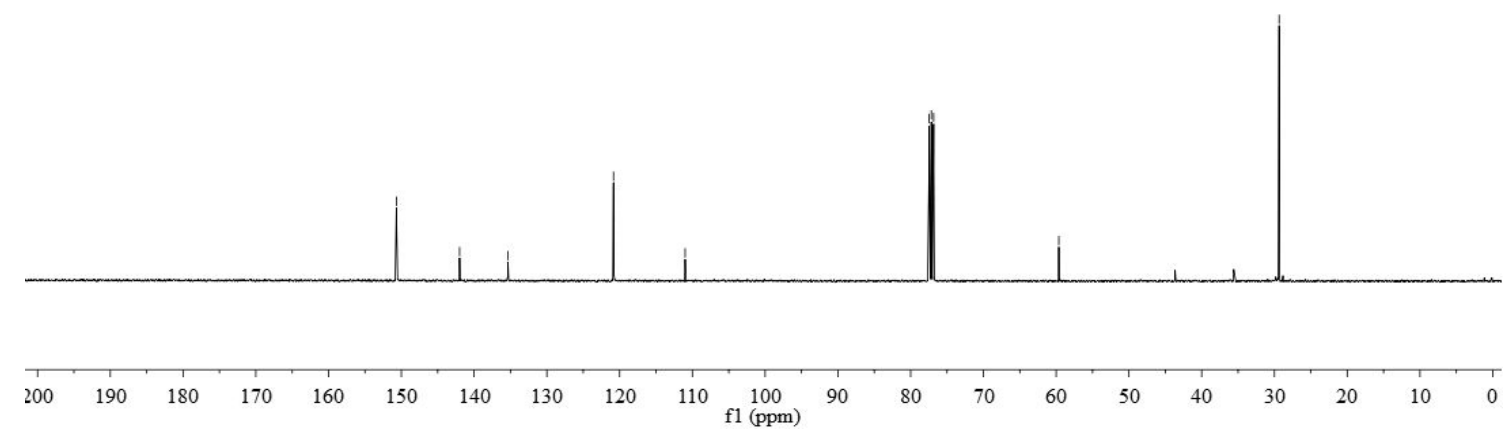
${ }^{1} \mathrm{H}$ NMR spectrum of compound $\mathbf{2 t}$

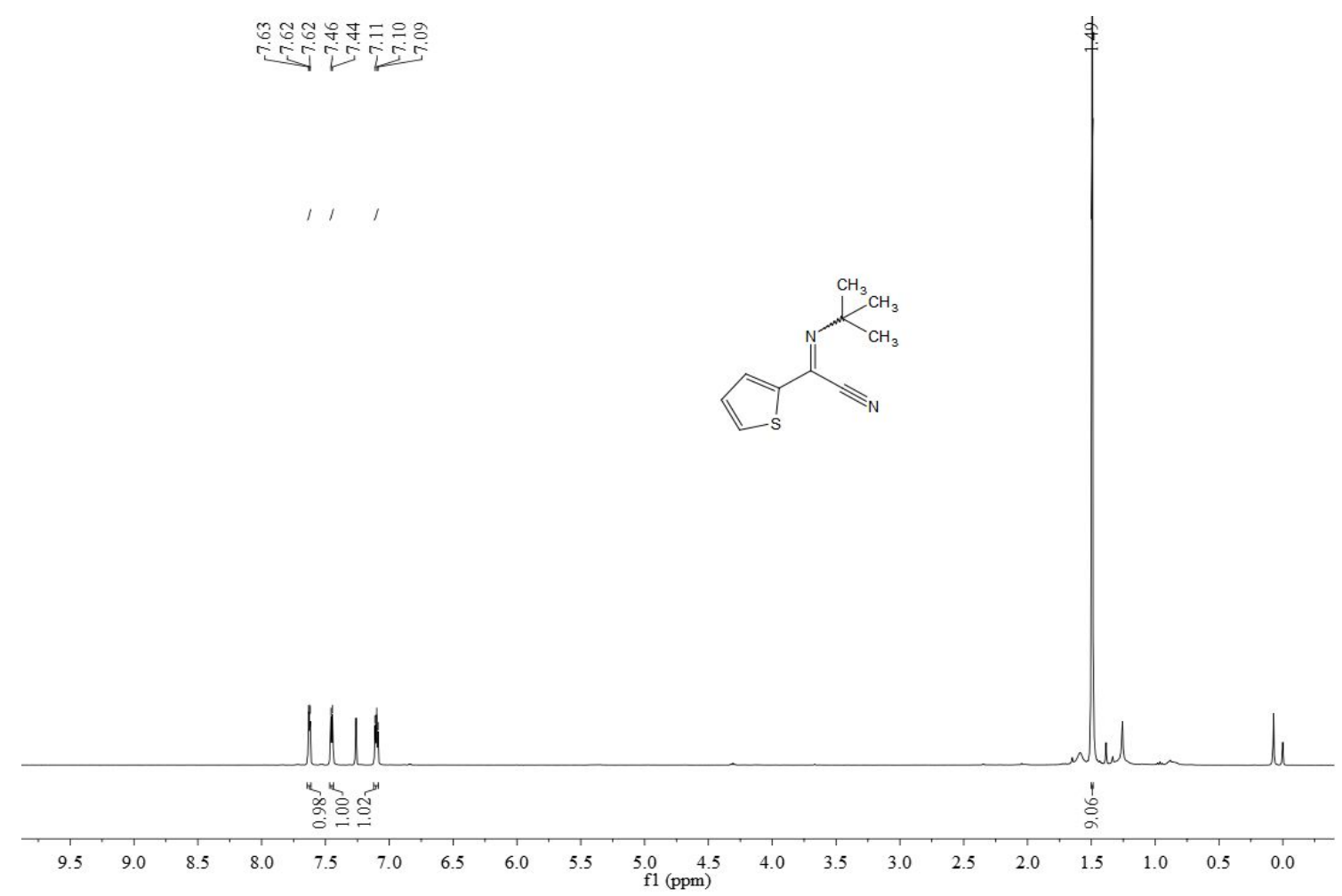

${ }^{13} \mathrm{C}$ NMR spectrum of compound $\mathbf{2 t}$

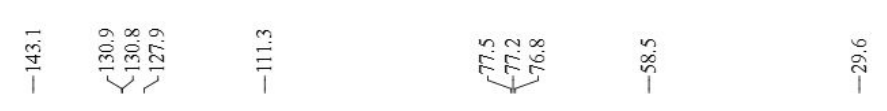

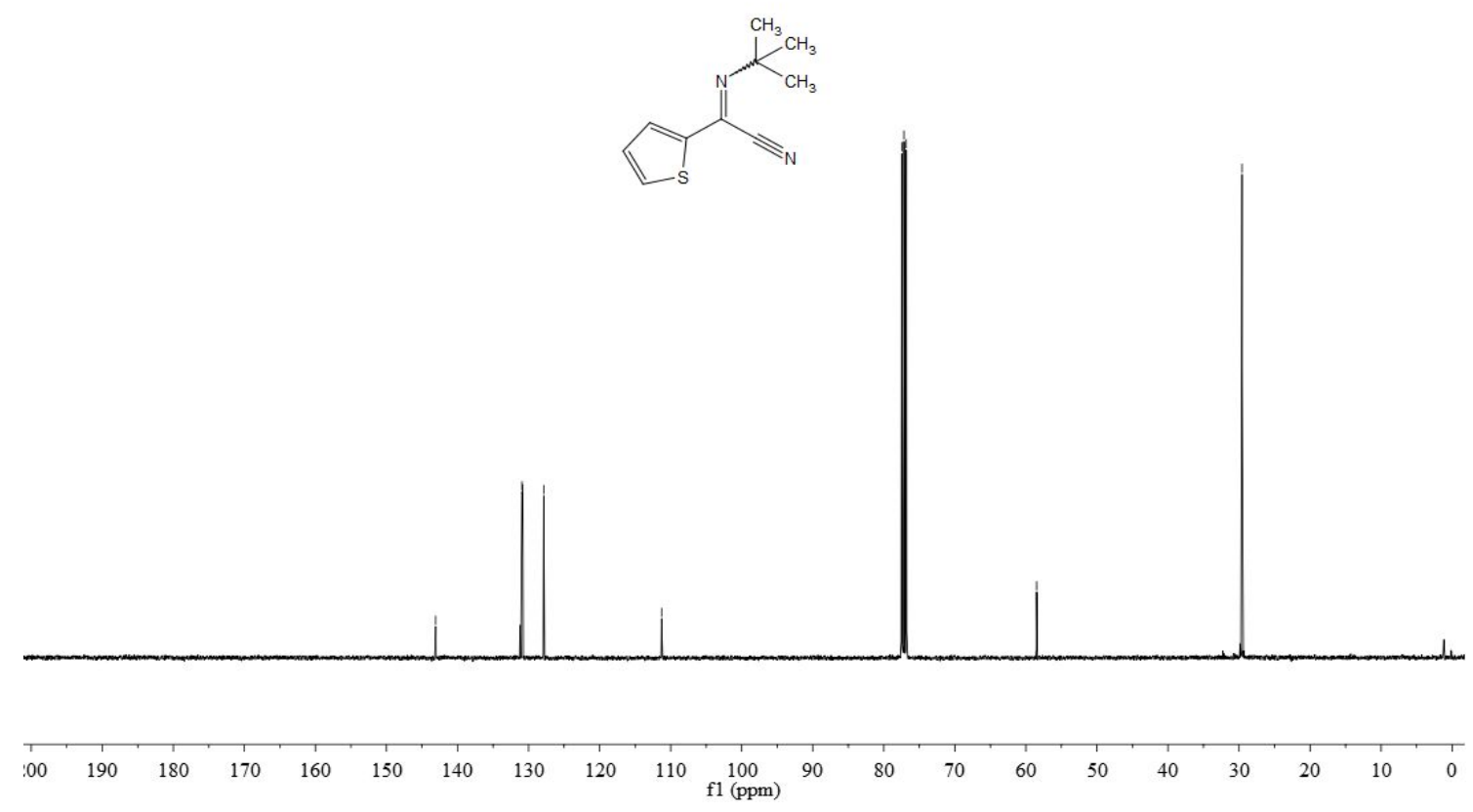


${ }^{1} \mathrm{H}$ NMR spectrum of compound $\mathbf{2 u}$

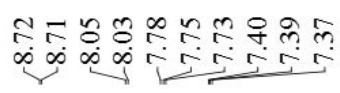

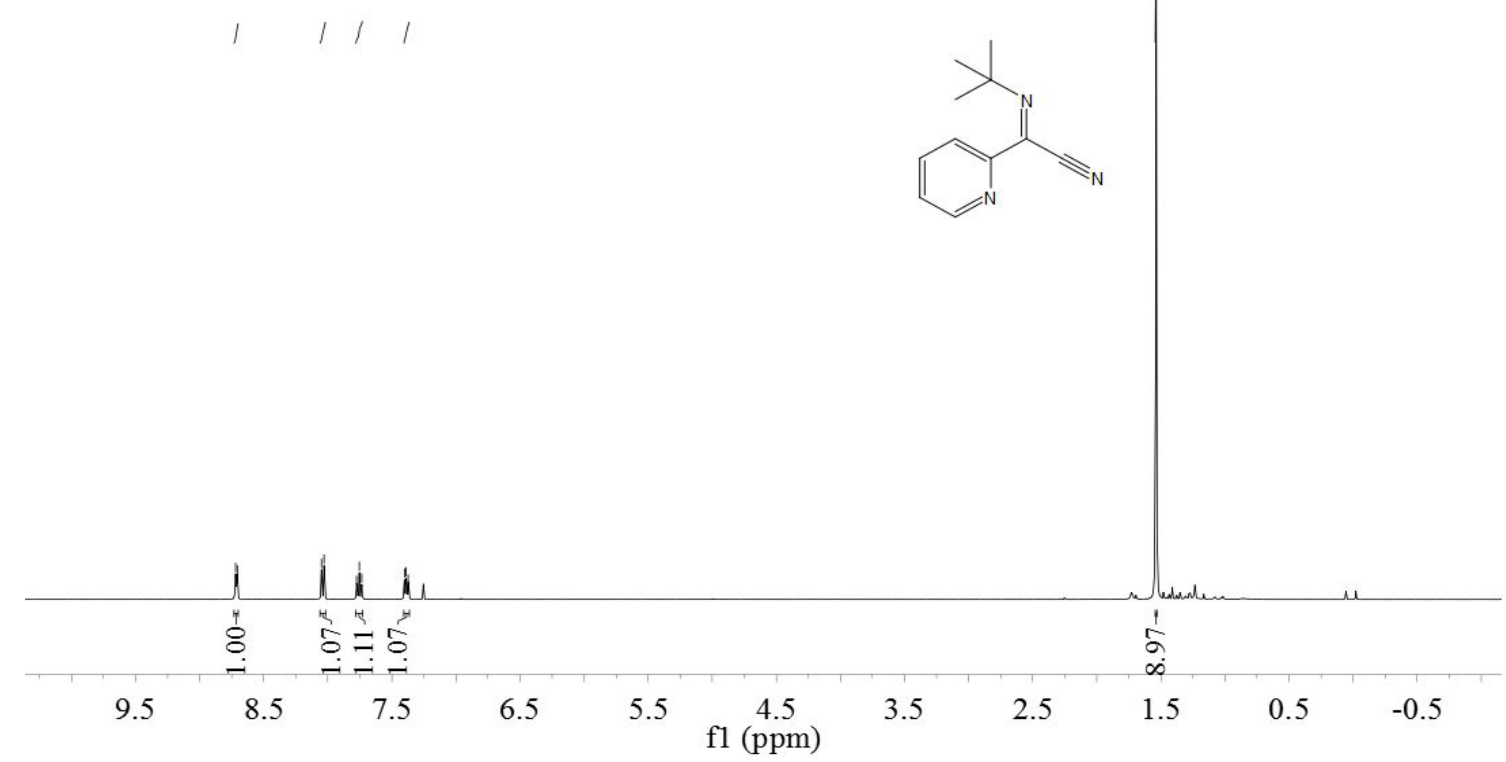

${ }^{13} \mathrm{C}$ NMR spectrum of compound $\mathbf{2 u}$
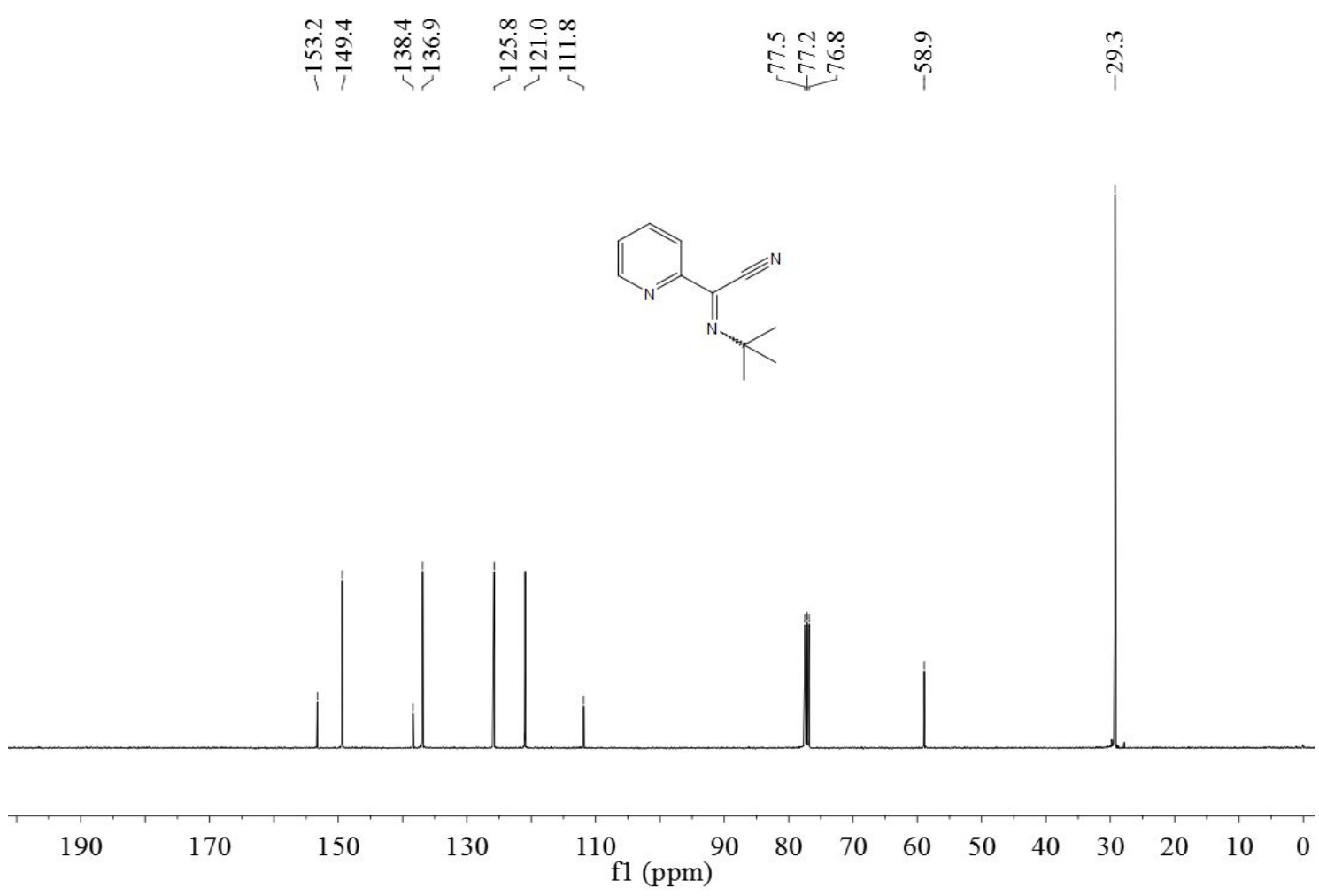
${ }^{1} \mathrm{H}$ NMR spectrum of compound $\mathbf{2 v}$
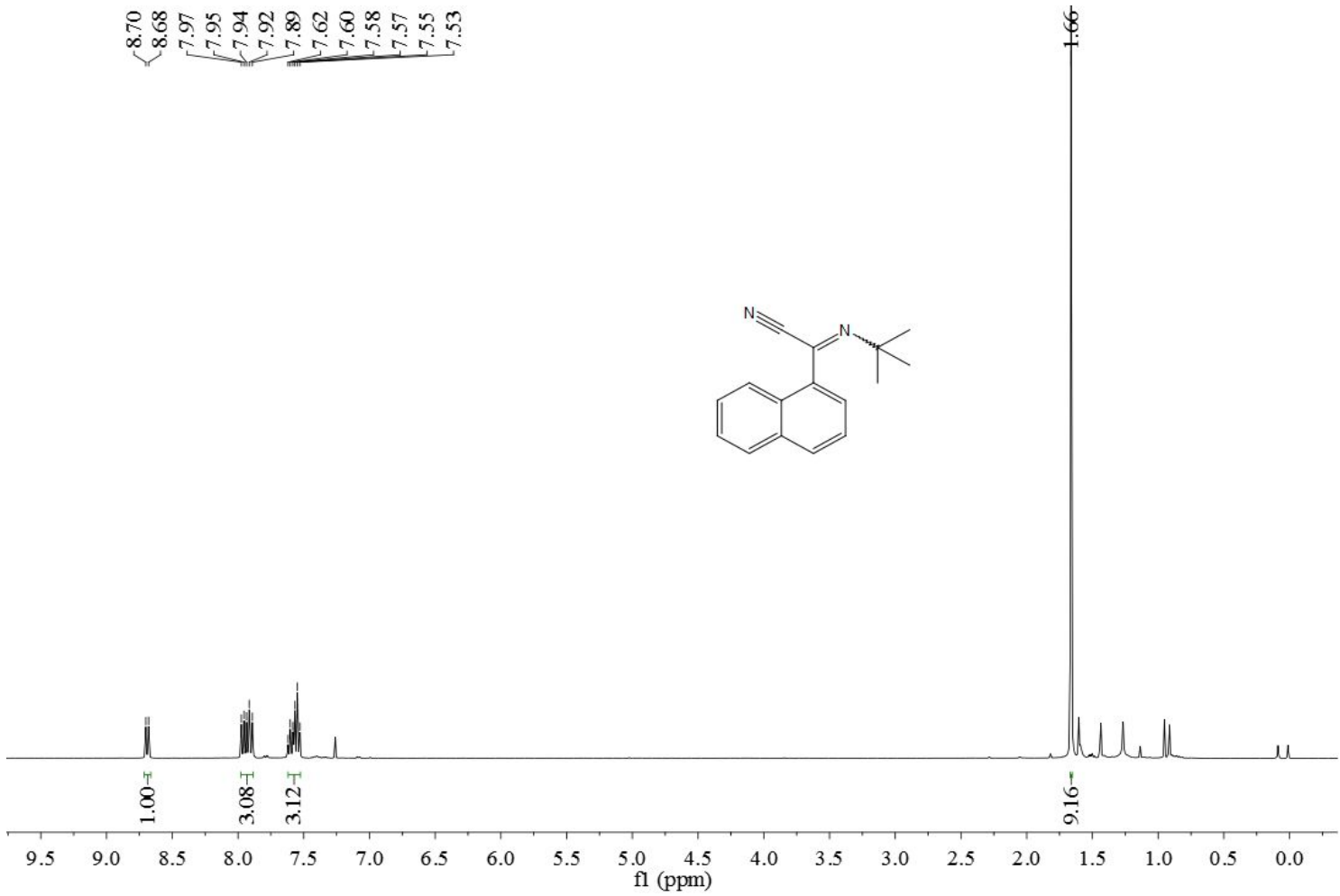

${ }^{13} \mathrm{C}$ NMR spectrum of compound $\mathbf{2 v}$

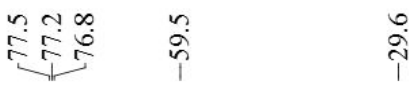
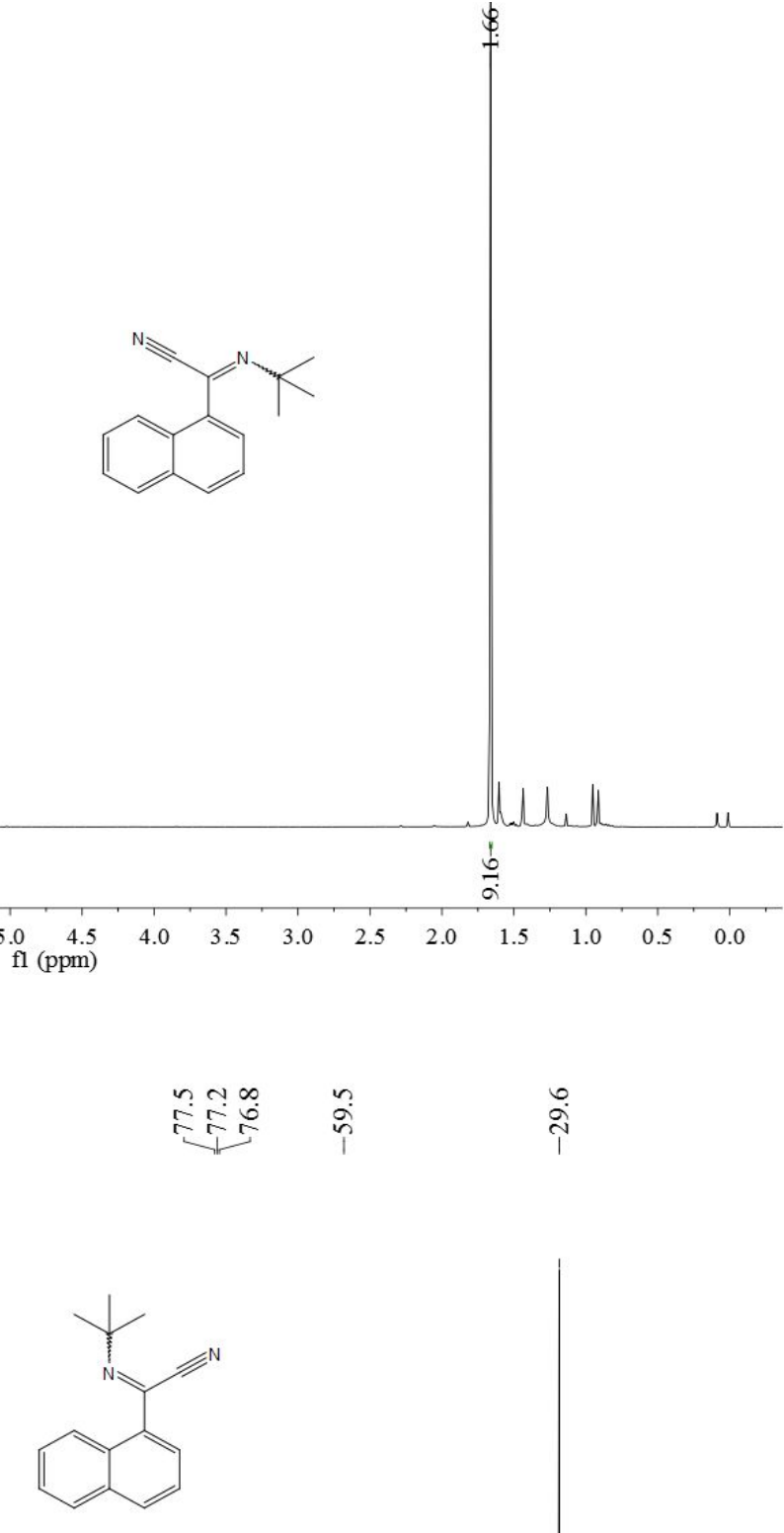

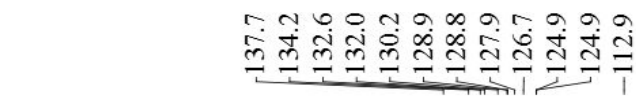

.
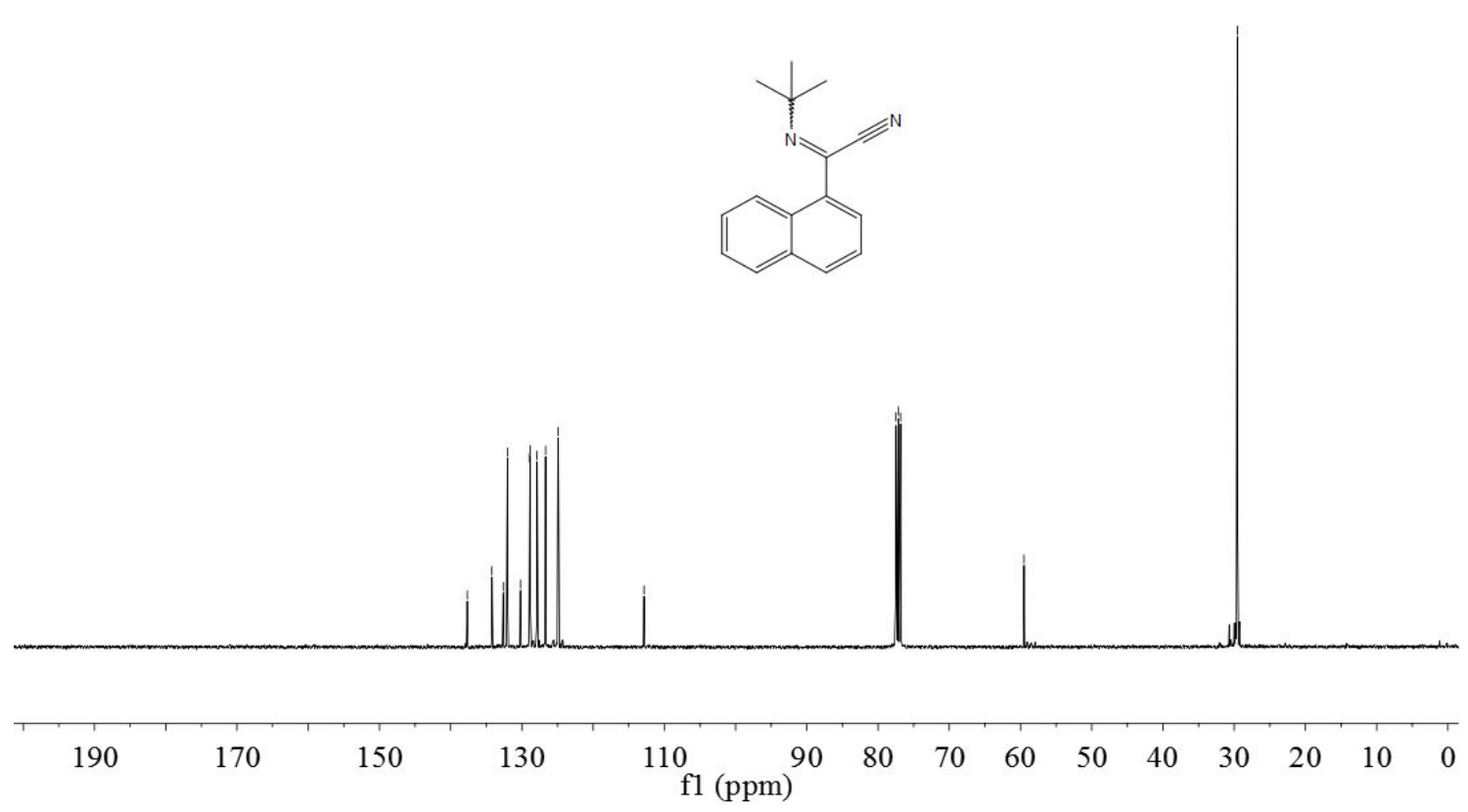
${ }^{1} \mathrm{H}$ NMR spectrum of compound $\mathbf{2} \mathbf{w}$

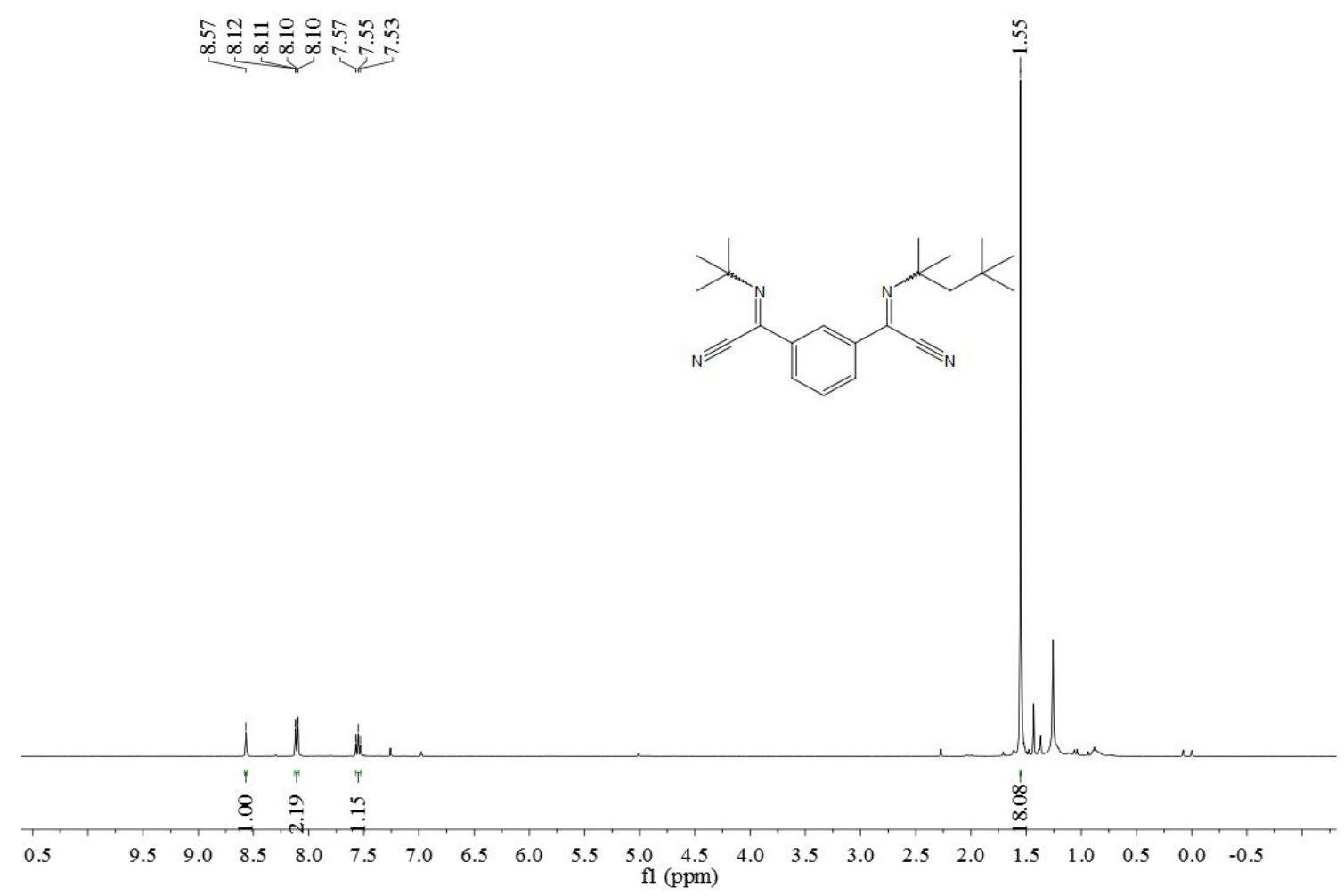

${ }^{13} \mathrm{C}$ NMR spectrum of compound $\mathbf{2 w}$

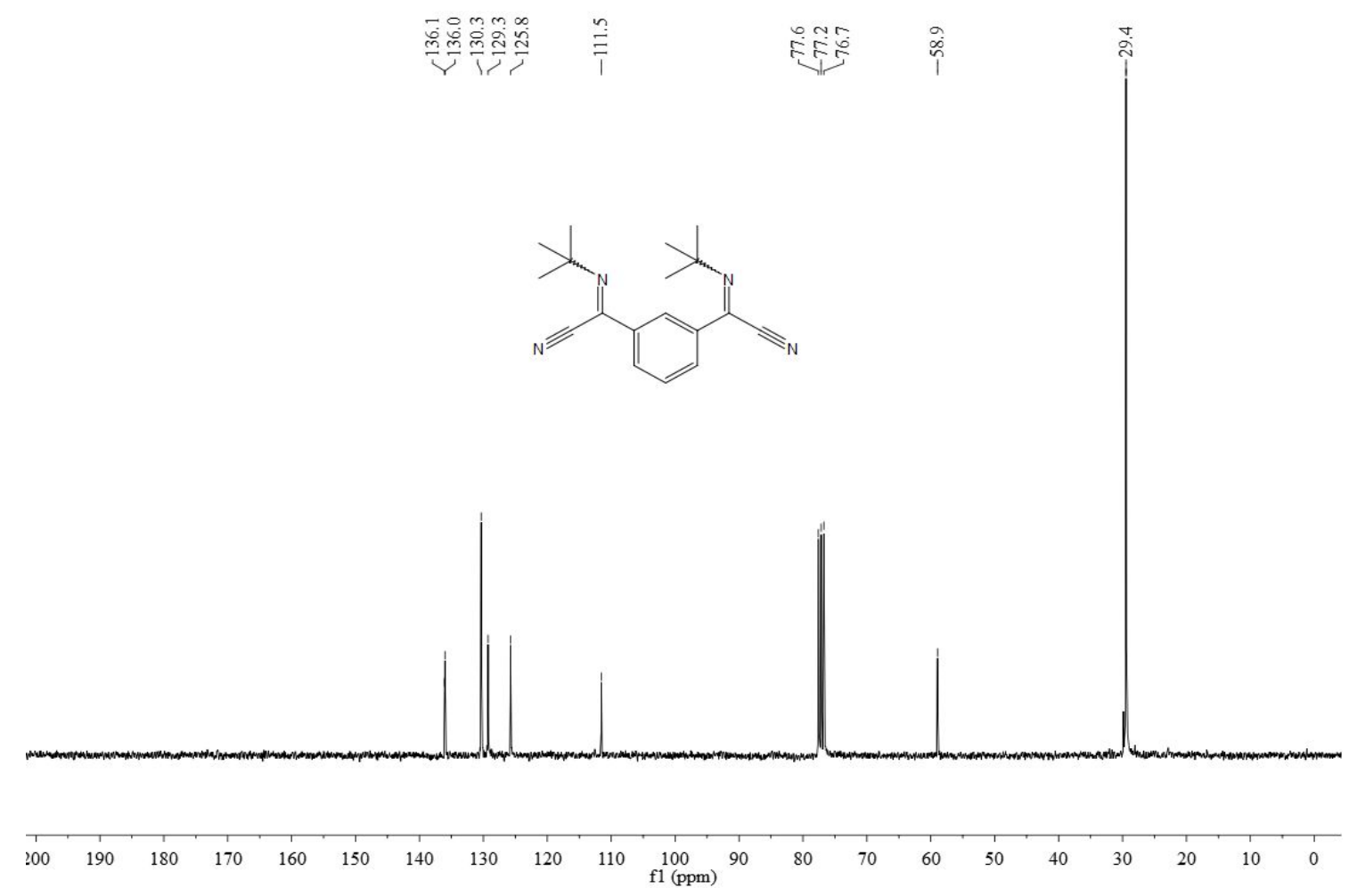


${ }^{1} \mathrm{H}$ NMR spectrum of compound $\mathbf{2} \mathbf{x}$ 娄

11111
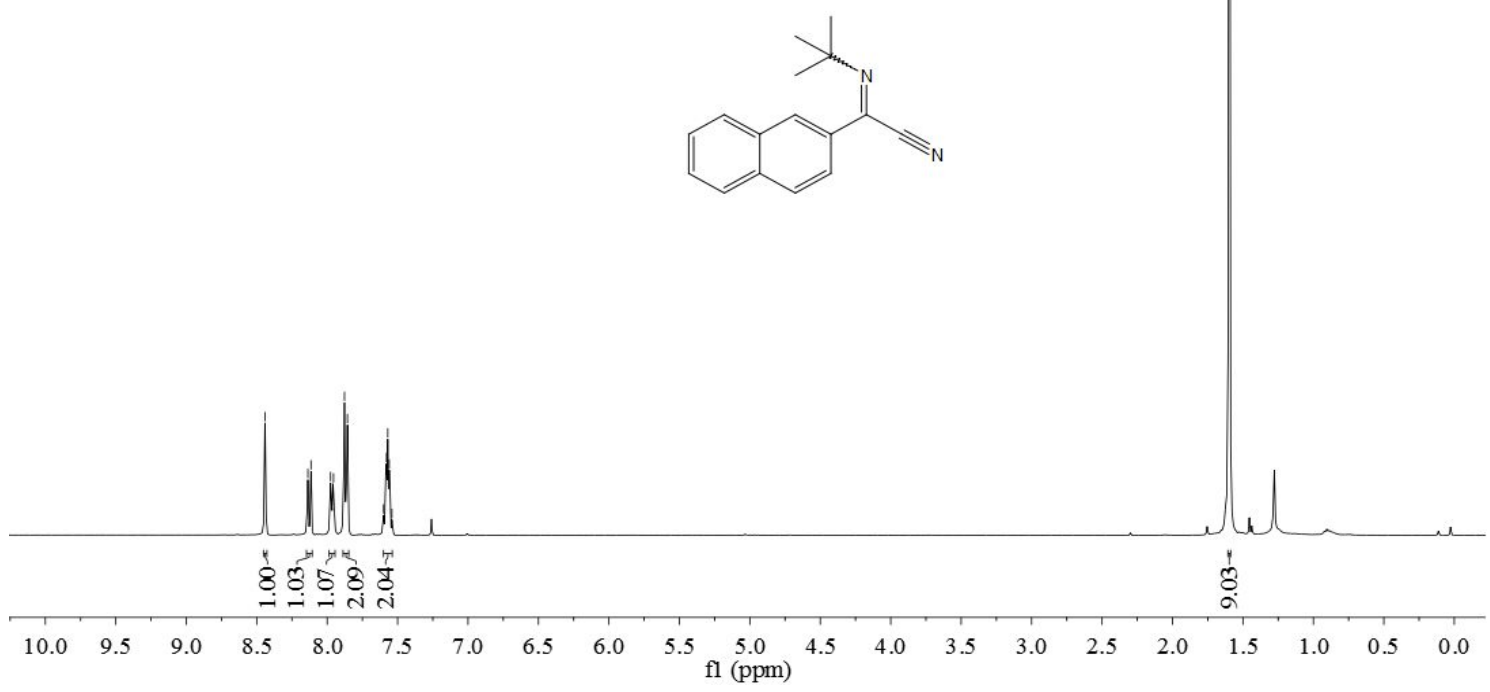

${ }^{13} \mathrm{C}$ NMR spectrum of compound $\mathbf{2 x}$

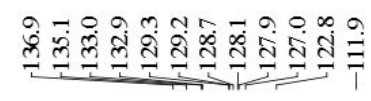

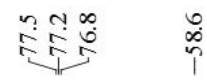

$\stackrel{\text { ì }}{i}$

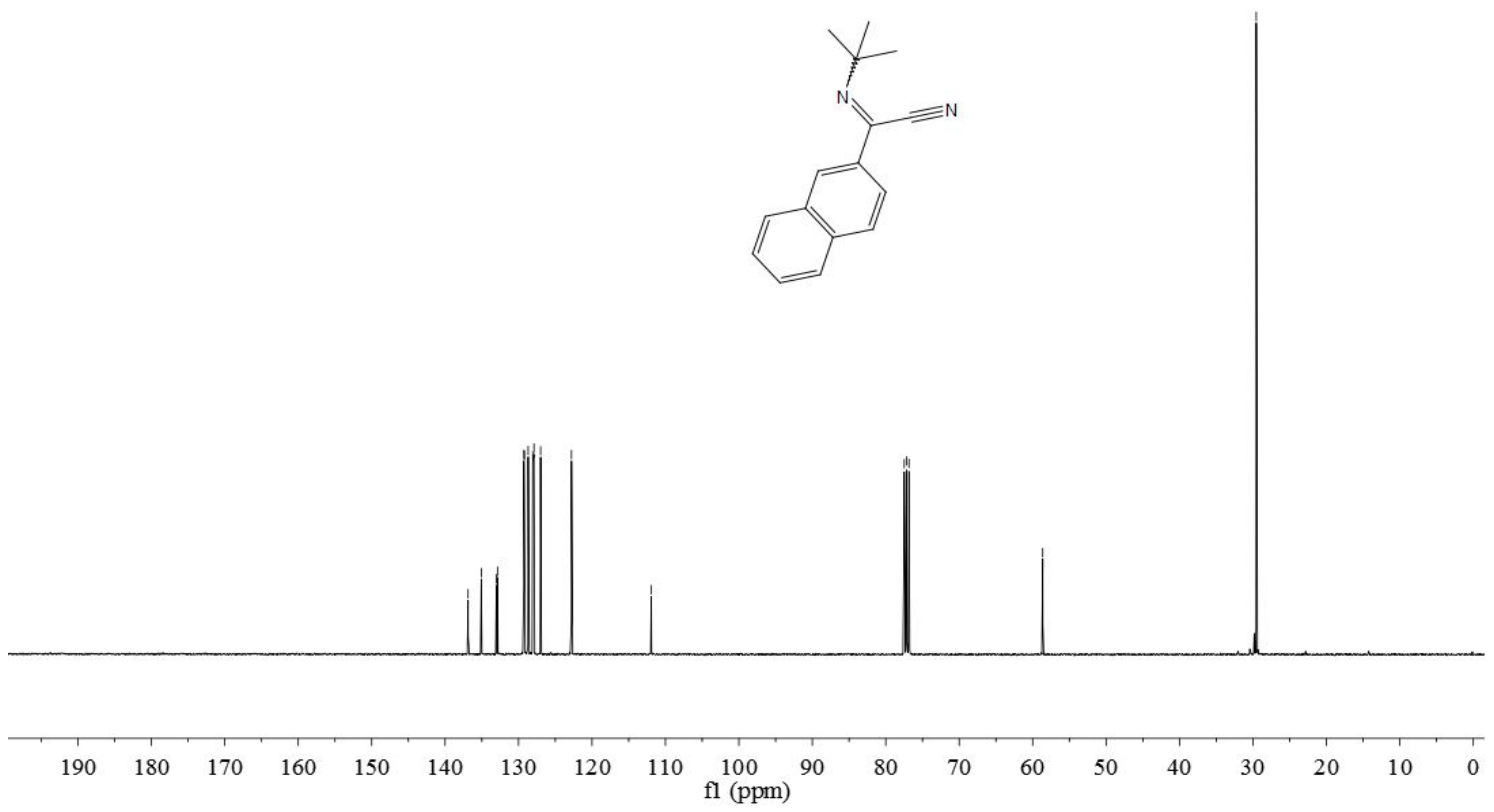


${ }^{1} \mathrm{H}$ NMR spectrum of compound $\mathbf{2 y}$

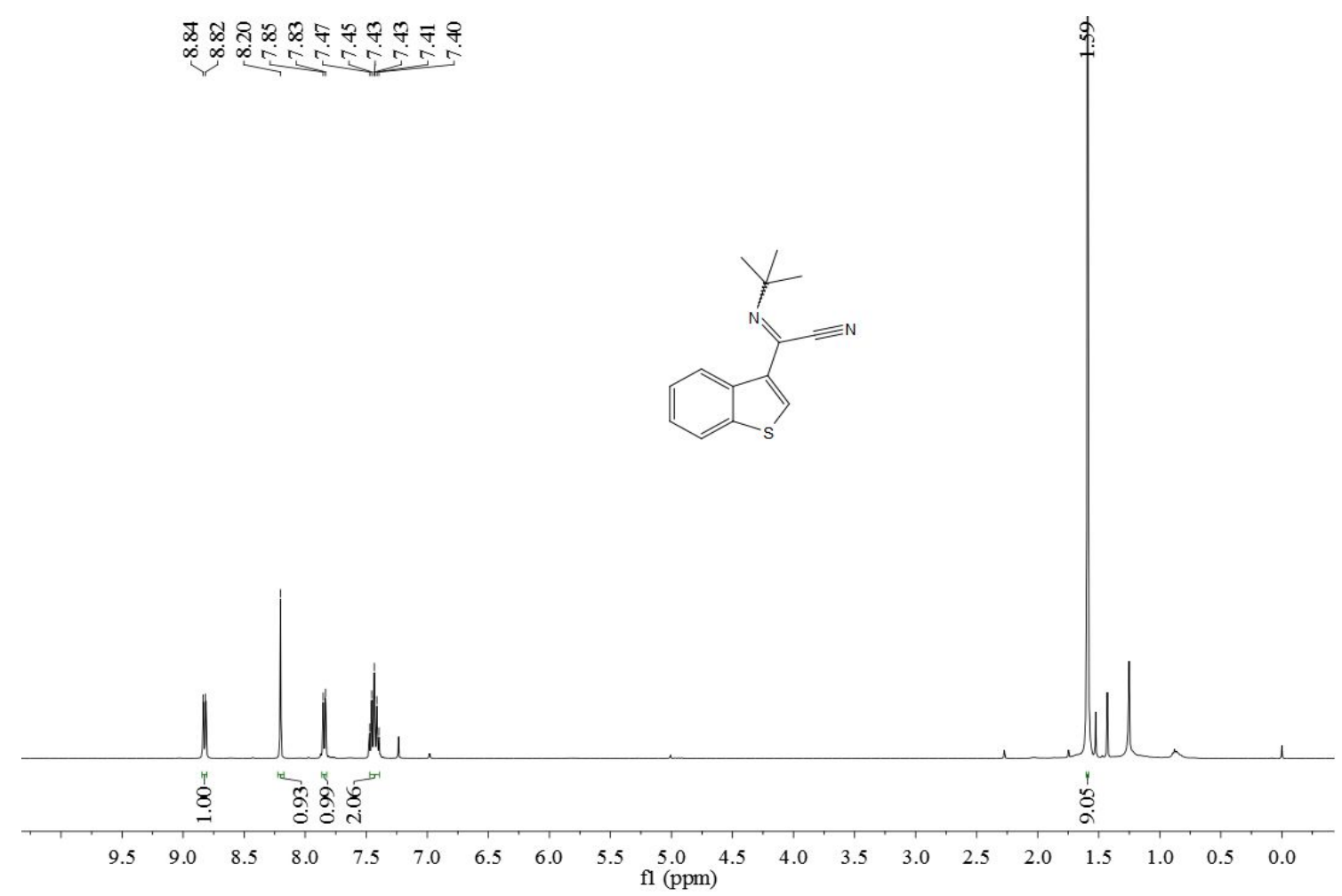

${ }^{13} \mathrm{C}$ NMR spectrum of compound $\mathbf{2 y}$

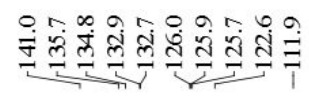

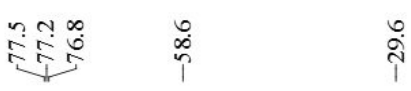
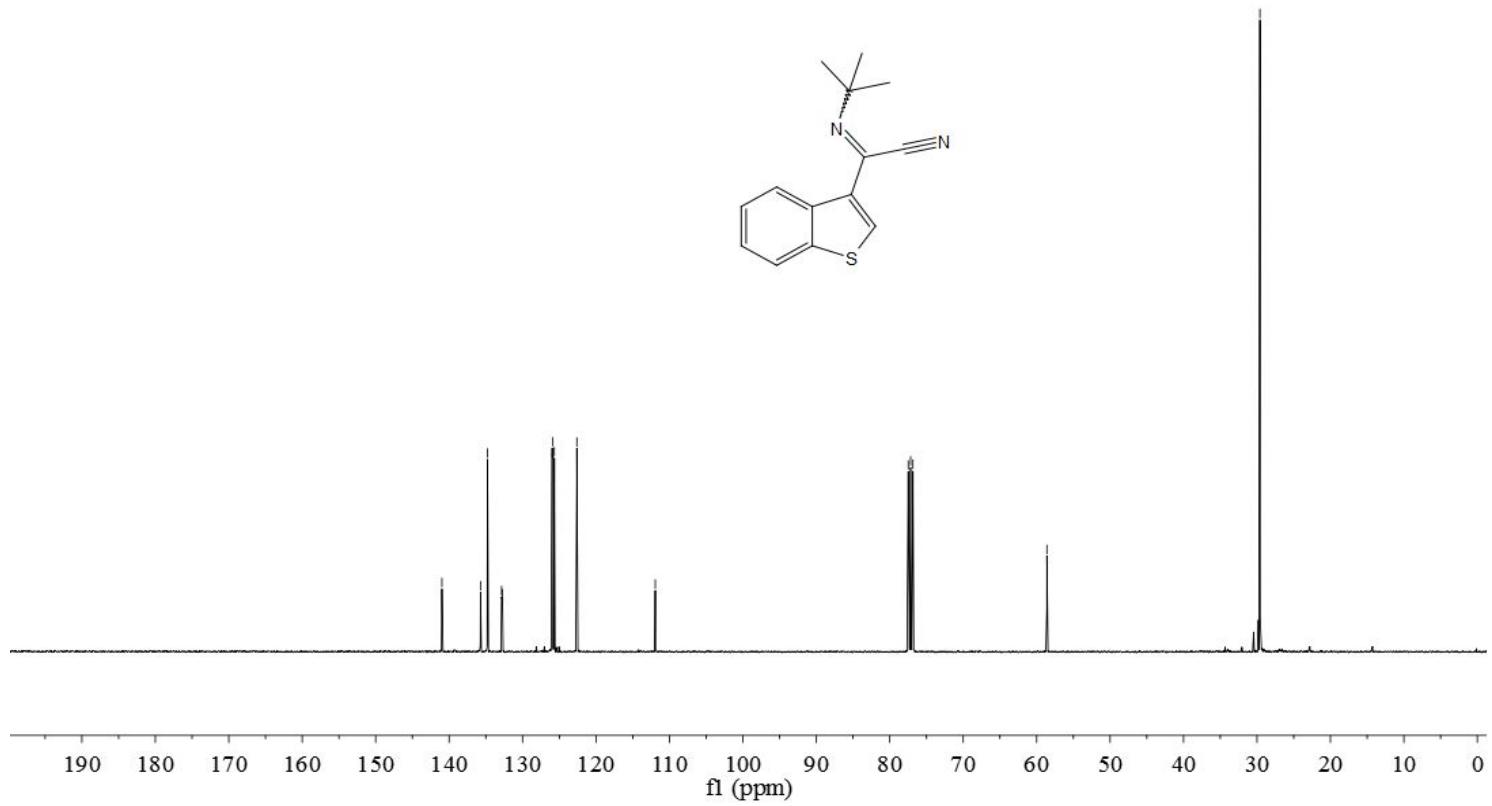
${ }^{1} \mathrm{H}$ NMR spectrum of compound $\mathbf{2 z}$ nู?

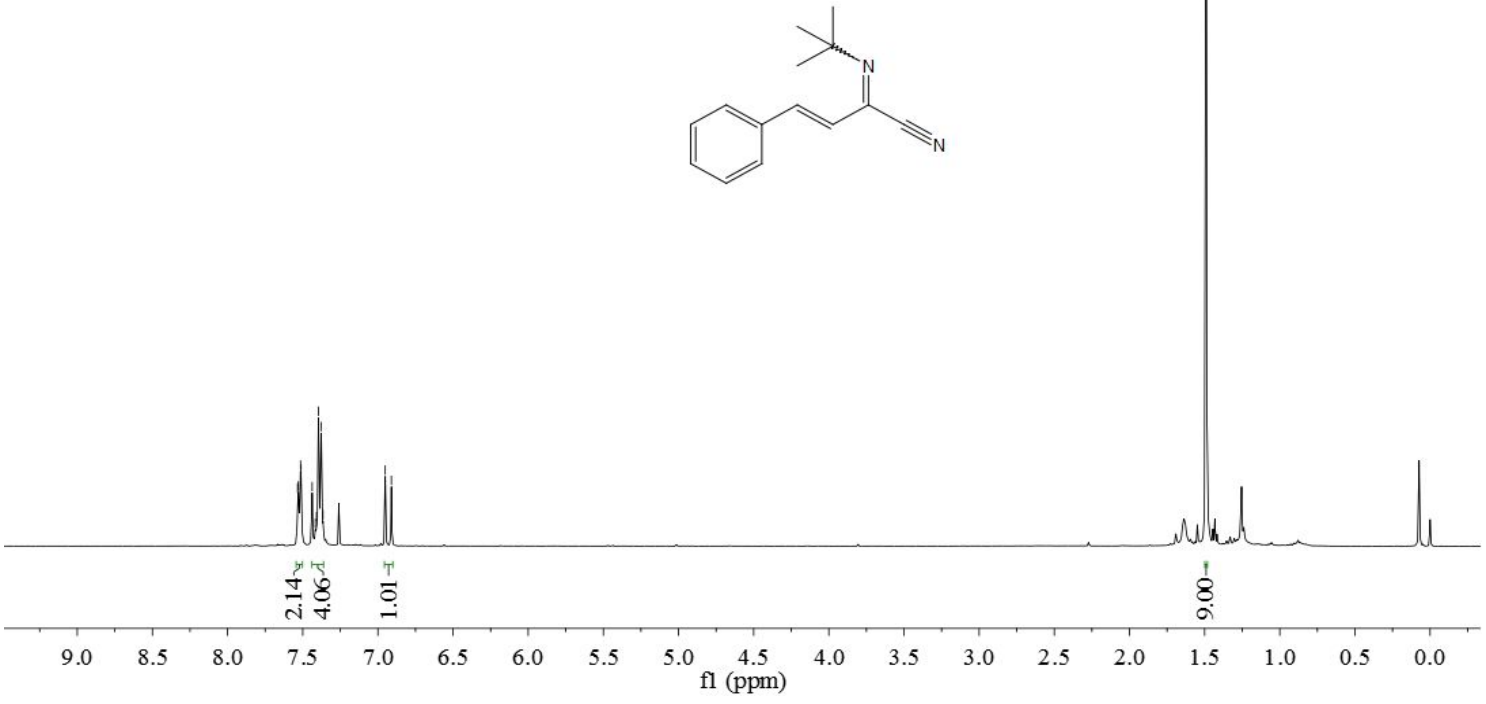

${ }^{13} \mathrm{C}$ NMR spectrum of compound $\mathbf{2 z}$

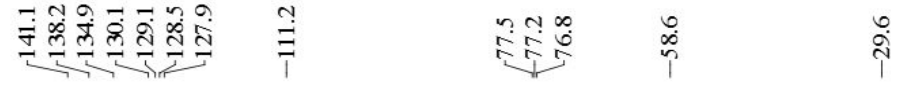

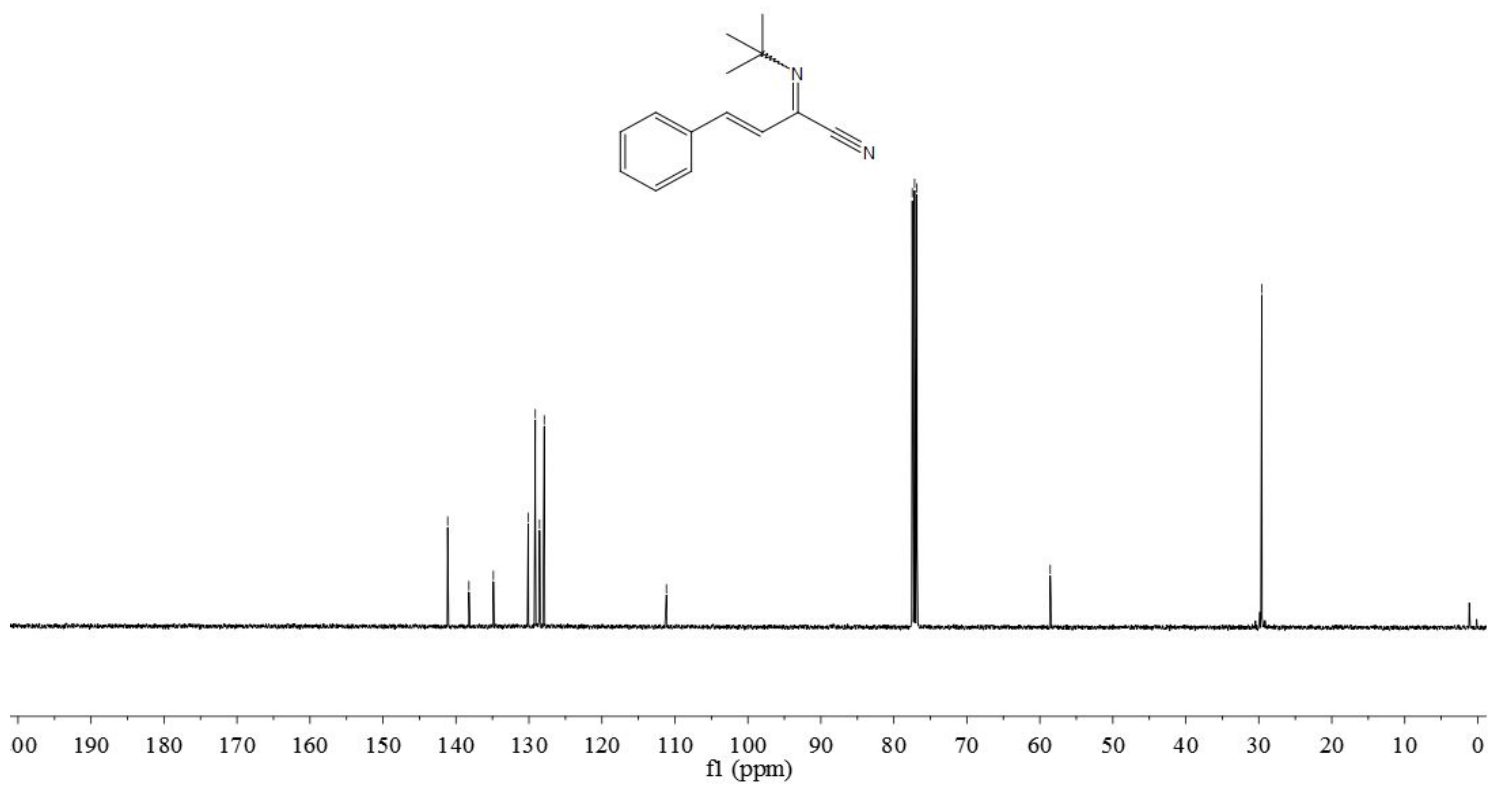


${ }^{1} \mathrm{H}$ NMR spectrum of compound $\mathbf{3 d}$

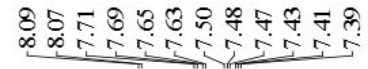

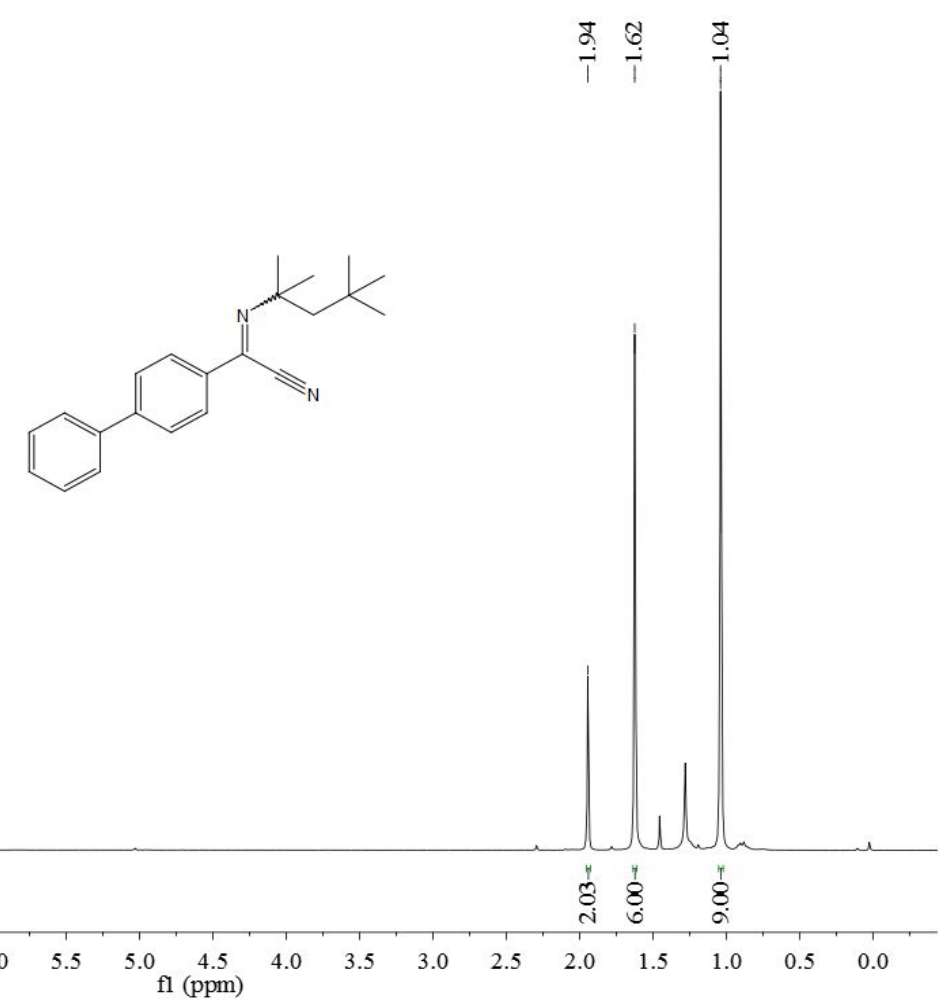

${ }^{13} \mathrm{C}$ NMR spectrum of compound $\mathbf{3 d}$
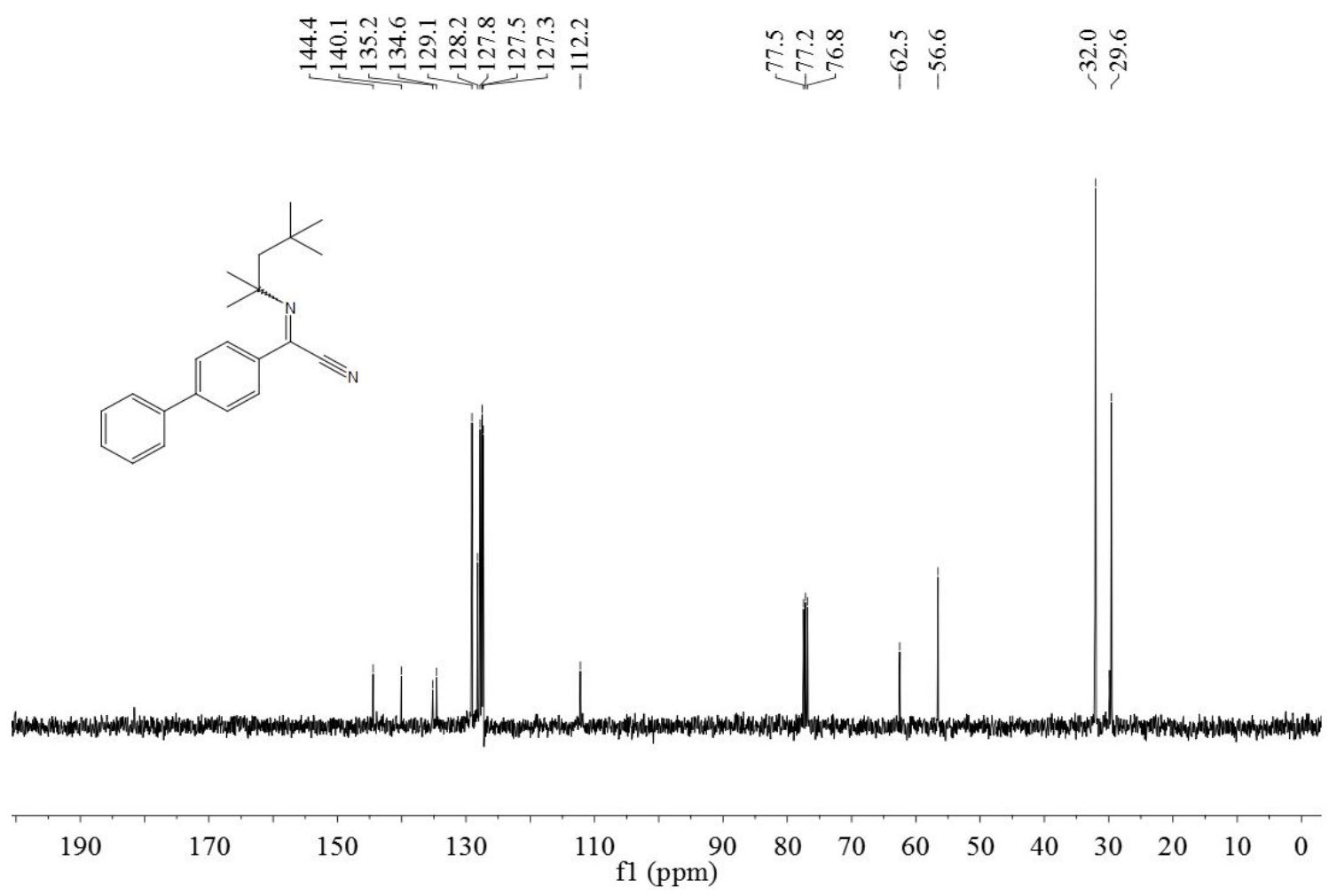
${ }^{1} \mathrm{H}$ NMR spectrum of compound $\mathbf{4 a}$
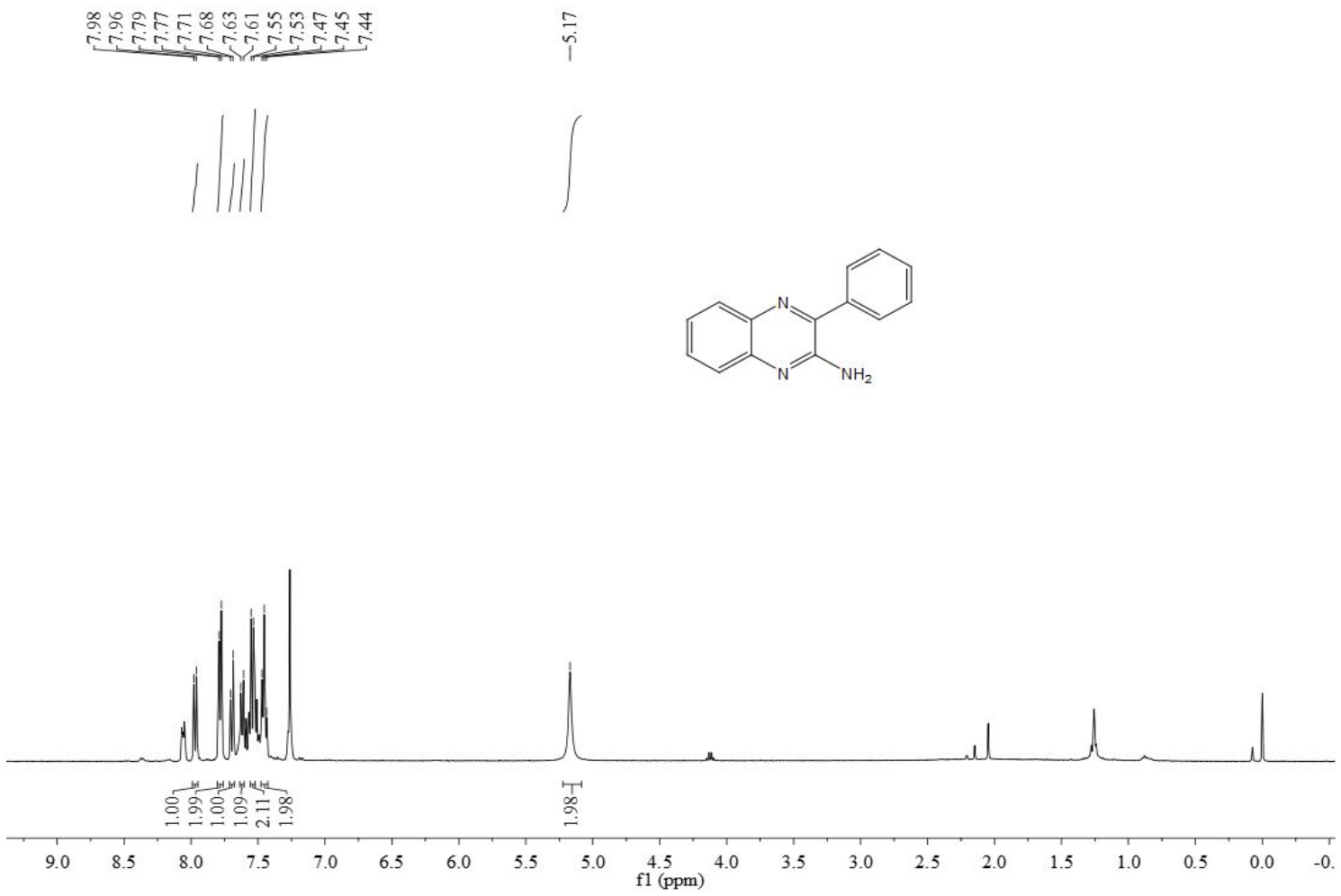

${ }^{13} \mathrm{C}$ NMR spectrum of compound $4 \mathrm{a}$
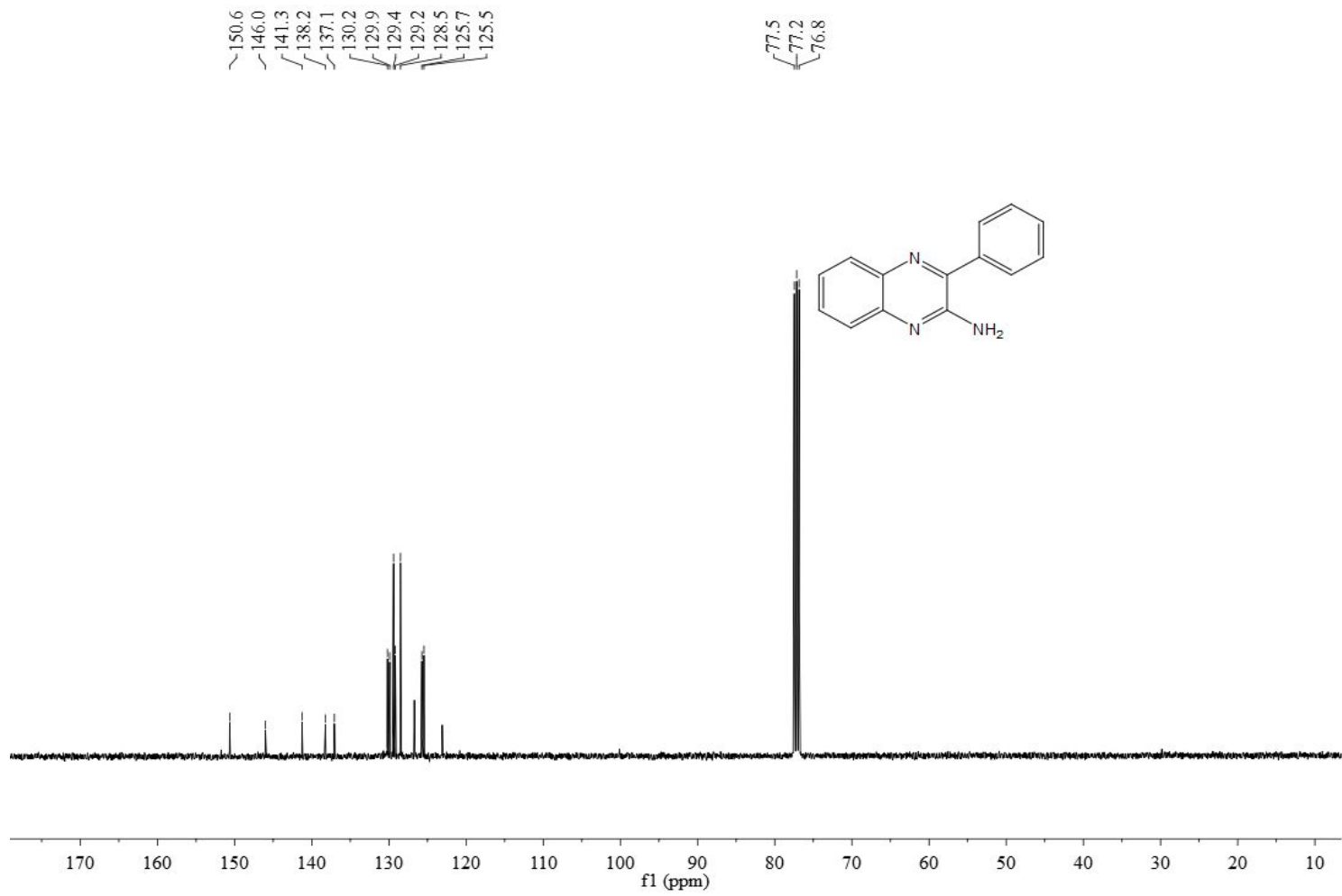
${ }^{1} \mathrm{H}$ NMR spectrum of compound $\mathbf{2 0 a}$
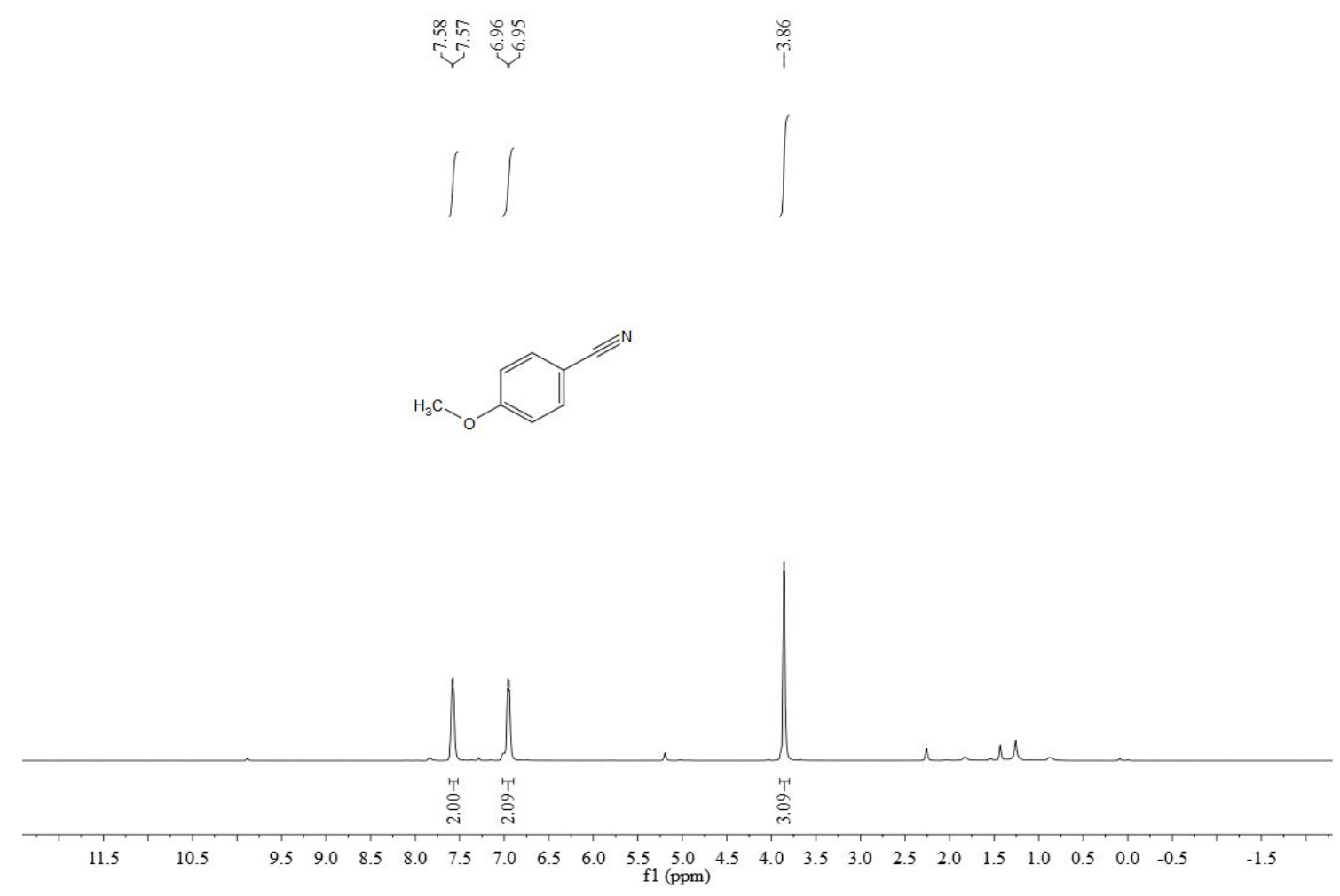

${ }^{13} \mathrm{C}$ NMR spectrum of compound $\mathbf{2 0 a}$
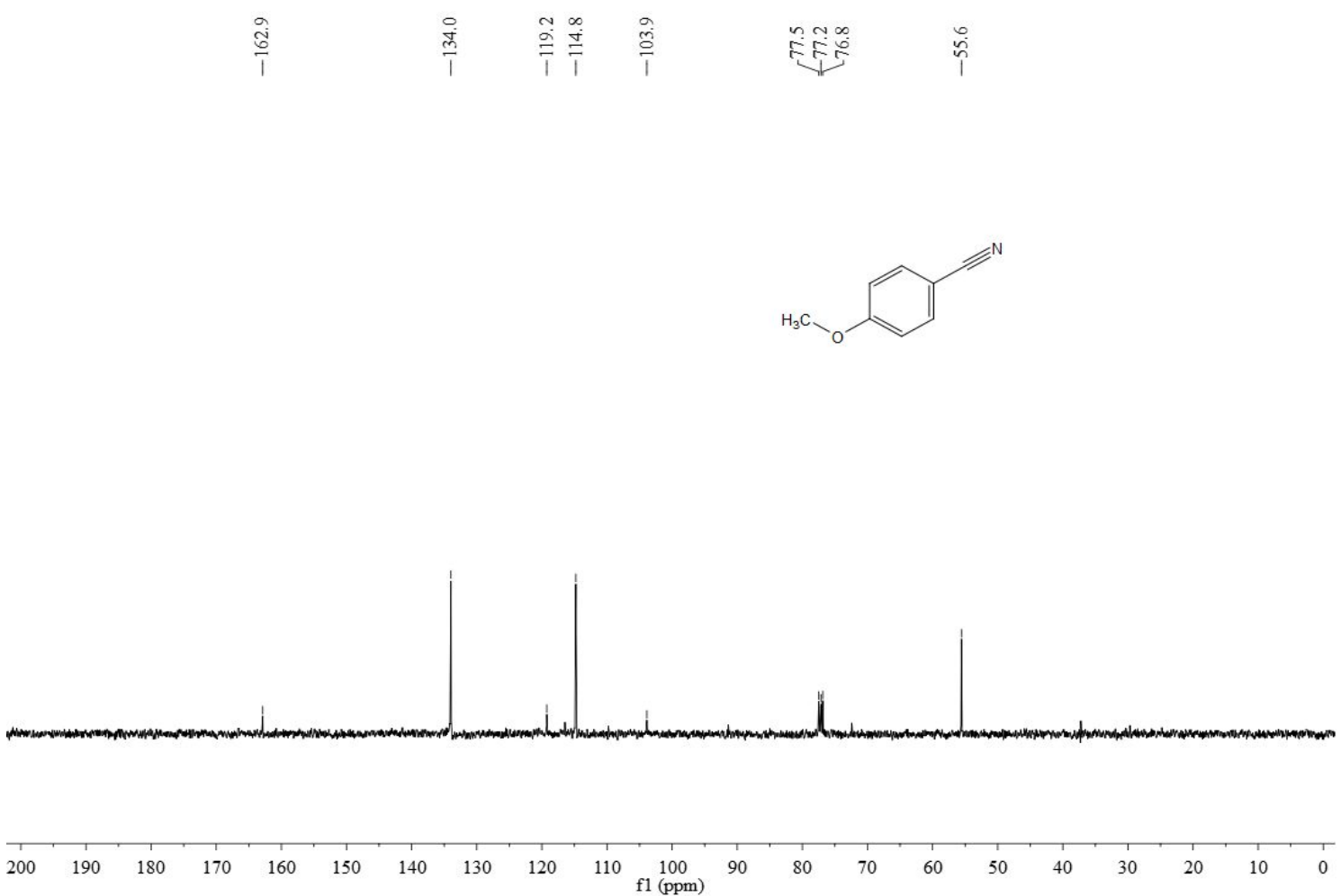